\title{
ESTUDO CEFALOMÉTRICO COMPUTADORIZADO DO ESPAÇO AÉREO FARÍNGEO DE PACIENTES SUBMETIDOS À CIRURGIA ORTOGNÁTICA PARA CORREÇÃO DE PROGNATISMO MANDIBULAR
}

Eduardo Sanches Gonçales

Tese apresentada à Faculdade de Odontologia de Bauru da Universidade de São Paulo, como parte dos requisitos para obtenção do título de Doutor em Odontologia, área de Estomatologia. 


\section{ESTUDO CEFALOMÉTRICO COMPUTADORIZADO DO ESPAÇO AÉREO FARÍNGEO DE PACIENTES SUBMETIDOS À CIRURGIA ORTOGNÁTICA PARA CORREÇÃO DE PROGNATISMO MANDIBULAR}

Eduardo Sanches Gonçales

Tese apresentada à Faculdade de Odontologia de Bauru da Universidade de São Paulo, como parte dos requisitos para obtenção do título de Doutor em Odontologia, área de Estomatologia.

Orientador: Prof. Dr. Eduardo Sant'Ana 


\begin{tabular}{|l} 
G586e \\
Gonçales, Eduardo Sanches \\
Estudo cefalométrico computadorizado do espaço aéreo \\
faríngeo de pacientes submetidos a cirurgia ortognática para \\
correção de prognatismo mandibular / Eduardo Sanches \\
Gonçales. - Bauru, 2006. \\
$142 p .:$ il.; $31 \mathrm{~cm}$. \\
Tese. (Doutorado) - Faculdade de Odontologia de Bauru. \\
OSP \\
Orientador: Prof. Dr. Eduardo Sant'Ana
\end{tabular}

Autorizo, exclusivamente para fins acadêmicos e científicos, a reprodução total ou parcial desta dissertação/tese, por processos fotocopiadores e outros meios eletrônicos.

Assinatura: 



\section{EduARdo SANCHES GonçaLES}

19 de janeiro de 1971

Presidente Venceslau - SP

1989 a 1992

1993 a 1995

1996 a 1997

1998-até a presente data

2003 a 2006
Nascimento.

Graduação em Odontologia - Faculdade de

Odontologia de Araraquara - UNESP.

Estágio e residência em Cirurgia e

Traumatologia Buco-maxilo-faciais -

Faculdade de Odontologia de Araraquara.

Curso de Pós-graduação em Cirurgia e Traumatologia Buco-maxilo-faciais, em nível de Mestrado, na Faculdade de Odontologia da Pontifícia Universidade Católica de Porto Alegre (PUCRS).

Professor Assistente das Disciplinas da área da Cirurgia e Traumatologia Buco-maxilofaciais na Universidade do Sagrado Coração, em Bauru, SP.

Curso de Pós-Graduação em Estomatologia, em nível de Doutorado, na Faculdade de Odontologia de Bauru, USP. 


\section{DEDICATÓRIA}

À minha esposa ANDRÉA e à minha filha LAURA

"seus olhos, meu clarão, me guiam dentro da escuridão; seus pés me abrem o caminho, eu sigo e nunca me sinto só ..." 
"Por mais prazerosa que seja a sua existência, se você não sente que está construindo algo, não se tornará feliz."

Amyr Klink 


\section{AGRADECIMENTOS}

À Faculdade de Odontologia de Bauru, da Universidade de São Paulo (FOBUSP), representada pelo seu Diretor, Prof. Dr. Luiz Fernando Pegoraro, por conceder a oportunidade e proporcionar os recursos para que fosse possível realizar o Curso de Pós-Graduação;

À Universidade do Sagrado Coração, representada pela diretora do Centro de Ciências da Saúde, IR. Adelir Webber, e pela Ir. MARIA IzABel Leite, pelo respeito e apoio no aperfeiçoamento docente;

Aos integrantes do Instituto Odontológico de Cirurgia e Prótese (IOCP), pela oportunidade de uma vida melhor;

Ao Prof. Dr. José Humberto Damante, Coordenador da Pós-Graduação em Estomatologia, da Faculdade de Odontologia de Bauru (USP), pelo respeito e dignidade ao ensinar;

Ao Prof. Dr. EDUARDO SANT'ANA, pela orientação durante a elaboração deste trabalho;

Às professoras Dr. ${ }^{a}$ Ana lúcia Álvares Capelozza, Dr. ${ }^{a}$ Izabel Regina Fischer RUBiRa BULlen e aos professores Dr. LUIz EduARDo Montenegro Chinellato, Dr. Júlio de Araújo Gurgel, Dr. Osny Ferreira Júnior, Dr. Paulo Sérgio Perri de Carvalho, pelo convívio e ensinamentos transmitidos;

Ao Prof. Dr. José Roberto Pereira lauris, pela análise estatística dos resultados e atenção dedicados; 
À minha esposa ANDRÉA e filha LAURA, pela ajuda essencial e por compreenderem e conviverem com minha ausência nesse período;

Aos meus pais, AURORA e CHRISTOVAM, principais responsáveis por tudo o que sou e serei nesta vida;

À minha irmã AlıNA, pela amizade e exemplo de dedicação e amor profissional;

À família do Dr. OdILON Guedes BARRETo, pelo respeito e atenção a mim dedicados;

À Sra. Deolinda Morceli, que se afastou do seio de sua família para me ajudar a cuidar da minha, permitindo-me realizar este trabalho;

Aos amigos Hugo Nary Filho, luis Eduardo Marques Padovan, Roberto Yoshio Kawakami, Paulo Domingos Ribeiro Jr., Mariza Akemi Matsumoto, Aparício fiúza Dekon de Carvalho, pois sem sua ajuda eu jamais conseguiria;

Aos colegas Docentes do Curso de Odontologia da Universidade do Sagrado Coração, pelo convívio, amizade, respeito e ensinamentos a mim transmitidos;

A todos os colegas da Pós-Graduação pela amizade que, certamente, deixará marcas em minha vida;

Ao amigo e colega de Pós-Graduação EDUARDO ANTÔNIO AYUB e família, pela atenção, respeito e exemplo de dedicação profissional e harmonia no lar; 
Aos funcionários da Faculdade de Odontologia de Bauru (FOB-USP), em especial marília Girão, fernanda aparecida daniel Cavalari, Roberto Salles Pontes, Camila Medina e Josiane Aparecida Tripodi Farinha, pela amizade e convivência proporcionadas;

A todos que direta ou indiretamente contribuíram para a elaboração deste trabalho, ensejando assim que um sonho se tornasse realidade,

meu sincero muito obrigado! 


\section{SUMÁRIO}

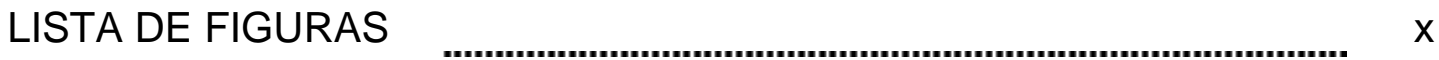

LISTA DE TABELAS _...........................................................................

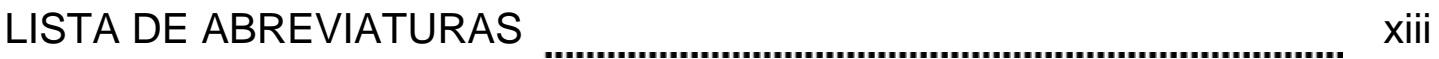

RESUMO _...................

1 INTRODUÇÃO

2 REVISÃO DE LITERATURA _....................................................... 9

2.1Considerações anatômicas sobre o espaço aéreo superior ……….... 9

2.2 Síndrome da Apnéia Obstrutiva do Sono (SAOS) _......................... 16

2.3 Inter-relação da SAOS com deformidade dento-facial-esquelética .... 31

2.4 Inter-relação entre SAOS, espaço aéreo e cirurgia ortognática ......... 45

3 PROPOSIÇÃO

4 MATERIAIS E MÉTODO _.................................................................... 65

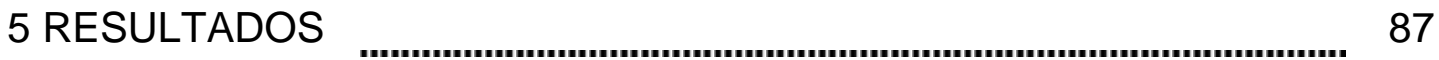

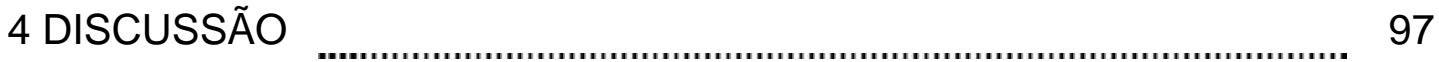

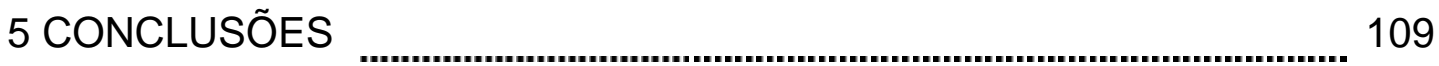

ANEXOS

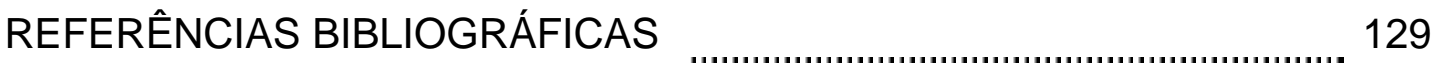

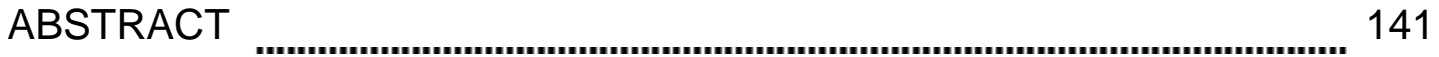




\section{LISTA DE FIGURAS}

FIGURA 4.1 - Telerradiografia digitalizada com a régua transparente específica

FIGURA 4.2 - Tela inicial do programa Dolphin Imaging 10.0 68

FIGURA 4.3 - Tela com o botão "new patient" sendo acionado 68

FIGURA 4.4 - Janela para identificação do paciente, após acionamento do ícone "new patient"

FIGURA 4.5 - Janela para registro do período da radiografia (inicial ou final) a ser captada

FIGURA 4.6 - Seleção da seqüência de imagens pré-determinada (radiografia cefalométrica lateral digitalizada e arquivada como imagem)

FIGURA 4.7 - Radiografia digitalizada selecionada do arquivo de imagens, juntamente com a régua digitalizada

FIGURA 4.8 - Imagem selecionada (de acordo com o paciente e período) reduzida em suas proporções

FIGURA 4.9 - Recursos disponíveis para melhorar o contraste, brilho, saturação e quantidade de branco, favorecendo a visualização de algumas estruturas anatômicas

FIGURA 4.10 - Telerradiografia final digitalizada, arquivada após melhora do contraste

FIGURA 4.11 - Seleção da análise cefalométrica, o tipo de radiografia e a sessão: passo inicial para digitalização dos pontos cefalométricos nas radiografias

FIGURA 4.12 - Telerradiografia com alguns pontos digitalizados e o traçado cefalométrico sendo construído, segundo análises Arnett/McLauglin e Quas/airway

FIGURA 4.13 - Representação esquemática dos pontos cefalométricos utilizados 
FIGURA 4.14 - Telerradiografia com pontos digitalizados e traçado cefalométrico construído segundo análises Arnett/McLau glin e Quas/airway

FIGURA 4.15 - Medidas lineares e angulares da análise de Quas/Airway ... 82

FIGURA 5.1 - Média inicial, final e da diferença entre final e inicial dos valores de $\mathrm{SN}(\mathrm{mm})$ e FH-NA (0) 90

FIGURA 5.2 - Média inicial, final e da diferença entre final e inicial dos valores de Nba-PtGn $\left({ }^{0}\right)$, FH-NPo $\left(^{0}\right)$, FT $\left(^{0}\right)$, FMA $\left(^{0}\right)$ e Ar-Go-Me $\left(^{0}\right)$

FIGURA 5.3 - Média inicial, final e da diferença entre final e inicial dos valores de SNA $\left({ }^{0}\right)$, SNB $\left({ }^{0}\right)$, ANB $\left(^{0}\right)$

FIGURA 5.4 - Média inicial, final e da diferença entre final e inicial dos valores de trespasse vertical (Overbite - $\mathrm{mm}$ ) e trespasse horizontal (Overjet - mm)

FIGURA 5.5 - Média inicial, final e da diferença entre final e inicial dos valores de UAFH (mm), ANS-Me $(\mathrm{mm})$ e N-Me $(\mathrm{mm})$

FIGURA 5.6 - Média Inicial, Final e da Diferença entre Final e Inicial dos valores de IAS (mm), MAS (mm), SPAS (mm), PNS$\mathrm{V}(\mathrm{mm})$ e PNSPa $(\mathrm{mm})$

FIGURA 5.7 - Média inicial, final e da diferença entre final e inicial dos valores de Hy-Me-MP $\left({ }^{0}\right)$, Hy-MPPerp $(\mathrm{mm})$ e HyS $(\mathrm{mm})$..... 92 


\section{LISTA DE TABELAS}

TABELA 4.1 - Grupos de medidas, unidade e legenda utilizados nas mensurações em 19 indivíduos submetidos à cirurgia ortognática para correção de prognatismo mandibular

TABELA 5.1 - Gênero, idade, período pós-operatório de 19 indivíduos submetidos à cirurgia ortognática para correção de prognatismo mandibular (avanço de maxila + recuo de mandíbula).. 87

TABELA 5.2 - Médias iniciais (Média I), finais (Média F), da diferença entre final e inicial (média dif), desvios padrão iniciais (DP I), finais (DP F), da diferença entre final e inicial, Teste T pareado $(\mathrm{t})$ e valor de $\mathrm{P}(\mathrm{P})$ das medidas de 19 indivíduos submetidos à cirurgia ortognática para correção de prognatismo mandibular

TABELA 5.3 - Média da medida 1 (Média 1) e 2 (Média 2), desvios padrão $1(\mathrm{DP} 1)$ e 2 (DP2), teste T pareado (t), valor de $\mathrm{P}$ $(\mathrm{P})$ e Erro para as medidas 10 radiografias de indivíduos submetidos à cirurgia ortognática para correção de prognatismo mandibular 


\section{LISTA DE ABREVIATURAS}

A

ANS

$\operatorname{Ar}$

Ar-Go-Me ângulo formado pela intersecção das linhas Ar-Go e Go-Me

B

$\mathrm{Ba}$

C2

C3

C4

Et

FH-NA

FH-NPo

Frankfurt e linha NA

ângulo formado pela intersecção do plano horizontal de Frankfurt e linha NPo

FMA ângulo formado entre o plano horizontal de Frankfurt e plano mandibular

FT

ponto mais profundo da curvatura maxilar entre a espinha nasal anterior e o osso alveolar

ângulo formado pela intersecção das linhas NA e NB

ponta da espinha nasal anterior

articular (borda posterior do pescoço do côndilo)

ponto mais posterior da concavidade anterior da sínfise

basio (ponto mais inferior do osso occipital na margem anterior

do forame occipital)

ponto mais superior e posterior da segunda vértebra cervical

ponto mais inferior e anterior da terceira vértebra cervical

ponto mais inferior e posterior da quarta vértebra cervical

ponto mais superior da epiglote

ângulo da conicidade facial; ângulo formado entre o plano mandibular (Go-Me) e o plano facial (N-Pg) 
Gn

gnátio anatômico (ponto médio entre os pontos mais anterior e inferior do mento ósseo)

Go gônio (ponto de maior convexidade ao longo da borda inferior do ramo)

H Hióide (ponto mais anterior e superior do corpo do osso hióide)

HC3 linha que passa pelos pontos $\mathrm{H}$ e $\mathrm{C} 3$

$\mathrm{H}-\mathrm{Gn} \quad$ linha que passa pelos pontos $\mathrm{H}$ e $\mathrm{Gn}$

H-Me-MP ângulo formado pela intersecção Hy-MP e Hy-Me

H-MP Perp linha perpendicular ao MP partindo do ponto Hy

HS linha que passa pelos pontos $\mathrm{Se} \mathrm{H}$

Hy Ângulo Hióideo (H-Gônio) ao (H-Mento)

IAA ponto mais anterior e inferior do espaço aéreo orofaríngeo

IAS inferior airway space (espaço aéreo inferior)

IPA ponto mais posterior e inferior do espaço aéreo orofaríngeo

MAS midle airway space (espaço aéreo médio)

Me mento (ponto mais inferior da sínfise)

MP plano mandibular

MPA ponto médio da parede posterior da faringe

N násio (intersecção da sutura internasal com a sutura nasofrontal)

$\mathrm{N}$-Me linha que passa por $\mathrm{Ne} \mathrm{Me}$

N.Ba-PtGn ângulo de eixo facial.

NREM non rapid eye movement (movimentos oculares lentos)

$\mathrm{Pa} \quad$ ponta da úvula 
PNS ponta da espinha nasal posterior

PNSPa linha que passa pelos pontos PNS e Pa

PNS-V linha que estende-se pelos pontos PNS e V.

Pó pório (ponto mais superior do meato ou conduto auditivo externo)

Pog ponto mais saliente do mento ósseo

PSP ponto mais superior e posterior do dorso da língua

PSPh ponto médio entre a ponta da úvula e MPA

PT pterigóide (intersecção da borda inferior do forâmen redondo e parede posterior da fissura pterigomaxilar)

REM rapid eye movement (movimentos oculares rápidos)

S Sela (centro da fossa pituitária do osso esfenóide)

SN base anterior do crânio - linha que passa por S e N

SNA intersecção das linhas SN e NA

SNB intersecção das linhas SN e NB

SPAS superior posterior airway space (espaço aéreo superior posterior)

V fundo da epiglote 


\section{Resumo}

A faringe é um órgão muscular que se sustenta nos ossos da face e crânio. Dividindo-se em naso, oro e hipofaringe, pode ser considerada um tubo colabável que atende aos sistemas respiratório e digestivo, participando da respiração, deglutição e fonação. Sua conformação anatômica permite que fatores como obesidade, hipotonia muscular e deficiência mandibular favoreçam sua obstrução, podendo gerar a Síndrome da Apnéia Obstrutiva do Sono (SAOS). Para os pacientes portadores de deficiência mandibular, o tratamento deve desobstruir a faringe por meio de avanço mandibular, aumentando as dimensões faríngeas. A determinação do local de obstrução é fundamental para o adequado tratamento, sendo a análise cefalométrica convencional ou computadorizada, ferramenta útil nesse processo. Da mesma forma que o avanço mandibular aumenta o espaço aéreo faríngeo, espera-se que o recuo de mandíbula reduza-o. Com o objetivo de avaliar as alterações cefalométricas do espaço aéreo faríngeo frente aos procedimentos de cirurgia ortognática para correção de prognatismo mandibular, realizou-se a análise cefalométrica pré e pós-operatória de 19 pacientes submetidos a recuo de mandíbula pela técnica da osteotomia sagital de mandíbula bilateral associada a avanço de maxila por meio de osteotomia Le Fort I, utilizando-se o Programa Dolphin Imaging 10.0. Os resultados obtidos com base nas características do grupo de pacientes estudado não evidenciaram alterações estatisticamente significativas nos 
espaços aéreos faríngeos superior ou nasofaríngeo, médio ou orofaríngeo e inferior ou hipofaríngeo, o que permitiu concluir que o Programa Dolphin Imaging 10.0 pode ser utilizado como ferramenta para análise cefalométrica do espaço aéreo faríngeo e que a cirurgia ortognática maxilo/mandibular, para correção de prognatismo mandibular, parece não alterar os espaços aéreos faríngeos.

Palavras-chave: Recuo mandibular. Espaço aéreo faríngeo. Apnéia obstrutiva. 
$1 \mathfrak{J} \int_{\mathfrak{n t r a t a} \mathfrak{u} \mathfrak{x} \tilde{\mathfrak{a}} \mathfrak{a}}$ 



\section{INTRODUÇÃO}

A faringe é um órgão muscular que se sustenta nos ossos da face e crânio. Dividindo-se em naso, oro e hipofaringe, pode ser considerada como um tubo colabável, que atende aos sistemas respiratório e digestivo, participando da respiração, deglutição e fonação. Sua conformação anatômica permite que fatores como obesidade, hipotonia muscular e deficiência mandibular (dentre outros) favoreçam sua obstrução, gerando a Síndrome da Apnéia Obstrutiva do Sono (SAOS).

A SAOS é uma desordem médica que potencialmente ameaça a vida e pode ser caracterizada por episódios de apnéia e hipopnéia, frente à presença de esforços respiratórios, durante o sono. Tem como causa uma obstrução da passagem do ar, decorrente da redução do espaço aéreo faríngeo e ocorre em 2 a 9\% da população acima dos 45 anos, predominando entre os homens e com uma prevalência estimada em mais de 18 milhões de pessoas.

Os aspectos clínicos mais comuns são: gênero masculino, obesidade, aumento da circunferência cervical, deposição excessiva de gordura no palato, língua (macroglossia) e faringe, além de palato mole alongado, retro-posicionamento mandibular e maxilar.

A SAOS associa-se à obstrução repetitiva da via aérea superior, que pode causar sonolência diurna e desordens cardiovasculares, 
reduzir a saturação de oxigênio sanguíneo (com conseqüente hipertensão, arritmia cardíaca, angina noturna e isquemia cardíaca) e fragmentar o sono (com sonolência excessiva diurna, deterioração da memória, alterações da personalidade e redução da capacidade de concentração). Clinicamente, pode ser diagnosticada pela história característica do paciente (ronco, sonolência diurna) e pelo exame físico (aumento da circunferência do pescoço), mas, a polissonografia noturna é necessária para confirmar a presença da desordem.

Para a determinação dos locais de obstrução, além do exame físico, são de grande valia a análise cefalométrica, a nasofaringoscopia, a endoscopia, a tomografia computadorizada, a ressonância magnética dinâmica, a cefalometria associada à videoendoscopia e a cefalometria associada à ressonância magnética.

A cefalometria é o exame por imagem mais comum para a avaliação de pacientes com SAOS, uma vez que revelam várias anormalidades nos tecidos duros e moles da via aérea, que predispõem o paciente à obstrução da faringe. Tal avaliação pode ser realizada pela utilização de análises cefalométricas computadorizadas.

Para os pacientes portadores de deficiência mandibular, o tratamento da SAOS deve desobstruir a faringe mediante o avanço maxilo/mandibular cirúrgico, uma vez que tal procedimento aumenta as dimensões faríngeas. Da mesma forma que o avanço mandibular aumenta o espaço aéreo faríngeo, espera-se que o recuo de mandíbula reduza tal espaço, 
possivelmente predispondo pacientes portadores de prognatismo mandibular a SAOS.

Desta forma, este estudo teve o objetivo de avaliar as alterações cefalométricas do espaço aéreo faríngeo, frente aos procedimentos de cirurgia ortognática para correção de prognatismo mandibular, utilizando o Programa Dolphin Imaging 10.0. Para tal, 19 pacientes foram submetidos ao recuo de mandíbula, pela técnica da osteotomia sagital de mandíbula bilateral, associada ao avanço de maxila, realizado por meio da técnica de osteotomia Lê Fort I. 



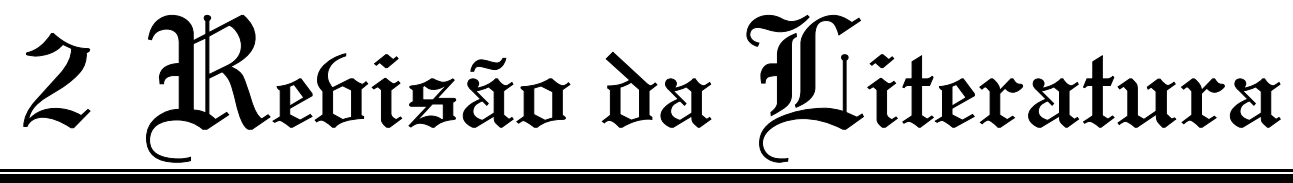





\section{REVISÃO DA LITERATURA}

\subsection{Considerações anatômicas sobre o espaço aéreo superior}

A via aérea faríngea é uma estrutura complexa que envolve várias funções fisiológicas, incluindo respiração, deglutição e fonação (SCHWAB et al. $\left.{ }^{118}, 1995\right)$.

A faringe tem cerca de $12 \mathrm{~cm}$ de comprimento, estendendo-se da base do crânio até a borda superior da cartilagem cricóide, próximo à sexta vértebra cervical, onde continua com o esôfago (JOHNSON; MOORE $\left.{ }^{49}, 1983\right)$ e com a traquéia (por meio da laringe) (GARDNER et al. $\left.{ }^{31}, 1978\right)$. Divide-se em três segmentos anatômicos: ${ }^{\text {a) }}$ nasofaringe (região entre os cornetos nasais e palato duro); b) orofaringe, que pode ser subdividida em retropalatal (velofaringe) e região retrolingual; e, ${ }^{\mathrm{c})}$ hipofaringe (região da base da língua até a laringe) (SCHWAB et al. $\left.{ }^{118}, 1995\right)$.

A nasofaringe inicia-se atrás da cavidade nasal e acima do palato mole. Em sentido inferior, comunica-se com a orofaringe por intermédio do istmo da faringe, que é a porção situada atrás do palato mole. Trata-se de porção do trato respiratório superior e, normalmente, não dá passagem a alimentos ou líquidos. A tuba auditiva abre-se na parede lateral da nasofaringe; posteriormente a essa abertura existe uma depressão chamada recesso da faringe (JOHNSON; MOORE $\left.{ }^{49}, 1983\right)$. 
O teto e a parede posterior da nasofaringe localizam-se imediatamente adjacentes ao corpo do osso esfenóide e à porção basilar do osso occipital. A adenóide e as tonsilas faríngeas (tecidos linfóides) localizamse na porção superior dessa parede (JOHNSON; MOORE $\left.{ }^{49}, 1983\right)$.

A orofaringe estende-se do palato mole até o nível da epiglote; a cavidade bucal abre-se, anteriormente, na orofaringe, pela abertura orofaríngea, que é cercada em cada lado por um saco de membrana mucosa, chamado arco palatoglosso (produzido pelo músculo palatoglosso). A parede lateral da orofaringe, atrás do arco palatoglosso, apresenta uma membrana mucosa mais rígida (o arco palatofaríngeo) produzida pelo subjacente músculo palatofaríngeo. Entre os dois arcos, localizam-se as tonsilas palatinas (JOHNSON, MOORE $\left.{ }^{49}, 1983\right)$.

A parede anterior da orofaringe é composta primariamente pelo palato mole, língua e tonsilas linguais, enquanto que a parede anterior da hipofaringe é composta pelo osso hióide e pelos músculos que controlam sua posição. A parede posterior da oro e hipofaringe é composta pelos músculos: ${ }^{a}$ constritor superior (surge dos 2/3 inferiores da borda posterior da placa pterigóide do osso esfenóide e da porção posterior terminal da linha milohioídea); ${ }^{\text {b) }}$ médio (aderido anteriormente à porção inferior do ligamento estilóide ao corno menor e à borda superior do corno maior do osso hióide, suas fibras passam ao redor da faringe e interdigitam-se com as fibras do lado oposto); e, ${ }^{c}$ inferior (divide-se em dois segmentos: tirofaríngeo e cricofaríngeo; o tirofaríngeo surge da linha oblíqua sobre a lâmina da cartilagem tiróide, 
enquanto que o cricofaríngeo adere-se anteriormente à porção lateral do arco da cartilagem cricóide), anteriormente à coluna cervical (SCHWAB et al. ${ }^{118}$, 1995).

Segundo JOHNSON; MOORE ${ }^{49}, 1983$, o músculo estilofaríngeo, que é um dos músculos da faringe, é o único inervado pelo nervo glossofaríngeo, enquanto todos os demais são inervados por ramos originados no nervo acessório. O suprimento sanguíneo é fornecido pelo feixe faríngeo ascendente (ramo da carótida externa), ramos palatino e tonsilar da artéria facial, ramos palatino e faríngeo da artéria maxilar, ramos da artéria lingual e ramos laríngeos superior e inferior das artérias tiroideanas superior e inferior, respectivamente.

Posteriormente, a faringe encontra-se em contato com a fáscia pré-vertebral e, anteriormente, as relações da faringe, no sentido crânio-caudal, são: aberturas nasais posteriores, palato mole, cavidade oral, superfície posterior da língua, epiglote e laringe (JOHNSON; MOORE $\left.{ }^{49}, 1983\right)$.

Os músculos que formam a parede lateral da faringe incluem o hipoglosso, estilo-glosso, estilo-hióideo, estilo-faríngeo, palatoglosso, palatofaríngeo, além dos constritores da faringe. Os músculos hipoglosso, constritor médio e estilo-hióideo se inserem no osso hióide, enquanto que os músculos estilo-glosso, estilo-hióideo e estilofaríngeo originam-se no processo estilóide e cada um desses músculos possui função específica para produzir a mobilidade da língua e palato (SCHWAB et al. $\left.{ }^{118}, 1995\right)$. 
Entre o osso hióide, a mandíbula e o processo estilóide se dispõe um grupo de formações musculares distribuídas em dois planos: superficial (músculos digástrico e estilo-hioídeo) e profundo (milo-hioídeo e genio-hióideo) (FIGÚN; GARINO27, 1989).

O músculo digástrico constitui-se de dois ventres musculares unidos por tendão intermediário que, no conjunto, descrevem um arco que se estende desde o processo mastóide até a mandíbula, lateralmente à linha mediana. O ventre posterior nasce na incisura mastóidea do osso temporal, possui trajeto descendente anterior e medial até confundir-se com o tendão intermediário (que passa acima do osso hióide internamente à expansão aponeurótica que fixa no corpo e corno maior do osso hióide) e terminar na fossa digástrica da mandíbula (localizada na região de sínfise, próximo à base, no aspecto lingual da mandíbula) (FIGÚN; GARINO $\left.{ }^{27}, 1989\right)$.

O músculo genio-hióideo pode ser considerado um fascículo muscular alongado, estendendo-se desde a espinha mental da mandíbula até o osso hióide, contatando sua borda medial com a borda do lado oposto. O músculo genioglosso insere-se na mandíbula (espinha mental superior), donde partem fibras musculares em direção radiada que terminam no corpo do osso hióide (FIGÚN; GARINO $\left.{ }^{27}, 1989\right)$.

Segundo $\mathrm{BARSH}^{10}$, 1998, o músculo digástrico pode ser considerado um músculo da faringe, pois sua função é produzir a elevação do osso hióide e o abaixamento da mandíbula. O músculo genioglosso protrui e abaixa a língua (fibras inferiores e médias, respectivamente), enquanto que o 
REVISÃo DE LITERATURA

músculo genio-hióideo eleva o osso hióide e abaixa a mandíbula. O músculo elevador do véu palatino eleva o palato mole; os músculos da úvula encurtamna e o músculo palatoglosso eleva a laringe, auxiliado pelo músculo salpingofaríngeo. O músculo estilo-glosso retrai e eleva a língua e o músculo estilo-hioídeo eleva e retrai o osso hióide; o músculo tensor do véu palatino abre a tuba auditiva e tensiona o palato mole.

Segundo ROBERTSON ${ }^{110}, 2000$, o hióide é o osso onde se origina a língua e é o local de inserção dos músculos do sistema biodinâmico que regula a respiração, mastigação, deglutição e fonação. Tal osso suspendese posterior e bilateralmente, a partir da base do crânio até uma adesão anterior próxima à linha média mandibular, e seus cornos delimitam a porção laríngea da faringe, onde a abertura superior da faringe está incluída.

O osso hióide é um osso único, não articulado com outros ossos, e suspenso no tecido mole por tendões e músculos. No início da vida, ocupa posição ao nível da borda inferior da mandíbula, porém, com o crescimento, desce gradualmente e acaba por ficar próximo à quarta vértebra cervical. Devido ao fato de não se articular com outros ossos, muda de posição de acordo com o posicionamento da cabeça, corpo e outros estados fisiológicos, além de mover-se durante várias funções orais em conjunto com a atividade da língua. Devido à inter-relação das fibras do músculo geniohióideo e genioglosso, também se move com a língua e assoalho da boca durante respiração e deglutição (PAE et al. $\left.{ }^{94}, 2004\right)$. 
No aspecto do desenvolvimento, no homem, o osso hióide assume funções adicionais quando comparado a outras espécies. Uma vez que os homens mudaram para uma posição ereta, a laringe e a traquéia estão próximas e podem sofrer mais a ação da gravidade. Como conseqüência, a via aérea patente só pode ser mantida pelos músculos que estão à frente do osso hióide. Para melhorar a eficiência respiratória, o grupo dos músculos supra e infra-hióideos puxam o osso hióide para frente para manter a patente da via aérea orofaríngea, durante a fase inspiratória da respiração (ROBERTSON ${ }^{110}$, 2000).

Ainda segundo ROBERTSON ${ }^{110}$, 2000, alguns estudos têm mostrado que o osso hióide apresenta-se mais inferiormente posicionado durante o crescimento e, no adulto, situa-se ao nível da vértebra C4. Segundo KOLLIAS; KROGSTAD ${ }^{55}$, 1999, com o envelhecimento, o osso hióide assume posição mais inferior em relação às outras estruturas esqueléticas em ambos os sexos. Para KOLLIAS; KROGSTAD ${ }^{56}$, 1999, o avanço da idade gera alterações, em homens e mulheres, que incluem: a) aumento do comprimento, espessura e área sagital do palato mole em ambos os sexos; b) encontra-se a língua em posição mais ereta, porém, com massas teciduais laterais estendidas caudalmente em ambos sexos, além de área sagital da língua aumentada no sexo masculino; e, ${ }^{\text {c) }}$ redução nas dimensões sagitais da orofaringe e na mínima distância entre a base da língua e a parede posterior da faringe em ambos os sexos. 
O tamanho do lúmen da faringe depende do balanço entre as forças resultantes da contração muscular e pressão subatmosférica luminal durante a inspiração (BARSH $\left.{ }^{10}, 1998\right)$. A faringe atua como um tubo colabável para controlar a respiração, fonação e deglutição. Em razão de os canais respiratório e alimentar correrem pela faringe, um mecanismo sofisticado leva esse tubo flexível ao colapso durante deglutição, protegendo a via aérea. Quando a deglutição começa, a mandíbula retrui, geralmente em oclusão cêntrica, formando uma base óssea estável para a contração dos músculos da língua, a elevação do osso hióide e a contração dos músculos do palato mole e os constritores da faringe. Uma vez que a deglutição se encerra, a via aérea retorna ao normal - pelo relaxamento dos músculos constritores e contração dos dilatadores (estilofaríngeo e palatofaríngeo) - levando a mandíbula à posição fisiológica de descanso ou de respiração. Nessa posição, os planos mandibular e maxilar estão paralelos e o movimento anterior da mandíbula traz os côndilos para baixo, na fossa articular, levando o pogônio para baixo e para frente em distância igual. Tal posição possui três funções: ${ }^{\text {a) }}$ o movimento de afastamento, em relação à maxila, estira e amplia a parede lateral da faringe e o músculo superior constritor, via sua adesão à porção medial da placa pterigóide, rafe pterigomandibular, assoalho de boca e língua; ${ }^{\text {b) }}$ o volume da cavidade oral aumenta, acomodando a língua; e, ${ }^{c}$ o pogônio traz os tubérculos genes à frente, provendo uma base óssea fixa. A língua, então, descansa atrás dos incisivos superiores e forma, independentemente, um selo com o palato mole e duro (THORNTON $\left.{ }^{134}, 1998\right)$. 
SCHWAB et al. ${ }^{118}$, 1995, relataram que a área média do espaço aéreo superior, em $\mathrm{mm}^{2}$, para pessoas normais, roncadores/apnéicos moderados e apnéicos severos, foi de $64,4,40,8$ e 29,3 respectivamente. O diâmetro lateral foi de $12,9 \mathrm{~mm}^{2}$ para pessoas normais, $8,5 \mathrm{~mm}^{2}$ para roncadores e $6,7 \mathrm{~mm}^{2}$ para apnéicos, enquanto que diâmetro antero-posterior foi de $5,8 \mathrm{~mm}^{2}, 5,6 \mathrm{~mm}^{2}$ e $4,7 \mathrm{~mm}^{2}$, respectivamente.

Segundo BARROS $^{9}, 2001$, a largura da nasofaringe pode ser medida linearmente, nas telerradiografias de perfil, de um ponto médio da parede posterior do palato mole até a parede posterior da faringe, onde houver maior fechamento da passagem aérea, sendo os valores normais para portadores de dentadura mista de $12 \mathrm{~mm}$ e 17,4 $\mathrm{mm}$ para os portadores de dentadura permanente. A largura da orofaringe pode ser avaliada, radiograficamente, no ponto onde a borda posterior da língua cruza com a borda inferior da mandíbula até a parede posterior da faringe (os valores considerados normais são de 10 a 12 mm).

\subsection{Síndrome da Apnéia Obstrutiva do Sono (SAOS)}

Para JOHNS et al. ${ }^{47}, 1998$, hipopnéia é o decréscimo de 50\% no fluxo de ar por mais de 10 segundos; segundo MIRANDA ${ }^{84}, 1999$, apnéia pode ser definida como parada total da respiração por mais de 10 segundos. 
O ronco e a SAOS são as duas extremidades de um espectro de comprometimentos da via aérea superior, relacionados com o sono; um indivíduo que se encontra no meio do espectro poderá roncar em certas ocasiões (dormir em decúbito dorsal ou durante o sono REM - rapid eye moviment) (KNEISLEY $\left.{ }^{54}, 1998\right)$.

Embora nem todas as pessoas que roncam tenham SAOS, o ronco é um sinal cardeal da síndrome, portanto, pode ser associado com o aumento da morbidade e da mortalidade. De acordo com BARSH ${ }^{10}, 1998$, o ronco tem sido considerado como a primeira evidência de obstrução da via aérea superior, um fator de risco para doença cardiovascular.

A respiração de pacientes com grau maior de obstrução da via aérea superior, durante o sono, caracteriza-se por ronco contínuo, pontuado por apnéias e hipopnéias durante sono REM, quando o tônus muscular se reduz ou quando, em posição supina, a força gravitacional sobre os tecidos moles da língua e do palato reduz o diâmetro da via aérea. Na extremidade severa do espectro, a via aérea faríngea repetidamente colapsa e se obstrui completamente durante o sono (KNEISLEY $\left.{ }^{54}, 1998\right)$.

A severidade da apnéia obstrutiva do sono é determinada pelo índice de apnéia/hipopnéia (IAH), que pode ser definido como o número médio de episódios de apnéia e hipopnéia por hora. Considera-se portador da SAOS os pacientes que apresentam IAH maior que 10 (JOHNS et al. $\left.{ }^{47}, 1998\right)$.

A SAOS é uma desordem respiratória do sono, resultante de obstruções anatômicas na via aérea superior (MARSHALL $\left.{ }^{81}, 1998\right)$, em nível 
da naso e orofaringe, estendendo-se comumente para a laringo-faringe (RAMA et al. $\left.{ }^{101}, 2002\right)$. BOHLMAN et al. ${ }^{13}, 1983$, observaram que $1 / 3$ das obstruções ocorriam em um único nível, enquanto que 2/3 ocorriam em dois ou mais níveis. RILEY et al. ${ }^{105}, 1987$, comentaram que as regiões principais de obstrução são: palato mole, parede lateral da faringe e base da língua (hipofaringe); LI et al. ${ }^{63}, 1999$, acrescentaram a essa relação o nariz.

Ocasionada pela obstrução da passagem do ar no trajeto do meio externo até os pulmões, a SAOS decorre de alterações anatômicas que reduzem o espaço aéreo faríngeo e deve-se a um componente funcional que permite o colapso das vias aéreas. Ocorre em 2 a 9\% da população acima dos 45 anos, com predomínio nos homens: oito casos no gênero masculino contra um caso no gênero feminino (MIRANDA $\left.{ }^{84}, 1999\right)$. A SAOS é uma desordem médica que potencialmente ameaça a vida, com uma prevalência estimada em mais de 18 milhões de pessoas nos Estados Unidos da América do Norte (PRINSELL $\left.{ }^{100}, 1999\right)$.

Para FRIEDLANDER et al. $^{30}, 2000$, nos Estados Unidos a SAOS ocorre em $2 \%$ das mulheres e $4 \%$ dos homens, sendo mais comum em obesos ( $40 \%$ dos homens e $3 \%$ das mulheres). Segundo GOODDAY et al. ${ }^{33}$, 2001, a prevalência cresce dramaticamente com o avanço da idade, estando estimada entre 28 a $67 \%$ nos homens idosos e 20 a 54\% nas mulheres idosas.

A patogênese do colapso da via aérea superior na SAOS é complexa e multifatorial: gênero masculino, idade e obesidade são os principais fatores de risco (LI et al. $\left.{ }^{66}, 2000\right)$. Para LI et al. ${ }^{65}, 2000$, a obesidade é o maior 
deles e está presente em $60 \%$ dos pacientes. Tal fato pode ser o fator mais significante na relação da severidade da síndrome (JOHNS et al. $\left.{ }^{47}, 1998\right)$. YOUNG et al. ${ }^{147}, 2002$, citaram o álcool, cigarro, congestão nasal e a redução dos níveis de estrógeno na menopausa como fatores de risco para a SAOS. STAUFFER et al. ${ }^{128}$, 1989 , citaram que os portadores de SAOS possuem úvula com maior quantidade de músculo e gordura, possivelmente contribuindo para o estreitamento da orofaringe.

Segundo FRIEDLANDER et al. ${ }^{29}, 2000$, os aspectos clínicos mais comuns são: gênero masculino, obesidade, aumento da circunferência cervical, deposição excessiva de gordura no palato, língua (macroglossia) e faringe, palato mole alongado, pequeno retroposicionamento mandibular e maxilar, ateromas calcificados da artéria carótida, visíveis nas radiografias panorâmicas e teleperfis.

VILLANEUVA et al. ${ }^{142}, 2005$, comentaram que o aumento da prevalência de SAOS entre adultos americanos e hispânicos pode ser principalmente explicado pelo aumento da obesidade. KUBOTA et al ${ }^{57}, 2005$, asseveraram que, nos japoneses, a obesidade também parece ser importante fator de risco, assim como o padrão dólico facial, referenciando que um SNA e SNB menor associam-se a uma SAOS mais severa em pacientes não obesos.

Para LI et al. ${ }^{69}, 2000$, a SAOS associa-se à obstrução repetitiva da via aérea superior, levando à sonolência diurna e desordens cardiovasculares. Segundo BAIK et al. ${ }^{7}, 2002$, a apnéia secundária à obstrução da via aérea superior induzida durante o sono, combinada a esforços 
respiratórios, é o tipo mais comum e classifica-se como SAOS. Tal síndrome resulta em redução da saturação de oxigênio sanguíneo (que pode levar à hipertensão, arritmia cardíaca, angina noturna e isquemia cardíaca) e fragmentação do sono (levando à sonolência excessiva diurna, deterioração da memória, alterações da personalidade e redução da capacidade de concentração).

Desordens ventilatórias durante o sono resultam em vários distúrbios fisiológicos e clínicos. Essas complicações podem ocorrer tanto por interferência na qualidade, na quantidade e na estrutura do sono, quanto por hipoxemia ou asfixia noturna (TANGUGSORN et al. ${ }^{131}, 2000$ ). Contudo, segundo PHILLIPSON ${ }^{98}, 1982$, as manifestações clínicas podem ser divididas em duas categorias: a primeira é a perturbação na estrutura do sono resulta em manifestações mais neuropsiquiátricas e comportamentais do que respiratórias. A alteração mais comum é a hipersonolência diurna que pode tornar-se perigosa (prejuízo na habilidade de dirigir e aumento na taxa de acidentes automobilísticos em pacientes portadores de SAOS) e incapacitante. Freqüentemente associados à hipersonolência, aparecem os sinais de perda do desempenho intelectual e de memória, delírios, cefaléia matinal e alterações de personalidade (VERSTRAETEN et al. ${ }^{139}$, 1996).

$\mathrm{Na}$ segunda categoria aparecem complicações relacionadas com a hipoxemia noturna ou asfixia; estas são predominantemente cardiovasculares e respiratórias (GUILLEMINAULT et al. ${ }^{37}, 1983$ ). Uma grande flutuação da pressão intratorácica e anormalidades das trocas gasosas, devido 
à apnéia, pode desencadear um aumento na atividade do sistema nervoso simpático e influenciar o retorno venoso, os baro-reflexos, o tônus vagal e a liberação de peptídeos reguladores de volume. Eventualmente, a resposta cardiovascular aguda pode incluir vasoconstrição pulmonar e sistêmica, hipertensão, redução do débito cardíaco e arritmias. Apesar disso, a parada recorrente da respiração, com simultâneo esforço respiratório durante a noite, é a principal característica da SAOS (SHEPARD $\left.{ }^{120}, 1992\right)$.

Salienta-se o fato de que o despertar é essencial para a reabertura da via aérea (JOHNS et al. ${ }^{47}$, 1998), gerando - em pacientes com SAOS - valores da Escala de Sono de Epworth (avalia nível de sonolência diurna) significativamente maiores $\left(\mathrm{JOHNS}^{48}, 1991\right)$. Em 2000, FRIEDLANDER et al. $^{30}$ lembraram que a sonolência diurna custou aos Estados Unidos da América do Norte cerca de US\$ 41 bilhões em gastos com cuidados médicos e perda de produtividade. SHERRING et al. ${ }^{122}, 2001$, estimaram um aumento de $25 \%$ na mortalidade por doença cardiovascular quando os portadores de SAOS são comparados com pessoas saudáveis do mesmo sexo e idade, além de grande aumento nas taxas de acidentes de trânsito e em indústrias.

Os episódios de apnéia ocorrem mais freqüentemente durante o sono REM, pois os músculos que usualmente dilatam a via aérea superior (geniohióideo, genioglosso e tensor do véu palatino), perdem (FRIEDLANDER et al. $\left.{ }^{30}, 2000\right)$ ou reduzem seu tônus (SIMMONS $\left.{ }^{123}, 1998\right)$.

A SAOS pode ser diagnosticada pela história característica do paciente (ronco, sonolência diurna) e pelo exame físico (aumento da 
circunferência do pescoço), mas a polissonografia noturna é necessária para confirmar a presença da desordem (MALHOTRA; WHITE $\left.{ }^{77}, 2002\right)$.

Os métodos para identificação dos locais de obstrução são: o exame físico, análise cefalométrica, nasofaringoscopia, endoscopia, tomografia computadorizada, ressonância magnética dinâmica (BAIK et al. $^{7}$, 2002), cefalometria associada à videoendoscopia (NAGANUMA et al. ${ }^{87}$, 2002) e cefalometria associada à ressonância magnética (DIEULEVEULT et al. ${ }^{18}$, 2000).

JOHNS et al. ${ }^{47}$, 1998, asseveraram que a cefalometria é o exame por imagem mais comum para a avaliação de pacientes com SAOS, uma vez que revelam várias anormalidades nos tecidos duros e moles da via aérea, que predispõem o paciente à obstrução da faringe.

Segundo ROBERTSON ${ }^{110}, 2000$, um dos métodos usados mais aceitos para avaliar a via aérea superior e a morfologia craniofacial, durante 0 período que o paciente portador de SAOS está acordado, é a cefalometria. Trata-se de um exame barato e que permite correlação com outros exames, além de possibilitar a análise estática da faringe, do palato mole, da língua e do osso hióide, com as estruturas craniocervicais adjacentes. Apesar da limitação bidimensional óbvia, considera-se que alterações grosseiras na posição da língua podem ser observadas pela análise de alterações do osso hióide e de seu posicionamento.

A radiografia cefalométrica é uma radiografia lateral padronizada da cabeça e pescoço, que permite o exame das estruturas ósseas 
e moles da via aérea superior. Trata-se de técnica larga e facilmente utilizada, além de ser mais barata do que a tomografia computadorizada e a ressonância magnética. Contudo, deve ser realizada em posição padronizada, com a cabeça estabilizada, e a tomada radiográfica deve ser obtida ao final da expiração, uma vez que o calibre da via aérea pode ser afetado com o ciclo respiratório. Mostra-se útil em quantificar estruturas moles e duras em pacientes com anormalidades faciais (como retrognatismo e prognatismo) (SCHWAB; GOLDBERG $\left.{ }^{117}, 1998\right)$.

Segundo ÁLVARES; TAVANO ${ }^{4}, 1998$, as radiografias cefalométricas laterais permitem clara visualização das estruturas anatômicas da face e crânio: oro e nasofaringe, língua, palato mole, epiglote, osso hióide, processo mastóide, coluna vertebral, seio frontal, seio maxilar, seio esfenoidal, sela túrcica, órbita (rebordo infra-orbitário), palato duro, soalho da fossa nasal, espinha nasal anterior, espinha nasal posterior, processo zigomático da maxila, fossa ptérigo-maxilar, apófise pterigóide, processo condilar, incisura da mandíbula, tubérculo articular, asa maior do esfenóide, canal mandibular, base da mandíbula, forame mentoniano, arco zigomático e tábua óssea interna da mandíbula.

SANTOS-PINTO et al. ${ }^{115}$, 2005/2006, lembraram que, apesar de fornecer informações de modo bidimensional, a telerradiografia em norma lateral possibilita a visualização das estruturas de tecido mole tão bem quanto das estruturas de tecido duro. VILELLA et al. ${ }^{141}$, 2006, utilizaram radiografias 
cefalométricas para avaliar comparativamente o padrão de crescimento da nasofaringe e adenóides em brasileiros brancos.

MALKOC et al. ${ }^{78}, 2005$, asseveraram que as dimensões da via aérea superior e as posições da língua e osso hióide são altamente reproduzíveis em radiografias cefalométricas; modernamente existem vários sistemas pelos quais a análise cefalométrica é realizada em uma radiografia cefalométrica digitalizada (EALES et al. ${ }^{20}, 1994$, HARRADINE; BIRNIE ${ }^{38}, 1985$, ISIK et al. ${ }^{45}$, 2006, MANKAD et al. ${ }^{79}$, 1999, SINCLAIR et al. ${ }^{124}$, 1995), utilizando-se sistemas computadorizados para visualização de objetivos de tratamento (VTO) (MAPLE et al. ${ }^{80}, 2005$, TSUIKI et al. $\left.{ }^{137}, 2005\right)$.

DONASTSKY et al. ${ }^{19}$, 1997, utilizaram programa de análise cefalométrica e simulação cirúrgica para verificar a precisão e estabilidade da cirurgia ortognática bimaxilar; observaram que o TIOPS (programa de cefalometria e planejamento para ortognática) foi útil na simulação cirúrgica, planejamento e predição, além da avaliação pós-operatória da precisão e estabilidade cirúrgica.

AHARON et al. ${ }^{2}, 1997$, testaram e compararam a acurácia das predições do perfil mole, geradas por dois programas de computador. Os resultados demonstraram que, em média, as previsões não se apresentaram diferentes do resultado pós-operatório, apesar de poderem variar de acordo com o montante de movimento, acarretando erros.

Com o objetivo de comparar a confiabilidade e reprodutibilidade de medidas cefalométricas obtidas por intermédio da DigiGraph Workstation 
(Dental Planner Software), com radiografias cefalométricas convencionais, TSANG; COOKE ${ }^{135}, 1999$, utilizaram 30 crânios secos e observaram que o método de erro da DigiGraph Workstation (Dental Planner Software) variou de 7 a $70 \%$, enquanto que os traçados obtidos nas radiografias variaram menos de 2\%; concluíram que deve-se interpretar com cautela as medidas realizadas na DigiGraph Workstation.

Em 2001, LOH et al. $^{74}$ realizaram estudo retrospectivo da precisão dos traçados preditivos efetuados pelo programa Quick Ceph Image Pro 3.0, por meio da comparação de tais traçados com resultados cefalométricos pós-operatórios. Concluíram que se deve ter cautela na utilização de tal programa, uma vez que o cirurgião pode não obter a posição planejada em algum paciente.

LOH; YOW ${ }^{75}, 2002$, avaliaram a acurácia das predições computadorizadas por meio da utilização do programa CASSOS 2001 (Computer - Assisted Simulation System for Orthognathic Surgery), produzido pela SoftEnable Technology; para isso, avaliaram 40 adultos que submeteramse à cirurgia ortognática. Seus resultados mostraram que o CASSOS 2001 foi preciso na previsão dos tecidos duros em cirurgia ortognática.

ECKHARDT; CUNNINGHAM ${ }^{21}, 2004$, compararam a precisão da previsão cirúrgica manual e computadorizada (OPAL - Orthognatic planning and analysis computer program), enfatizando os tecidos moles. Seus resultados evidenciaram marcada variação individual quando se planeja manualmente ou por meio do programa OPAL, especialmente em cirurgias 
combinadas. Concluíram que, apesar da utilidade da predição informatizada ser conhecida, deve-se utilizá-la com cautela.

SMITH et al. ${ }^{126}, 2004$, investigaram as diferenças perceptíveis na capacidade dos programas Dentofacial Planner Plus, Dolphin Imaging 8.0, Orthoplan, Quick Ceph Image, e Vistadent em simular o resultado em cirurgia ortognática. Os resultados obtidos indicaram o programa Dentofacial Planner Plus como o melhor simulador de resultados, enquanto que o Dolphin Imaging 8.0 e QuickCeph Image foram considerados de segunda linha.

GOSSETT et al. $^{34}, 2005$, compararam a precisão dos programas de VTO (Dolphin Imaging System 8.0) com os procedimentos de VTO convencionais. Concluíram que ambos os meios podem ser utilizados, com a mesma precisão.

POWER et al. $.^{99}, 2005$, citaram que a versão 8.0 do programa Dolphin Imaging necessitava de revisão para correção de erros no programa, que resultavam em uma inexatidão de cálculo clinicamente significante.

O tratamento da SAOS deve ser multidisciplinar e incluir médicos especializados em problemas respiratórios, otorrinolaringologistas, doenças do sono, cirurgiões buco-maxilo-faciais e cirurgiões-dentistas especialistas em outras áreas (SHERRING et al. $\left.{ }^{122}, 2001\right)$. O tratamento pode ser conservador ou cirúrgico: o tratamento conservador utiliza a máscara de pressão positiva contínua de ar (Continuous Positive Air Pressure - CPAP) ou aparelhos intrabucais, que visam avançar a mandíbula e mantê-la em uma relação oclusal de protrusão durante o sono (PANULA; KESKI-NISULA ${ }^{95}$, 
2000). KNEISLEY ${ }^{54}, 1998$, citou ainda a perda de peso, os dilatadores nasais e os tratamentos comportamentais (treinamento postural para dormir, higiene do sono e elevação da cabeceira) como tratamentos paliativos possíveis para a SAOS. LIU et al. ${ }^{72}, 2000$, asseveraram que o reposicionador mandibular pode ser efetivo no tratamento da SAOS e que se atribui a redução da freqüência dos episódios de apnéia, especialmente aos efeitos do aparelho sobre as estruturas da orofaringe. Apesar disso, ALMEIDA et al. $^{3}, 2006$, referiram que o uso prolongado dos aparelhos reposicionadores mandibulares pode gerar alterações na posição dentária e afetar a postura mandibular, enquanto que OTSUKA et al. $^{92}, 2006$, correlacionaram o ganho de peso com resultados insatisfatórios no tratamento da SAOS com aparelhos intrabucais.

$\mathrm{LI}^{71}, 2005$, comentou que, a despeito das vantagens da terapia de pressão positiva para a SAOS, o uso do CPAP é um problema para muitos pacientes, o que torna os procedimentos cirúrgicos opções viáveis para aqueles que não toleram a terapia de pressão positiva.

O objetivo da avaliação pré-cirúrgica é documentar a SAOS e isolar a área de obstrução, pois o tratamento é direcionado para o sítio da obstrução (RILEY et al. ${ }^{109}, 1993$, TANGUGSORN et al. ${ }^{132}$, 1995). O tratamento cirúrgico consta de duas fases: a) abordagem conservadora, que inclui uvulopalatofaringoplastia e/ou osteotomia mandibular com avanço do genioglosso e miotomia com suspensão do hióide; e, ${ }^{\text {c) }}$ avanço maxilomandibular (RILEY et al. ${ }^{109}$, 1993). 
O manejo cirúrgico da SAOS baseia-se na obtenção de trajeto para passagem do ar, removendo o tecido oclusor ou reposicionando-o para reduzir sua frouxidão. Uma vez que foram determinados os locais de obstrução, a decisão de qual procedimento deve ser realizado visará à necessidade de aumentar a via aérea e sua estabilidade. Isso inclui osteotomia mandibular inferior associada à suspensão do hióide (RILEY et al. ${ }^{106}, 1989$, avanço maxilo-mandibular associado ao avanço do osso hióide (RILEY et al. ${ }^{108}$, 1990), redução da base da língua, avanço maxilo-mandibular (SHER et al. ${ }^{121}$, 1996), amigdalectomia e adenoidectomia (MARSHALL ${ }^{81}$, 1998), uvulopalatofaringoplastia (convencional ou a laser), avanço do genioglosso e suspensão do osso hióide, e traqueotomia (KIM et al. ${ }^{53}, 1998$; MARSHALL ${ }^{81}$, 1998).

Em 2001, segundo LI et al. $^{70}$, a uvulopalatofaringoplastia (UPPP) era o tratamento cirúrgico mais comum para a SAOS, pois possuía potencial para aumentar as dimensões do espaço aéreo faríngeo e reduzir o colapso faringiano. Contudo, mostrou resultados satisfatórios em somente $50 \%$ dos portadores, visto que as causas para a persistência da SAOS após UPPP podem ser o colapso persistente em nível faringeano e a presença de obstrução na hipofaringe. O avanço maxilo-mandibular tem sido preconizado para pacientes que respondem de maneira incompleta a UPPP, pois, o movimento anterior do complexo mandíbula/língua aumenta as dimensões do espaço aéreo hipofaríngeo, enquanto melhora a tensão da musculatura suprahioidea. O movimento anterior da maxila/palato mole resulta no aumento das 
dimensões da via aérea faríngea enquanto melhora a tensão da musculatura velo-faríngea, decrescendo a possibilidade de colapso faríngeo.

VILASECA et al. ${ }^{140}, \quad 2002$, asseveraram que a uvulopalatofaringoplastia associada ao avanço do músculo genioglosso e osso hióide pode ser benéfica para pacientes com média e moderada SAOS e obstrução multinível.

O músculo genioglosso é o maior dilatador da faringe e tem sido sugerido como um fator importante na obstrução noturna da via aérea superior. A idéia básica do avanço desse músculo é colocá-lo sob tensão, restringindo o colapso da língua para o interior do espaço aéreo, durante a hipotonia do sono. Aparentemente, a técnica da osteotomia retangular captura os tubérculos genes e permite que o músculo seja adequadamente avançado (Ll et al. $\left.{ }^{67}, 2001\right)$.

Para LI et al. ${ }^{62}$, 2002, a distensão osteogênica é aplicável para o avanço esquelético para tratamento da SAOS, apesar de suas desvantagens (inflamação no distensor, desconforto na ATM e parestesia temporária). WANG et al. ${ }^{143}, 2003$, asseveraram que a distensão osteogênica é um método efetivo para correção de micrognatia acompanhada de SAOS, pois se trata de método de baixa morbidade, simples manipulação, alta taxa de sucesso, baixa taxa de recidiva e resultados estáveis. Em 2006, CONLEY; LEGAN ${ }^{17}$ relataram que a distensão osteogênica transversal bimaxilar, associada com posterior avanço maxilo-mandibular, produziu melhora importante na oclusão, na morfologia facial e na SAOS. Seus resultados revelaram que a expansão transversal tem 
papel importante no tratamento de pacientes portadores de SAOS e de deformidade dento-facial esquelética.

Reconhecendo que a deficiência ântero-posterior maxilo-mandibular foi identificada em alguns pacientes portadores da SAOS, o avanço maxilo-mandibular tem sido relatado como opção de manejo da SAOS desde a metade dos anos 80. Apesar do alto sucesso dessa modalidade de tratamento, cerca de $40 \%$ dos portadores da SAOS não seriam candidatos ao avanço maxilo-mandibular, pois não apresentam padrões esqueléticos desproporcionais, e esse tipo de intervenção poderia acarretar alterações do perfil facial e nas articulações têmporo-mandibulares (LI et al. ${ }^{65}, 2000$ ).

LI et al. ${ }^{63}, 1999$, publicaram os seguintes critérios para a indicação do avanço maxilo-mandibular: SAOS severa, obesidade mórbida, disposição do paciente para submeter-se ao procedimento e saúde que o permita, além de falha em outros métodos de tratamento.

O avanço maxilo-mandibular expande o arcabouço esquelético na faringe e hipofaringe, que leva ao aumento das dimensões da via aérea superior. Outrossim, o movimento anterior do complexo maxilo-mandibular resulta em aumento da tensão na musculatura supra-hioidea e velo-faríngea e, conseqüentemente, reduz a colapsibilidade da via aérea (LI et al. ${ }^{66}$, 2000; LI et al. $\left.{ }^{68}, 2001\right)$.

NIMKARN et al. ${ }^{91}$, 1995, relataram que mesmo os grandes avanços maxilo-mandibulares em pacientes portadores de SAOS resultam em reposicionamento estável de ambos os ossos por longos períodos pós- 
operatórios. YU et al. ${ }^{148}, 1994$, estudaram as dimensões ântero-posteriores da orofaringe em telerradiografias laterais, em períodos pré e pós-operatório médio de 15 meses, mediante análise cefalométrica de traçados manuais de 26 pacientes submetidos a avanço mandibular. Como resultado, observaram um aumento das dimensões sagitais da orofaringe, porém, com tendência de decréscimo com o tempo, sugerindo que o avanço mandibular pode ser um método inseguro para o tratamento da SAOS. Segundo PRINSELL ${ }^{100}, 1999$, o avanço maxilo-mandibular nos pacientes portadores de SAOS apresenta taxa de $100 \%$ de sucesso, além de ser um método seguro e definitivo para 0 tratamento cirúrgico de casos de SAOS com múltiplos locais de desproporção da anatomia velo-faríngea.

\subsection{Inter-relação da SAOS com deformidade dento-facial-esquelética}

Define-se deformidade dento-facial-esquelética como defeito no crescimento e desenvolvimento dos ossos da face (especialmente na maxila e mandíbula), que resultam em alteração desses ossos propriamente ditos, no posicionamento dos dentes e na sua inter-relação, na função mastigatória, na deglutição, na fonação, nas articulações têmporo-mandibulares, na respiração, na harmonia e estética da face (NARY FILHO et al. $\left.{ }^{89}, 2004\right)$.

Tais deformidades podem ocorrer pelo hipo ou hiperdesenvolvimento ósseo, na maxila ou na mandíbula, em ambas ou em 
partes delas, ou em conjunto com todos os demais ossos da face e do restante do corpo. Na face apresentam características marcantes, sendo classificadas segundo padrões transversais, verticais e ântero-posteriores. Paralelamente, existem as alterações assimétricas, ou seja, hemihiperplasia (hemihipertrofia) ou mesmo hemiatrofias, anomalias de desenvolvimento geralmente associadas a síndromes, cuja abordagem é bastante complexa (NEVILLE et al. $\left.{ }^{90}, 1998\right)$.

Entre as possíveis deformidades, as antero-posteriores (AP) são as mais comuns e denominadas genericamente de prognatismos (deformidade por excesso de crescimento) ou retrognatismos (deformidade por deficiência de crescimento). Caracterizam-se por projeção horizontal maior de um arco em relação ao outro e a prognatismo mandibular é, sem dúvida, a situação que mais leva os pacientes a buscarem tratamento ortodônticocirúrgico (BAILEY et al. ${ }^{8}$, 2001), em decorrência do grande prejuízo estético e funcional que essas características trazem ao seu portador.

Além de ocorrerem em sentidos variados (vertical, horizontal e transversal), as deformidades dento-facial-esqueléticas podem ocorrer em graus variados. Pode-se ter um paciente portador de excesso de crescimento horizontal de mandíbula discreto, com pequena discrepância maxilo/mandibular, com poucas repercussões funcionais e estéticas - que eventualmente podem ser tratadas com compensações ortodônticas corrigindo somente posicionamento dentário. Contudo, outros pacientes poderão ser portadores do mesmo tipo de deformidade dento-facial esquelética, porém, em maior severidade quanto ao excesso horizontal de mandíbula, algo que 
repercute de forma avassaladora na função e estética, e que obrigatoriamente deverá ser tratado com descompensação dentária ortodôntica e cirurgia ortognática (NARY FILHO et al. $\left.{ }^{89}, 2004\right)$.

Por esses motivos, as deformidades são ditas dento-esqueléticas e, invariavelmente, são associadas às más oclusões; não se observa pacientes com deformidade óssea e alinhamento dos arcos adequados para cirurgia. Sempre existe uma acomodação dos dentes e uma tentativa natural de compensação do defeito esquelético, alvo do preparo précirúrgico. Sendo assim, sempre o tratamento se inicia com ortodontia, tendo como objetivo a correção da má oclusão (NARY FILHO et al. $\left.{ }^{89}, 2004\right)$.

A classificação das más oclusões, descrita por $A N G L E^{5}, 1899$, também é utilizada nesta abordagem, ou seja, Classe I (relação anteroposterior normal, evidenciada pela relação molar) e Classe II (primeiro molar permanente inferior situa-se distalmente ao primeiro molar permanente superior). A Classe II de Angle subdivide-se em Divisão $1^{\text {a }}$ (relação molar em Classe II e vestibularização dos incisivos superiores) e Divisão $2^{\mathrm{a}}$ (relação molar de Classe II e lingualização ou verticalização dos incisivos superiores). ANGLE $^{5}$, 1899, ainda, classificou como Classe III as más oclusões, nas quais o primeiro molar permanente inferior encontra-se mesializado em relação à cúspide mésio-vestibular do primeiro molar superior.

Muito embora o padrão facial não determine nem seja determinado pelo tipo de oclusão, as relações são muito comuns. No paciente Classe I, de Angle, é freqüente a presença de perfil facial reto e equilíbrio das 
funções da musculatura peribucal, mastigadora e da língua. No paciente Classe II, predomina um perfil facial convexo e, na Classe III, cujo perfil geralmente é côncavo, a musculatura está desequilibrada (MARTINS; COTRIM-FERREIRA ${ }^{82}$, 2001). Nesse ínterim, cumpre ressaltar que os efeitos deletérios da presença das deformidades poderão ser sentidos nos ossos, dentes, músculos, articulação têmporo-mandibular, sistema digestivo e espaço aéreo superior, podendo ser traduzidos por dores articulares e musculares, dificuldades mastigatórias, fonoarticulatórias e de deglutição, além de reabsorção óssea (especialmente alveolar) e perda de elementos dentais (decorrentes de trauma oclusal sofrido pelos dentes em posição inadequada), desconforto gástrico, desnutrição e dificuldade respiratória. É importante lembrar, ainda, que esses efeitos poderão variar em função da capacidade de adaptação individual dos tecidos envolvidos e da condição reacional do paciente.

Além das repercussões funcionais, destacam-se nos pacientes portadores de deformidades dento-faciais esqueléticas as alterações da harmonia e estética da face. Parece claro que pacientes portadores desse tipo de deformidade terão evidente prejuízo de sua estética, que variará de acordo com o tipo e o grau de deformidade. Portadores de deformidades dento-faciais esqueléticas apresentam, ainda, prejuízo emocional, decorrente, principalmente, de sua insatisfação com a aparência. Contribuindo negativamente para sua auto-estima, a estética insatisfatória traduz-se em 
alterações comportamentais como a introspecção (especialmente em mulheres) (NARY FILHO et al. $\left.{ }^{89}, 2004\right)$.

ZHOU et al. $^{151}, 2001$, estudaram 140 pacientes chineses, portadores de deformidade dento-facial esquelética tipo Classe III, objetivando avaliar a sua motivação para o tratamento ortodôntico cirúrgico. Concluíram que aproximadamente a metade dos pacientes possuía um apelido relacionado à sua deformidade e que a maioria sentia-se embaraçada, triste $\mathrm{e}$ desencorajada. Os pacientes esperavam, ainda, que a cirurgia melhorasse a sua vida social.

Entre as repercussões funcionais dessas deformidades, destaca-se o comprometimento respiratório, especialmente a Síndrome da Apnéia Obstrutiva do Sono (SAOS).

O comprometimento respiratório, representado primordialmente pela SAOS, relaciona-se à deformidade dento-facial esquelética decorrente do retrognatismo mandibular, que reduz o espaço aéreo. O estudo de LOWE et al. $^{76}, 1986$, que avaliou 25 homens adultos com idade média de 48 anos, portadores de SAOS, cita a presença de deficiência mandibular, redução das dimensões e prejuízo da estabilidade do espaço aéreo superior.

RILEY et al. ${ }^{107}$, 1990, após análise cefalométrica obtida mediante traçados manuais baseados em radiografias cefalométricas laterais de 40 pacientes portadores da SAOS, concluíram que estes possuíam deficiência mandibular, aumento de palato mole e osso hióide localizado mais inferiormente. 
YILDIRIN et al. ${ }^{145}, 1991$, avaliaram o efeito da postura nas dimensões da via aérea superior. Para isso, utilizaram cefalometrias laterais de 33 pacientes saudáveis e 29 portadores de SAOS. Observaram que, em ambos os grupos, a largura da úvula estava aumentada na posição supina, associando esse fato a uma significante redução do espaço aéreo retropalatino dos pacientes. Verificaram, também, que na posição supina havia movimento anterior do hióide e flexão do pescoço, em ambos os grupos. Os autores concluíram que a postura é determinante para as dimensões da via aérea superior.

BATTAGEL; L'ESTRANGE ${ }^{12}, 1996$, avaliaram 59 pacientes (35 com SAOS e 24 sem história de doença respiratória - grupo controle), por meio de telerradiografias de perfil, das quais foram obtidos traçados manuais e posteriormente digitalizados. Observaram significante redução do corpo da mandíbula, da base do crânio e da largura do espaço aéreo e um aumento da área do palato mole no grupo de pacientes portadores de SAOS.

O estudo cefalométrico de SOLOW et al. ${ }^{127}, 1996$, possuía o objetivo de descrever o diâmetro ântero-posterior da via aérea de 50 homens portadores de SAOS, comparar esses resultados com o de 103 homens não portadores e correlacionar tais diâmetros com posicionamento da coluna. Observaram que acontecia maior discrepância na região posterior ao palato mole, com mais de $50 \%$ de estreitamento da via aérea faríngea nos pacientes portadores de SAOS. 
Pacientes com SAOS têm mostrado alongamento do palato mole, osso hióide posicionado inferiormente, redução do comprimento mandibular e maxilar, aumento do tamanho da língua, redução do espaço aéreo posterior, ângulo do plano mandibular acentuado, aumento da altura maxilar, redução do SNA, SNB, S-N, S-N-Ba e Ba-PNS (JOHNS et al. $\left.{ }^{47}, 1998\right)$.

MIYAMOTO et al. $^{85}$, 1998, concluíram que a postura mandibular de adultos saudáveis durante o sono é significantemente influenciada pelo estágio do sono, porém, não pela posição do osso hióide; além disso, a mandíbula está mais aberta no sono REM do que no leve sono não-REM (NREM - Non rapid eye movement).

Os resultados de MORTIMORE et al. $^{86}, 1998$, evidenciaram que o volume do pescoço era $10 \%$ maior em não obesos e $67 \%$ maior em obesos portadores de SAOS do que nos controles saudáveis. O excesso de gordura no pescoço, nos não obesos e obesos portadores de SAOS, localizava-se na área anterolateral da via aérea superior, com uma diferença de 52 e $88 \%$, respectivamente.

LI et al. ${ }^{61}$, 1999, avaliaram cefalometricamente as possíveis diferenças entre asiáticos e brancos portadores de SAOS. Estudaram 53 homens asiáticos e 293 homens brancos, cuja média de idade era 44,1 e 47,5 anos, respectivamente, com índices de distúrbio respiratório semelhantes. Os asiáticos mostraram-se com protrusão maxilo-mandibular, ângulo da base do crânio mais estreito, espaço aéreo posterior mais amplo e osso hióide posicionado mais superiormente. 
JOHNSTON; RICHARDSON ${ }^{50}$, 1999, investigaram as alterações morfológicas da faringe ocorridas entre os adultos jovens e de idade média. Para isso, analisaram traçados cefalométricos manuais, obtidos com base em radiografias cefalométricas de 16 jovens adultos (idade média de 20,2 anos) e em radiografias cefalométricas dos mesmos pacientes após 32 anos. Observaram que, na orofaringe, o espaço aéreo diminuíra e o palato mole tornara-se mais longo e espesso com a idade, indicando que essas tendências poderiam explicar o aumento da incidência de SAOS em indivíduos com idade mais avançada.

Em 2000, ROBERTSON ${ }^{110}$, lembrando que, em portadores de SAOS, o osso hióide encontra-se posicionado mais inferiormente em relação à distância vertical ao plano mandibular (em nível de C4-C6) e que, nos indivíduos não portadores, encontra-se em nível de C3-C4, realizou análise cefalométrica dos efeitos a longo prazo do avanço mandibular efetuado por aparelhos intrabucais sobre os tecidos moles e duros da via aérea superior, bem como analisou o relacionamento do osso hióide com o crânio e a coluna cervical. $\mathrm{O}$ autor não observou alterações na hipofaringe e verificou que a posição do osso hióide permaneceu inalterada em relação à base do crânio e à coluna cervical, concluindo que tais aparelhos podem ser utilizados para o tratamento da SAOS.

LI et al. ${ }^{60}, 2000$, utilizando análise cefalométrica, investigaram as possíveis diferenças entre homens asiáticos do extremo oriente e brancos portadores de SAOS. Os resultados mostraram que a maioria dos asiáticos não 
era obesa, porém, possuía SAOS mais severa. Apesar do espaço aéreo posterior e a distância do plano mandibular ao osso hióide ser menos anormal nos asiáticos, as dimensões da base do crânio eram significantemente reduzidas.

PAOLI et al. ${ }^{97}, 2001$, examinaram as características craniofaciais de pacientes com SAOS e as relacionaram com o índice de massa corpórea (BMI). Para tal, utilizaram radiografias cefalométricas de 85 homens portadores de SAOS, divididos em dois grupos, de acordo com o BMI (menor que 30 e maior ou igual a 30), e observaram que os pacientes com BMI menor que 30 possuíam um assoalho da fossa anterior do crânio e mandíbula menores, além de mandíbula retroposicionada, quando comparados com os pacientes severamente obesos (BMI maior que 30).

FINKELSTEIN et al. ${ }^{28}, 2001$, desenvolveram um estudo cujo objetivo foi avaliar a utilização de cefalometrias frontais e laterais. Os autores comentaram que o uso da cefalometria para a avaliação do espaço aéreo apresenta algumas limitações, pois se trata de um recurso bidimensional utilizado para a avaliação de uma estrutura tri-dimensional. Observaram que os pacientes que apresentavam comprometimento respiratório durante o sono, possuíam osso hióide posicionado mais inferiormente, espessamento dos tecidos moles, da parede posterior e estreitamento do lúmen do espaço velofaríngeo, concluindo que a análise da cefalometria frontal provê informações adicionais à cefalometria lateral. 
O estudo cefalométrico lateral e frontal de SETO et al. ${ }^{119}, 2001$, revelou que pacientes portadores de SAOS possuem arcos maxilares mais estreitos e curtos do que os não roncadores ou não portadores de SAOS.

Anormalidades dento-faciais têm sido extensivamente reportadas em pacientes com SAOS: observa-se retrognatia, micrognatia, face longa, posicionamento inferior do osso hióide, tendência à redução do comprimento e angulação da base do crânio, grande ângulo ANB, plano mandibular acentuado, estreitamento do espaço aéreo superior, palato mole longo e largo, além de língua larga. Entre os pacientes, o local do estreitamento e obstrução da via aérea varia grandemente (BAIK et al. ${ }^{7}$, 2002).

Com objetivo de obter dados normativos para medidas cefalométricas da via aérea superior na população chinesa, SAMMAN et al. ${ }^{113}$, 2003, examinaram cefalometricamente 74 pacientes saudáveis (29 homens e 45 mulheres), com perfil facial normal, sem história de ronco, SAOS, doença da via aérea superior, tonsilectomia ou adenoidectomia, obesidade ou patologia da faringe. Utilizaram 20 medidas cefalométricas da via aérea superior, incluindo tamanho da língua, palato mole, naso e orofaringe, hipofaringe e posição relativa do osso hióide e valécula. Os pontos cefalométricos foram digitalizados e medidos em um programa de computador, e os resultados mostraram significante dimorfismo sexual na maioria das medidas, exceto a profundidade mínima da via aérea, profundidade da orofaringe e o ângulo formado entre o palato mole e palato duro. 
HOEKMA et al. ${ }^{42}$, 2003, compararam cefalometricamente 31 homens portadores de SAOS e 37 homens não portadores; seus dados indicaram um relativo posicionamento anterior da maxila, aumento da altura média facial e osso hióide localizado mais inferiormente nos portadores.

ENDO et al. ${ }^{26}, 2003$, valendo-se de cefalometrias laterais, investigaram as características de japoneses portadores de SAOS. Para isso, avaliaram 103 portadores de SAOS e 98 indivíduos não portadores. Seus resultados evidenciaram que a micrognatia é o maior fator de risco para a SAOS em japoneses e que o estreitamento da hipofaringe deve-se ao osso hióide localizado mais inferiormente, especialmente em obesos.

Ainda em 2003, YU et al. ${ }^{149}$ utilizaram radiografias de 62 homens com SAOS (33 obesos e 29 não obesos, além de 13 roncadores simples), com o objetivo de avaliar as características cefalométricas de pacientes com SAOS e correlacionar as variáveis cefalométricas com a severidade do IAH. Os resultados evidenciaram que os pacientes portadores de SAOS possuíam osso hióide posicionado mais inferiormente, palato mole alargado e estreitamento do espaço aéreo superior na altura do palato mole, quando comparados com os pacientes que somente roncavam. Um aumento de volume dos tecidos moles mais extensos e severos foi observado nos obesos. Além disso, observou-se que o deslocamento anterior do hióide e o retroposicionamento da mandíbula eram determinantes para um IAH mais severo nos portadores de SAOS. Os autores ainda concluíram que as características da estrutura óssea craniofacial, tais como o estreitamento da 
nasofaringe e orofaringe e o aumento dos tecidos moles da via aérea superior, podem ser importantes fatores de risco para a SAOS em não-obesos. Nos obesos, a deposição de gordura em tais tecidos pode agravar sua severidade.

Com o objetivo de avaliar cefalometricamente a relação entre a SAOS e o posicionamento do osso hióide, BUCCHERI et al. ${ }^{14}$, 2004, compararam 15 pacientes portadores de SAOS (de ambos os sexos) com 15 pacientes saudáveis (de ambos os sexos). Observaram que o osso hióide apresenta-se localizado mais inferior e posteriormente nos pacientes portadores da síndrome, concluindo que essa posição alterada do osso hióide pode influenciar a posição da língua e a patente da via aérea.

LAM et al. ${ }^{58}$, 2004, avaliaram o relacionamento entre os parâmetros cefalométricos, os fatores morfológicos da via aérea superior e a SAOS em 92 chineses. Comparados com sujeitos normais, os portadores de SAOS estavam mais pesados e velhos, possuíam menores tamanhos nas regiões velo e hipofaríngea, o osso hióide estava posicionado mais inferiormente, o palato mole era mais longo e espesso, e a mandíbula encontrava-se posicionada mais retrognaticamente em relação à maxila.

JOHAL; CONAGHAN ${ }^{46}, 2004$, asseveraram que a constrição maxilar e a etiologia da SAOS não estavam claras; os dados obtidos em seu estudo cefalométrico suportaram a teoria da constrição maxilar como fator etiológico da SAOS.

Com objetivo de avaliar as características cefalométricas de crianças com SAOS, com ou sem hipertrofia adenotonsilar, ÖZDEMIR et al. ${ }^{93}$, 
2004, avaliaram 39 crianças com idade entre 4 e 12 anos, portadoras de SAOS. Os resultados mostraram que: os ângulos da base do crânio correlacionavam-se com um aumento dos níveis de apnéia/hipopnéia; a protusão de maxila e da mandíbula não se correlacionavam com tais índices e o espaço aéreo posterior mínimo era inversamente correlacionado com os índices de apnéia/hipopnéia; existiu correlação positiva entre os dados cefalométricos e a hipertrofia adenotonsilar.

YOUNG; $\quad$ MCDONALD ${ }^{146}, \quad 2004, \quad$ investigaram cefalometricamente a correlação do diagnóstico clínico entre posição vertical do osso hióide em relação às estruturas do esqueleto dentofacial, a severidade da SAOS e as decisões de manejo dessa condição. Observaram correlação estatisticamente significante entre todas as medidas lineares que localizam o osso hióide no plano vertical e os índices de apnéia/hipopnéia (IAH). As relações lineares foram menos confiáveis para sujeitos com IAH maior que 100, possivelmente em razão da limitação do organismo em responder posturalmente para manter a via aérea patente. Isso, por sua vez, sugere que as radiografias cefalométricas podem ser utilizadas como uma ferramenta de diagnóstico reproduzível.

INGMAN et al. $^{44}$, 2004, com objetivo de comparar cefalometricamente alterações entre as posições ereta e supina em pacientes com Síndrome de Resistência da Via Aérea Superior ${ }^{*}$ (SRVAS) e com SAOS, 
analisaram cefalometricamente 82 portadores de SAOS (70 homens com idade média de 49 anos e 12 mulheres com idade média de 45,9 anos), em ambas as posições, e não observaram alterações significantes nos tecidos moles, tanto da naso quanto da hipofaringe, entre as duas posições. Contrastando com isso, a distância da ponta do palato mole e da parede posterior da orofaringe estava significativamente mais curta na posição supina. Adicionalmente, na posição supina, observou-se discreto espessamento do palato mole, porém, sem aumento de seu comprimento, além de a língua apresentar-se mais curta e espessa.

SMITH; BATTAGEL ${ }^{125}, 2004$, realizaram um estudo prospectivo cefalométrico para avaliar as alterações radiográficas que ocorrem na faringe e nas estruturas adjacentes, decorrentes da variação de postura entre as posições supina e ereta, investigando também o efeito da protrusão mandibular, na posição supina, nas dimensões das estruturas avaliadas. Concluíram que, na posição supina, houve redução significante nas medidas da via aérea faríngea de roncadores não apnéicos. A protrusão mandibular, mesmo na posição supina, produz um aumento no espaço funcional para a língua.

YUCEL et al. ${ }^{150}, 2005$, examinaram, em cortes transversais, as alterações da via aérea superior em cada fase da respiração, em diferentes graus de SAOS, utilizando tomografia computadorizada dinâmica, polissonografia e cefalometria. Os resultados evidenciaram que pacientes com SAOS severa possuíam estreitamento significativo em nível da úvula na 
expiração, osso hióide posicionado mais inferiormente e palato mole mais espesso, quando comparados com pacientes com SAOS moderadas e saudáveis. Adicionalmente, os portadores de SAOS severa apresentavam maior circunferência cervical.

\subsection{Inter-relação entre SAOS, espaço aéreo e cirurgia ortognática}

TAKAGI et al. ${ }^{130}$, 1967, estudaram, cefalometricamente, a posição do osso hióide de nove portadores de prognatismo mandibular, tratados pela técnica de osteotomia bilateral deslizante da mandíbula, e observaram que existia alteração mínima na relação do osso hióide com a vértebra cervical, indicando que devem existir mecanismos que previnam o deslocamento lingual para o interior da via aérea.

WICKWIRE et al. ${ }^{144}$, 1972 , por meio de radiografias cefalométricas de perfil realizadas em 22 pacientes submetidos a recuo de mandíbula pela técnica de osteotomia vertical do ramo, verificaram que ocorreu deslocamento posterior do osso hióide em 19 dos 22 pacientes. Os autores referiram que, provavelmente, a língua acompanha o movimento do osso hióide.

RILEY et al. ${ }^{104}, 1987$, relataram dois casos de pacientes submetidos a recuo mandibular $(7$ e $10 \mathrm{~mm}$ ) que desenvolveram SAOS subseqüente e discutiram que não havia sido surpresa o desenvolvimento da 
SAOS, uma vez que tal procedimento causa o estreitamento da via aérea superior, em decorrência da alteração da posição da língua e do osso hióide. Tal estreitamento acentua-se pela atonia muscular e pelo colapso da faringe durante o sono, resultando em apnéia. O exame das radiografias pré e pósoperatórias de ambos os pacientes confirmaram o estreitamento da faringe e evidenciaram que o osso hióide estava em posição inferior, como resultado da cirurgia.

REYNOLDS et al. ${ }^{103}, 1988$, estudaram, cefalometricamente, o comportamento do complexo muscular supra-hióideo frente a grandes avanços mandibulares $(6,5 \mathrm{~mm})$ em 12 macacos. Observaram recidiva mandibular em $27 \%$ dos animais submetidos à fixação maxilo-mandibular exclusivamente dental. Verificaram, também, que o complexo muscular alongou-se levemente menos que a mandíbula e que as maiores adaptações ocorreram na interface osso-músculo, interface músculo-tendão e no ventre anterior do músculo digástrico. Concluíram que as adaptações do complexo muscular ocorreram primeiro no tecido conjuntivo de adesão muscular e posteriormente, no ventre muscular propriamente dito.

GRECO et al. $^{35}$, 1990, após avaliação retrospectiva cefalométrica do espaço aéreo hipofaríngeo de 11 pacientes submetidos a recuo mandibular pela técnica da osteotomia sagital mandíbula bilateral (BSSO) e fixação interna rígida, asseveraram que o recuo de mandíbula produz relativo estreitamento do espaço aéreo hipofaríngeo, o que, em casos isolados, pode contribuir para o desenvolvimento da SAOS. 
ATHANASIOU et al. ${ }^{6}, 1991$, avaliaram 52 pacientes submetidos à cirurgia ortognática para recuo de mandíbula pela técnica de osteotomia vertical extra-oral do ramo (EVRO). Para tal, valeram-se de telerradiografias laterais e de traçados cefalométricos manuais, obtidos no pré-operatório e cerca de um ano após. Asseveraram que a hipótese do recuo mandibular reduzir o espaço aéreo na altura da segunda e quarta vértebras cervicais não pode ser suportada por seus resultados.

ENACAR et al. ${ }^{25}, 1994$, desenvolveram um estudo cujo objetivo foi mensurar as alterações na posição do osso hióide, língua e espaço aéreo hipofaríngeo em 15 pacientes submetidos a recuo mandibular pela osteotomia sagital bilateral da mandíbula. Para realizar essa mensuração, fizeram uma análise cefalométrica computadorizada com medidas obtidas de radiografias cefalométricas realizadas nos períodos pré-operatório e pós-operatório médio de 1,5 anos. Concluíram que o espaço aéreo hipofaríngeo diminuiu, em decorrência do recuo mandibular, e que isso havia acontecido por causa do movimento mais posterior e inferior da língua.

HOCHBAN et al. ${ }^{41}, 1996$, baseados em análises cefalométricas obtidas de traçados manuais de 16 pacientes submetidos a recuo mandibular pela osteotomia sagital bilateral da mandíbula, no período pré-operatório e pósoperatório de uma semana, três meses e um ano, sugeriram que apesar de ocorrer uma redução do espaço aéreo nos pacientes portadores de prognatismo mandibular submetidos a recuo mandibular, isso parece não predispor o paciente à SAOS, uma vez que o espaço aéreo pré-operatório 
desses indivíduos apresentava-se aumentado (quando comparado com a população normal).

NAKAGAWA et al. $^{88}, 1998$, investigaram as alterações morfológicas nas estruturas da orofaringe em 25 pacientes portadores de prognatismo mandibular (12 homens e 13 mulheres), após cirurgia ortognática de recuo mandibular mediante osteotomia sagital bilateral mandibular. Utilizaram traçados cefalométricos construídos manualmente e digitalizados posteriormente, em quatro períodos distintos: pré-operatório e pós-operatório de três, seis e 12 meses. Concluíram que as alterações morfológicas no espaço aéreo superior, após cirurgia para recuo mandibular, variaram consideravelmente entre os gêneros e que houve redução da área da hipofaringe somente nos homens.

BATTAGEL et al. ${ }^{11}, 1999$, avaliaram 58 pacientes portadores de SAOS, submetidos ao avanço mandibular postural; para isso utilizaram traçados cefalométricos manuais. Concluíram que o avanço mandibular pode ser associado a um proporcional aumento das dimensões orofaríngeas e que existe grande variação no montante e na direção da resposta do osso hióide à protrusão mandibular.

TSELNIK; POGREL ${ }^{136}, 2000$, valendo-se de um estudo cefalométrico baseado em telerradiografias de perfil realizadas em períodos pré e pós-operatórios de 15 dias e seis meses, em 14 pacientes, asseveraram que a cirurgia para recuo da mandíbula causa uma redução no espaço aéreo faríngeo. Consideraram, ainda, que em pacientes que possuem outros fatores 
de risco (como sobrepeso, pescoço curto e macroglossia), o recuo mandibular pode predispor o paciente ao desenvolvimento da SAOS.

PAOLI et al ${ }^{96}, 2000$, lembraram que o risco de apnéia deve ser incluído como um parâmetro para a indicação ou não do recuo de mandíbula.

TURNBULL; BATTAGEL ${ }^{138}, 2000$, por intermédio de digitalização de telerradiografias laterais pré e pós-operatórias, analisaram 32 pacientes submetidos à cirurgia ortognática de mandíbula, e concluíram que ocorre significante decréscimo nas dimensões do espaço aéreo retrolingual após recuo mandibular.

ACHILLEOS et al. ${ }^{1}, 2000$, avaliaram cefalometricamente 31 homens adultos que se submeteram à correção de prognatismo por meio de recuo mandibular e concluíram que ocorreram alterações nos tecidos moles, decorrentes do procedimento. Observaram mudanças na posição do osso hióide, aumento do comprimento e inclinação do palato mole, língua mais ereta e redução do espaço aéreo orofaríngeo.

GU et al. ${ }^{36}, 2000$, avaliaram, o processo de recidiva após recuo mandibular em 62 pacientes submetidos à osteotomia sagital bilateral da mandíbula (BSSO). Para tal, utilizaram cefalometrias seriadas até três anos após a cirurgia e analisaram a morfologia crânio-facial, o posicionamento do osso hióide, a via aérea faríngea e o posicionamento da cabeça. Os resultados mostraram que a recidiva mandibular ocorreu principalmente nos seis primeiros meses: o osso hióide moveu-se para baixo e para trás e a cabeça estava 
elevada. Somente a posição do hióide era previsivelmente correlacionada com a morfologia mandibular e a postura da cabeça.

HIYAMA et al. ${ }^{40}, 2001$, com o propósito de examinar as alterações na posição mandibular e nas estruturas orofaciais, induzidas pelo uso de colar cervical durante o sono, avaliaram 10 adultos saudáveis (7 homens e 3 mulheres) utilizando radiografias cefalométricas na posição supina com e sem o colar, no final da expiração, durante os estágios 1 e 2 do sono NREM. Observaram que o montante de abertura bucal foi significativamente reduzido nos usuários do colar, assim como as dimensões sagitais da via aérea superior, apesar de não ocorrerem alterações significativas no posicionamento antero-posterior mandibular e nas dimensões verticais da via aérea. Apesar de o osso hióide e a terceira vértebra cervical se moverem para anterior com o uso do colar, o relacionamento da sínfise mandibular, osso hióide e C3 não se alteraram. Esses resultados sugeriram que o colar reduz as dimensões sagitais da via aérea durante o sono, embora não ocorra significante deslocamento da mandíbula para anterior.

MEHRA et al. ${ }^{83}, 2001$, por meio de análise cefalométrica obtida com base em traçados manuais feitos em radiografias de perfil, realizadas no pré e pós-operatório médio de 29,6 meses, avaliaram o efeito da cirurgia combinada (maxilo/mandibular) com rotação anti-horária do complexo maxilomandibular no espaço aéreo faríngeo. Observaram um aumento no espaço aéreo faríngeo de $47 \%$ junto ao palato mole e $76 \%$ na base da língua, em 50 pacientes submetidos a avanço maxilo-mandibular. No grupo que recebera 
avanço maxilar e recuo mandibular, entretanto, ocorreu um decréscimo de $47 \%$ do espaço aéreo, na altura do palato mole, e $65 \%$ na base da língua. Concluíram que a cirurgia combinada com rotação anti-horária do complexo maxilo-mandibular afeta significativamente o espaço aéreo faríngeo e a anatomia velofaringeana.

Segundo LI et al. ${ }^{59}, 2002$, o avanço maxilo-mandibular promove expansão da via aérea superior, especialmente da parede lateral da faringe. Esses achados explicam as altas taxas de sucesso decorrentes da utilização de avanço maxilo-mandibular para o tratamento da SAOS.

LIUKKONEN et al. ${ }^{73}, 2002$, em estudo cefalométrico manual e computadorizado de 22 indivíduos com idade média de 30 anos, submetidos à osteotomia sagital mandibular bilateral para recuo mandibular, concluíram que o recuo mandibular com rotação posterior pode causar estreitamento do espaço aéreo posterior e ser um fator predisponente para o desenvolvimento de desordens respiratórias decorrentes do aumento da resistência à passagem do ar. Particularmente, isso pode ocorrer se fatores predisponentes, como padrão facial específico e/ou obesidade estão presentes ou quando a adaptação neuromuscular é insuficiente para compensar a redução do espaço aéreo. Portanto, deve ser realizada uma cuidadosa análise da via aérea, particularmente em pacientes com grandes discrepâncias antero-posteriores.

SAMMAN et al. ${ }^{114}, 2002$, avaliaram as alterações no espaço aéreo superior após correção cirúrgica de prognatismo mandibular, por meio de análise cefalométrica pré e pós-operatória (6 meses) de 70 pacientes 
submetidos a recuo mandibular. Concluíram que, após o recuo mandibular, a língua ocupa posição mais posterior e a hipofaringe apresenta-se reduzida, aumentando a possibilidade de SAOS. Apesar disso, alterações compensatórias na morfologia do palato mole podem explicar a baixa incidência disso na prática.

KAWAKAMI et al. ${ }^{52}, 2004$, examinaram o efeito da glossectomia parcial sobre a estabilidade esquelética e alterações pós-operatória decorrentes do recuo mandibular. Avaliaram radiografias telecefalométricas digitalizadas nos períodos pré e pós-operatórios (imediatas e um ano após cirurgia), de 21 pacientes submetidos à BSSO associada à redução de língua e de 19 pacientes submetidos à BSSO sem redução de língua. Os resultados em ambos os grupos sugeriram um movimento posterior e inferior do osso hióide e o estreitamento da via aérea superior faríngea, na base da língua, imediatamente após a cirurgia, retornando à sua posição após um ano. A redução da língua teve um efeito preventivo frente ao estreitamento do espaço aéreo posterior e evidenciou uma tendência a reduzir a rotação horária da mandíbula após o recuo, porém, não existiu diferença significante entre os dois grupos em relação às posições horizontal e vertical do incisivo após um ano.

SAITOH ${ }^{112}, 2004$, após longo período pós-operatório, avaliou as alterações na morfologia da via aérea faríngea, após cirurgia para recuo mandibular em 10 mulheres portadoras de prognatismo mandibular. Seus resultados sugeriram que, apesar de a morfologia facial inferior e da via aérea 
faríngea terem mostrado alterações após BSSO, a morfologia faríngea exibiu readaptação fisiológica. Contudo, porque a morfologia facial inferior estava mantida e estável por um longo período, considerou-se normal a adaptação da morfologia faríngea após a cirurgia, que melhorou o relacionamento dos tecidos duros.

Com o objetivo de propor um modelo matemático para prever as alterações no espaço aéreo faríngeo associadas à cirurgia para reposicionamento posterior da mandíbula, CHEN et al. ${ }^{15}, 2005$, avaliaram cefalometricamente 23 mulheres adultas, portadoras de deformidade dentofacial-esquelética tipo classe III, submetidas a recuo mandibular pela técnica osteotomia sagital mandibular bilateral, em períodos que variaram de seis a 18 meses. Concluíram que o modelo matemático previu as possíveis alterações do espaço aéreo e que, em pacientes que possuíam outros fatores de risco, tais como obesidade, pescoço curto, macroglossia, úvula grande e grande quantidade de tecido mole ao redor da região nasofaríngea, a cirurgia para recuo da mandíbula poderia predispor à SAOS.

EGGENSPERGER et al. ${ }^{22}$, 2005, com a intenção de determinar as alterações a longo prazo no osso hióide e no tamanho da via aérea superior de pacientes submetidos a recuo cirúrgico de mandíbula, avaliaram cefalogramas de 12 pacientes em períodos pré e pós-operatório (uma semana, seis meses, 14 meses e 12 anos). Seus resultados evidenciaram que o recuo mandibular médio de 5,6 $\mathrm{mm}$ estava associado ao movimento inferior e posterior do osso hióide. Nos controles de longo prazo, observaram que o osso 
hióide estava localizado cerca de 1,5 mm horizontalmente mais posterior do que no pré-operatório. Imediatamente após a cirurgia, o comprimento dos músculos supra-hióideos correlacionava-se com o montante do movimento cirúrgico (encurtaram cerca de $4 \mathrm{~mm}$ e permaneceram até um ano). Após a redução inicial, o tamanho do espaço aéreo inferior permaneceu inalterado; os espaços aéreo superior e médio continuaram a reduzir seu tamanho e, no pósoperatório de 12 anos, encontravam-se menores do que no pré-operatório, cerca de 1,5 e $3 \mathrm{~mm}$ respectivamente.

TSUIKI et al. $\left.{ }^{137}, 2005\right)$ investigaram as alterações no tamanho da via aérea superior, na posição ereta e supina, em homens portadores de SAOS tratados com aparelhos intrabucais. Utilizaram radiografias cefalométricas supinas de 14 pacientes com aparelhos intrabucais e avaliaram as alterações na posição da mandíbula, com e sem o aparelho intrabucal, com uma estação de trabalho DigiGraphi (Dolphin Imaging Systems, Valencia, Calif). Entre os resultados, destacaram o fato de que o tamanho da velofaringe supina, mas não a orofaringe supina, estava significantemente aumentado na posição mandibular avançada.

$\mathrm{CHOU}$ et al. $\left.{ }^{16}, 2005\right)$ analisaram as alterações nos tecidos moles e duros do perfil facial de pacientes tailandeses submetidos a recuo mandibular pela BSSO, utilizando cefalometrias pré e pós-cirúrgicas de 28 homens e 36 mulheres portadores de má oclusão tipo Classe III. Concluíram que ocorre significante montante de recidiva após um ano de cirurgia. 
Com o objetivo de determinar as alterações na posição do osso hióide e no tamanho da via aérea faríngea após longo período pós-operatório, bem como avaliar a relação entre o comprimento da musculatura supra-hioidea e a recidiva esquelética, EGGENSPERGER et al. ${ }^{23}, 2005$ ) realizaram um estudo cefalométrico por 12 anos, com 15 pacientes submetidos a avanço de mandíbula. Observaram, entre outras coisas, que a posição final do hióide era mais posterior do que no pré-operatório e que as vias aéreas faríngeas superiores e média estavam mais estreitas, apresentando valores menores do que os do pós-operatório. Concluíram que as alterações mandibulares influenciam a posição do hióide durante todo o período pós-operatório estudado, uma vez que o estiramento da musculatura supra-hioidea parece contribuir para a recidiva esquelética. $\mathrm{O}$ avanço mandibular por si só não pode fornecer um aumento estável da via aérea faríngea por um período de 12 anos.

A resposta postural da língua após recuo mandibular é clinicamente importante para manter a respiração. Apesar de o osso hióide mover-se progressivamente para uma adaptação fisiológica após tal cirurgia, não está claro se o seu reposicionamento tem um efeito sobre a via aérea faríngea (KAWAKAMI et al. $\left.{ }^{51}, 2005\right)$.

KAWAKAMI et al. $^{51}$, 2005, por meio de radiografias cefalométricas digitalizadas realizadas no pré-operatório, um mês e um ano após cirurgia para recuo mandibular, avaliaram a anatomia da faringe e o posicionamento do osso hióide. Observaram um significante movimento inferior do osso hióide, um mês após a cirurgia, enquanto as dimensões da faringe 
estavam mantidas. Um ano após, o osso hióide havia voltado à posição original, resultando em significante decréscimo nas dimensões do espaço aéreo retro-lingual. Essas observações permitiram aos autores concluir que o recuo de mandíbula causa estreitamento tardio do espaço aéreo após a cirurgia, enquanto que, nos momentos iniciais pós-cirurgia, o espaço fica mantido.

Para STUCK et al. ${ }^{129}, 2005$, a suspensão do hióide é efetiva somente em um subgrupo de pacientes e não leva a mudanças relevantes da via aérea nos pacientes acordados. De acordo com os autores, seus efeitos parecem decorrer mais de alterações funcionais na colapsibilidade do que do aumento da via aérea.

RAMESH et al. ${ }^{102}, 2005$, avaliaram prospectivamente os efeitos do recuo cirúrgico de mandíbula em oito pacientes, por meio de análise cefalométrica realizada em períodos pré-operatório e pós-operatório de três meses, e observaram que a via aérea faríngea reduziu-se consideravelmente em todos os pacientes. Citaram ainda que, tal fato, pode predispor o paciente à SAOS; logo, grandes discrepância antero-posteriores devem ser corrigidas por meio de osteotomias maxilo-mandibulares combinadas.

TECCO et al. ${ }^{133}, 2005$, avaliando o efeito da expansão rápida de maxila no espaço aéreo nasofaríngeo, postura da cabeça e morfologia da face, em crianças com obstrução nasal, concluíram que a expansão rápida de maxila é capaz de aumentar as dimensões da nasofaringe e que esse fato leva ao decréscimo da angulação craniocervical. 
HELLER et al. ${ }^{39}, 2006$, em estudo com pacientes portadores de síndrome de Treacher Collins e Nager ${ }^{*}$, verificaram que a utilização da distensão osteogênica para mentoplastia permite grande avanço e reduz a taxa de recidiva, quando comparada com procedimentos agudos isolados (osteotomia e avanço cirúrgico do mento). Concluíram ainda que distensão osteogênica do mento com avanço do osso hióide é uma técnica útil para a resolução da SAOS ou para permissão da remoção da traqueotomia nos pacientes sindrômicos que se submeteram a avanço mandibular e encontramse com oclusão tipo Classe I.

GONÇALVES et al. $^{32}$, 2006, estudaram as alterações na orofaringe e a sua estabilidade, após rotação anti-horária cirúrgica e avanço maxilo-mandibular. Quarenta e oito mulheres e oito homens, com idades entre 15 e 51 anos, foram tratados com osteotomia Le Fort I e osteotomia sagital bilateral da mandíbula para avanço maxilo-mandibular com rotação antihorária. A média de controle pós-operatório foi de 34 meses e utilizaram radiografias e traçados cefalométricos para estimar as alterações cirúrgicas e pós-cirúrgicas. Concluíram que avanço maxilo-mandibular, com rotação antihorária, produz imediato aumento nas dimensões médias e inferiores da orofaringe, ocasionado por alterações da postura cefálica, porém, mantinhamse estáveis no período pós-cirúrgico.

\footnotetext{
* Síndromes que podem causar hipoplasia mandibular, com colapso posterior da base da língua e redução da orofaringe.
} 
EGGENSPERGER et al. $^{24}, 2006$, asseveraram que a recidiva após um ano de avanço mandibular é de cerca de 25\%, enquanto que após 12 anos é de $50 \%$.

Com o objetivo de examinar os efeitos da expansão rápida de maxila associada à protração maxilar sobre as dimensões sagitais da via aérea, SAYINZU et al. ${ }^{116}$, 2006, fizeram a análise cefalométrica de sete meninos e 12 meninas, com idade média de 10,5 anos, portadores de retrognatismo maxilar. Seus resultados evidenciaram que pequenas correções transversais, associadas à protração maxilar, aumentam as dimensões da via aérea nasofaríngea, porém, não interferem nas dimensões da orofaringe.

SAITO et al. ${ }^{111}, 2006$, relataram que o avanço maxilar, por meio da distensão osteogênica, altera a função nasorespiratória, melhorando-a. 


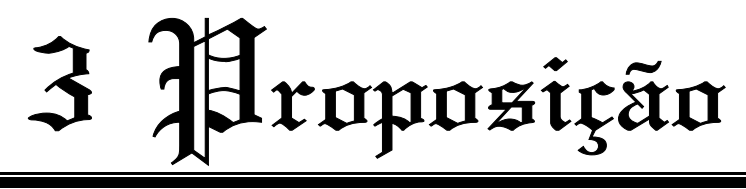





\section{PROPOSIÇÃo}

Avaliar as alterações cefalométricas do espaço aéreo faríngeo, frente aos procedimentos de cirurgia ortognática para correção de prognatismo mandibular (recuo mandibular e avanço de maxila combinados), utilizando o Programa Dolphin Imaging 10.0. 



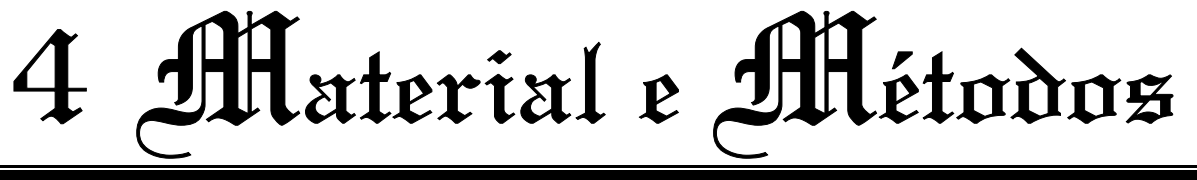





\section{MATERIAL E MÉTODOS}

Esta pesquisa, após a aprovação do Comitê de Ética (Anexo A) realizou a análise cefalométrica computadorizada retrospectiva de 19 pacientes não portadores de SAOS submetidos à cirurgia ortognática maxilo-mandibular, para correção de prognatismo mandibular por meio da osteotomia sagital bilateral mandibular para recuo e osteotomia Lê fort I total maxilar para avanço. Todos os procedimentos foram realizados pela mesma equipe cirúrgica, com uso de fixação interna rígida e fixação maxilo-mandibular trans-operatória. Tais análises foram realizadas no programa Dolphin Imaging 10.0 (Fabricante: Dolphin/3M - USA), registrado para Universidade de São Paulo, Faculdade de Odontologia de Bauru.

Utilizou-se como critério de inclusão dos pacientes neste estudo:

a) ter sido portador de prognatismo mandibular;

b) ter sido submetido à cirurgia ortognática para correção de prognatismo e operado pela mesma equipe cirúrgica;

c) possuir radiografia cefalométrica de perfil, em pelo menos dois períodos, ou seja, uma radiografia pré-operatória (inicial) e uma radiografia de pelo menos seis meses pósoperatórios (final), com a obrigatoriedade que ambas tivessem sido realizadas em um único centro de 
d) documentação radiológica e dentro dos padrões estabelecidos para esse tipo de tomada radiográfica: paciente posicionado no cefalostato com plano sagital mediano perpendicular ao solo e plano horizontal de Frankfurt paralelo ao solo, filme perpendicular ao solo, distância foco-filme de 1,52 m e feixe central de Raios $X$ posicionado no centro do chassi (ALVARES; TAVANO ${ }^{4}$, 1998).

e) as radiografias cefalométricas laterais deveriam ainda permitir clara visualização das estruturas anatômicas da face e crânio (oro e nasofaringe, língua, palato mole, epiglote, osso hióide, processo mastóide, coluna vertebral, seio frontal, seio maxilar, seio esfenoidal, sela túrcica, órbita (rebordo infra-orbitário), palato duro, soalho da fossa nasal, espinha nasal anterior, espinha nasal posterior, processo zigomático da maxila, fossa ptérigo-maxilar, apófise pterigóide, processo condilar, incisura da mandíbula, tubérculo articular, asa maior do esfenóide, canal mandibular, base da mandíbula, forame mentoniano, arco zigomático, tábua óssea interna da mandíbula) (ÁLVARES; TAVANO $\left.{ }^{4}, 1998\right)$, necessárias à confecção do traçado cefalométrico. 
Após seleção, as telerradiografias foram digitalizadas em scanner UMAX, modelo Astra 2600, com leitor de transparência, com 600 dpi, no formato TIFF, sempre com a presença de uma régua específica do programa Dolphin Image 10.0, que permite a visualização de pontos distantes entre si $100,0 \mathrm{~mm}$, marcados diretamente na radiografia e paralelos à borda lateral do filme (Figura 4.1).

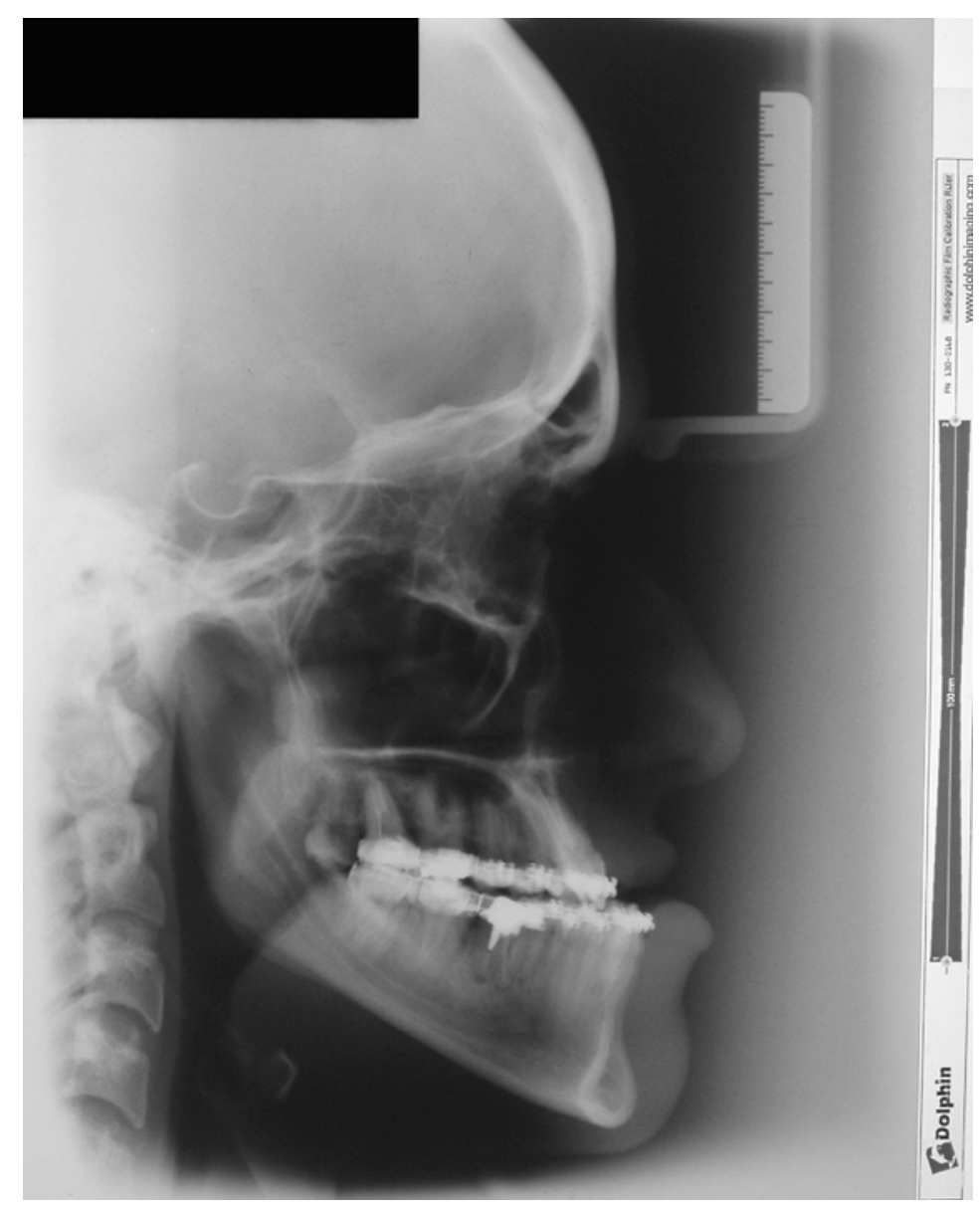

FIGURA 4.1- Telerradiografia digitalizada com a régua transparente específica

A seguir, são apresentadas as imagens capturadas do programa Dolphin Imaging 10.0 (tela a tela), com os passos realizados para a análise cefalométrica digital, que desenvolveu-se da seguinte maneira: 
- inicializou-se o programa (Figura 4.2);

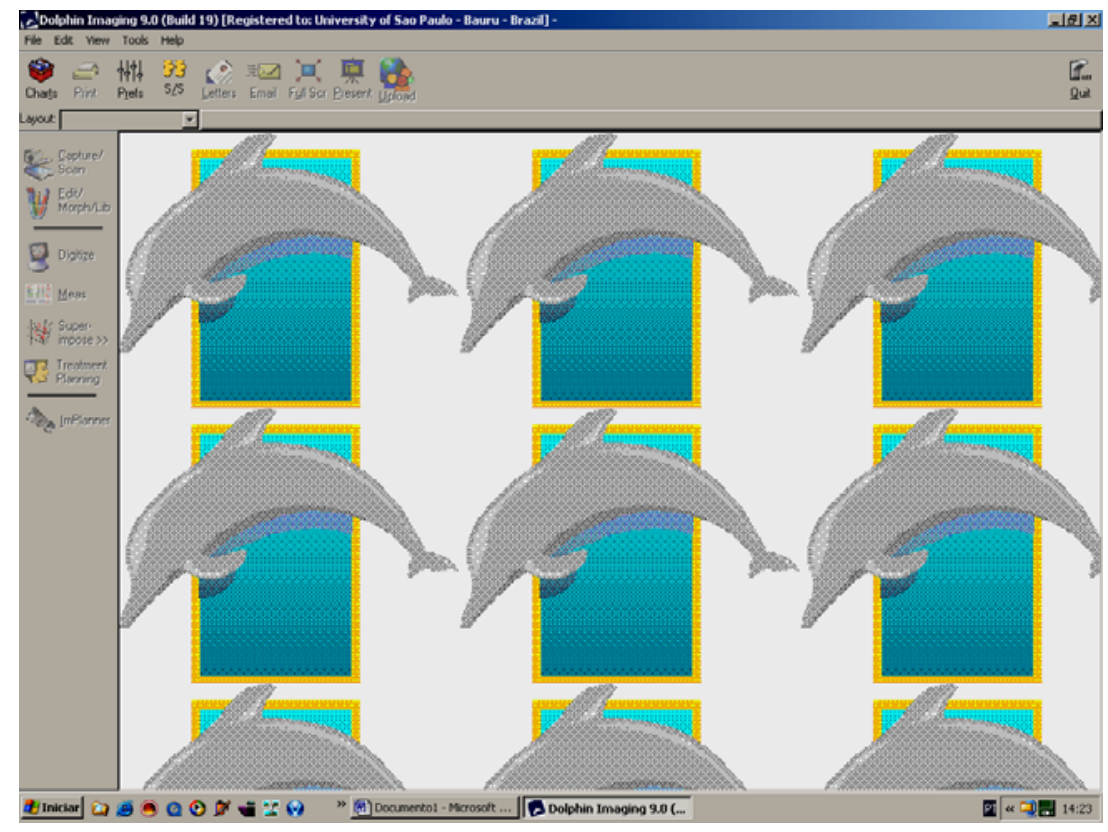

FIGURA 4.2- Tela inicial do programa Dolphin Imaging 10.0

- selecionou-se new patient (Figura 4.3);

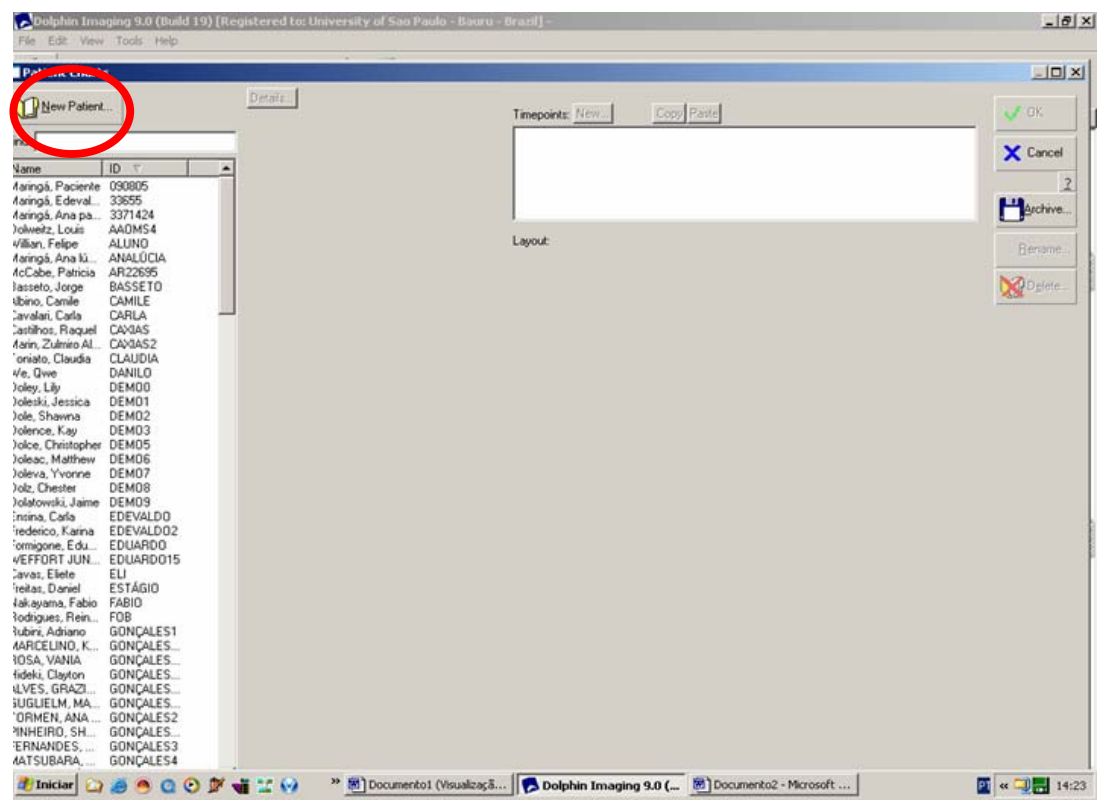

FIGURA 4.3- Tela com o botão "new patient" sendo acionado 
- identificou-se o paciente (Figura 4.4);

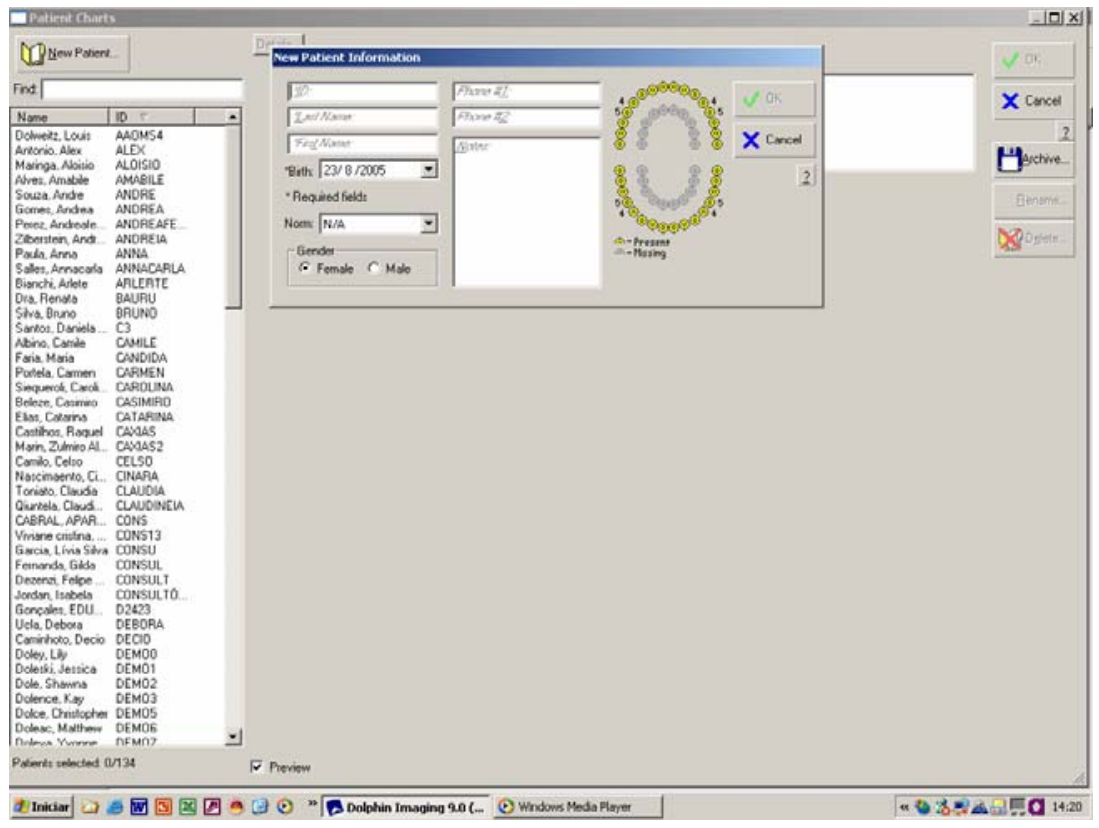

FIGURA 4.4- Janela para identificação do paciente, após acionamento do ícone "new patient"

- registrou-se o período da radiografia (inicial ou final) a ser captada (Figura 4.5);

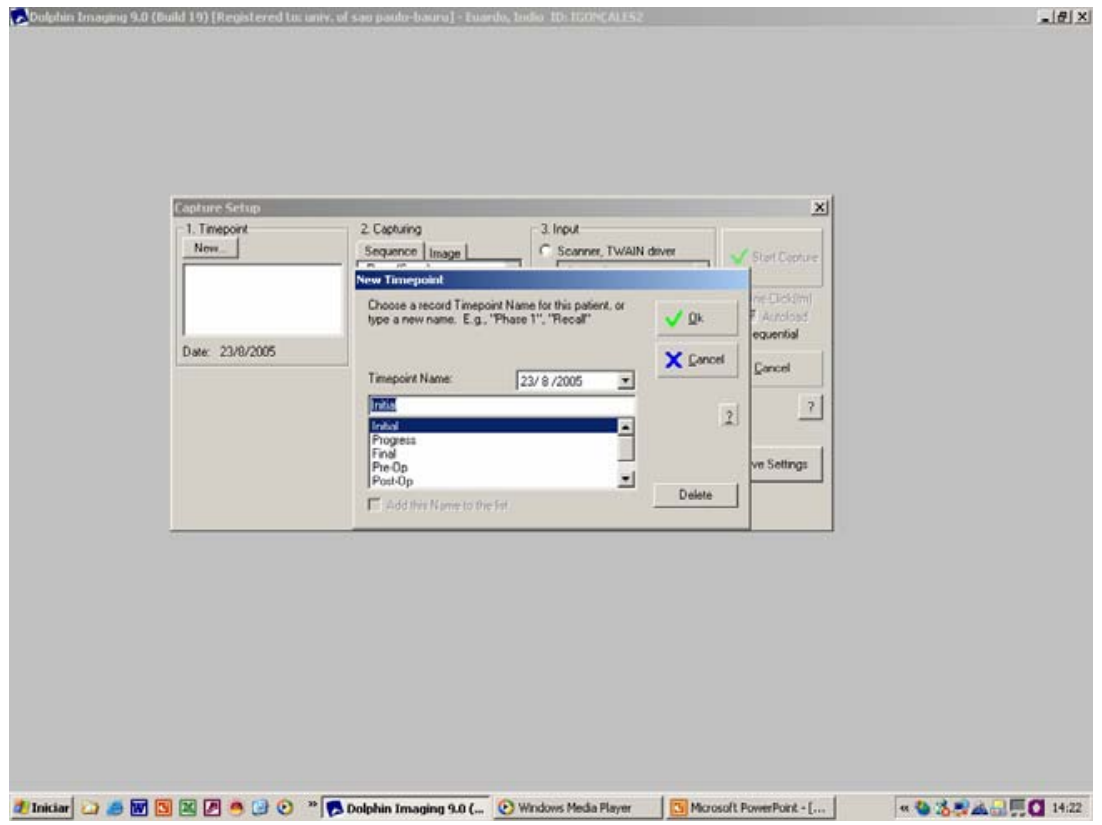

FIGURA 4.5- Janela para registro do período da radiografia (inicial ou final) a ser captada 
- selecionou-se a seqüência de imagens pré-determinada (radiografia cefalométrica lateral digitalizada e arquivada em arquivo de imagem) (Figura 4.6);

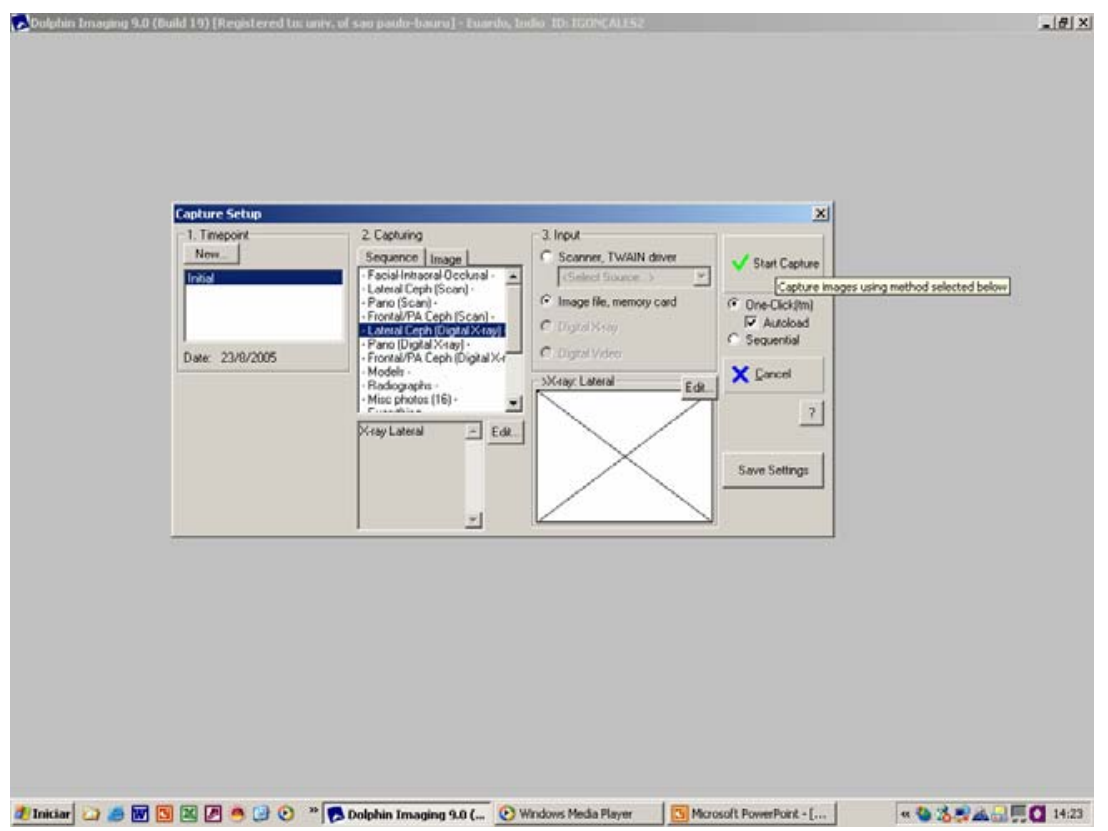

FIGURA 4.6- Seleção da seqüência de imagens pré-determinada (radiografia cefalométrica lateral digitalizada e arquivada como imagem)

- selecionou-se a radiografia digitalizada no arquivo de imagens (Figura 4.7); 
MATERIAL e MÉtodos

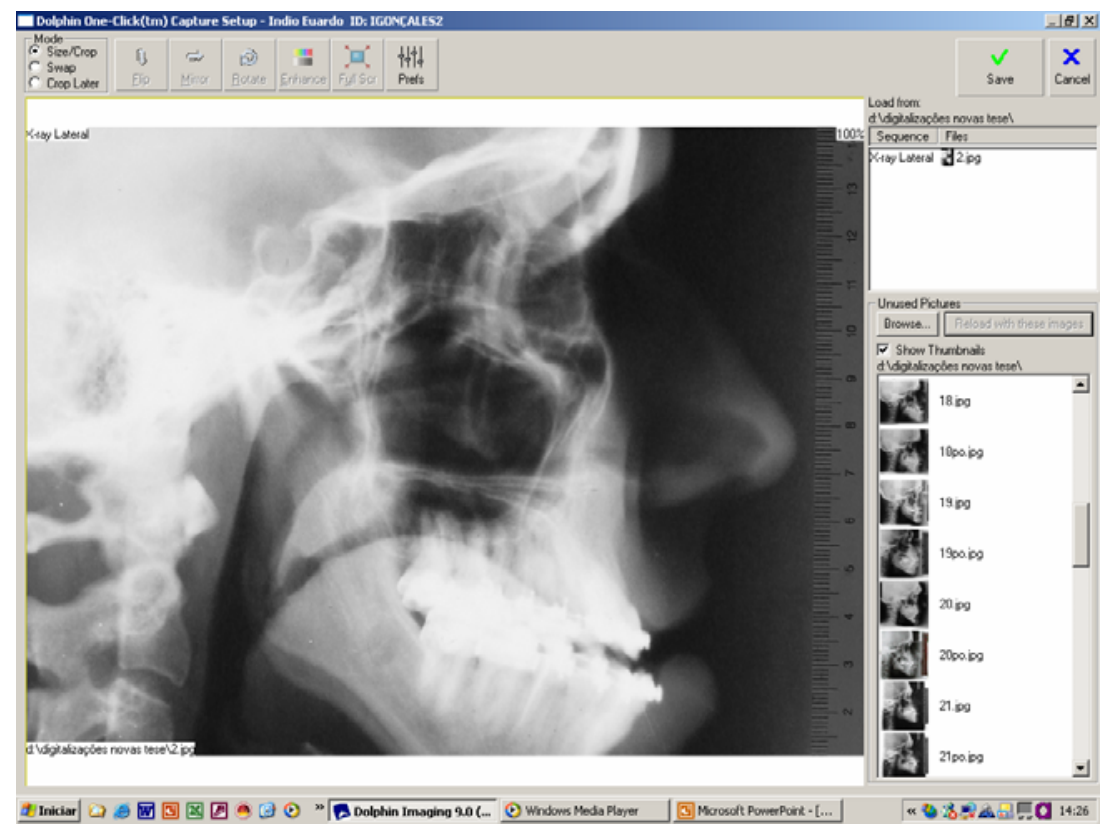

FIGURA 4.7-Radiografia digitalizada selecionada do arquivo de imagens, juntamente com a régua digitalizada

- reduziu-se as proporções da imagem selecionada (Figura 4.8);

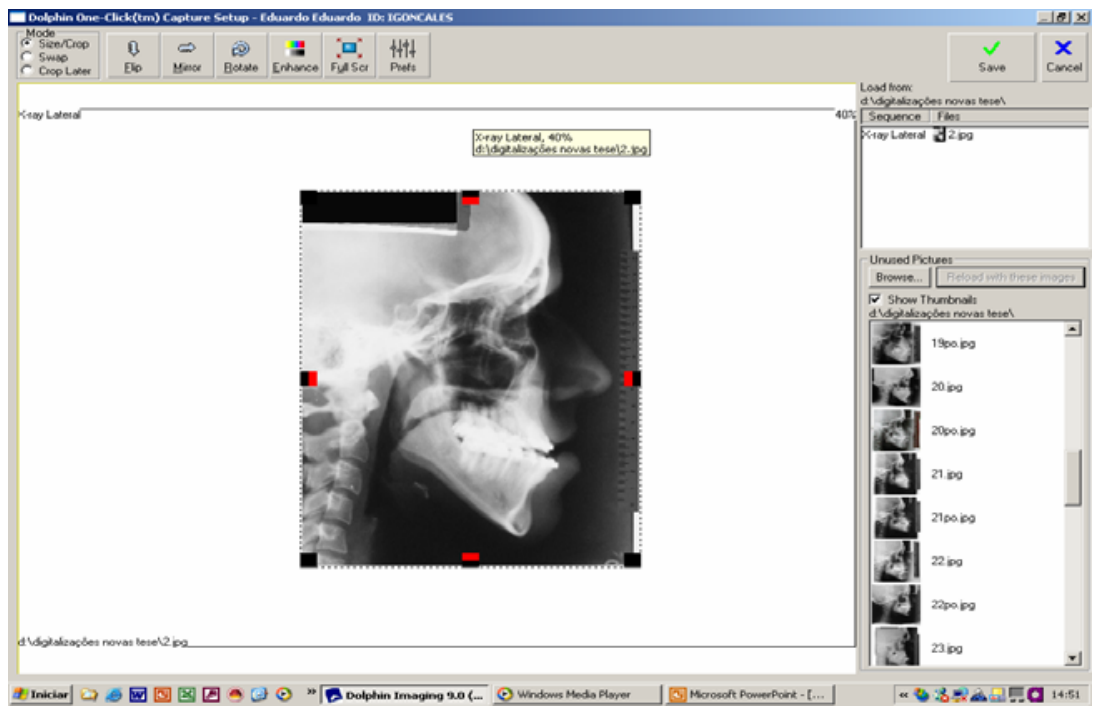

FIGURA 4.8- Imagem selecionada (de acordo com o paciente e período), reduzida em suas proporções 
- corrigiu-se o contraste, brilho, saturação e quantidade de branco das radiografias, favorecendo a visualização de algumas estruturas anatômicas (Figura 4.9);

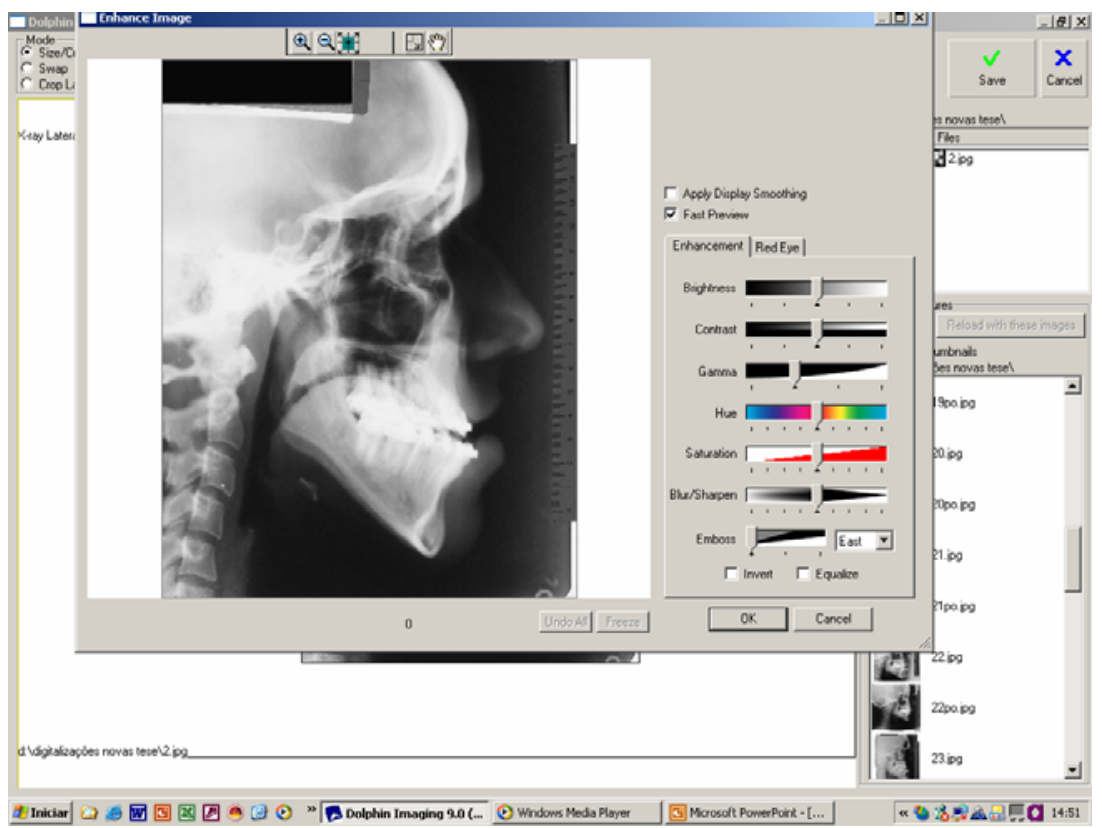

FIGURA 4.9- Recursos disponíveis para melhorar o contraste, brilho, saturação e quantidade de branco, favorecendo a visualização de algumas estruturas anatômicas

- após melhora do contraste, armazenou-se as telerradiografias digitalizadas de cada paciente, em ambos os períodos (Figura 4.10); 
MATERIAL E MÉtodos

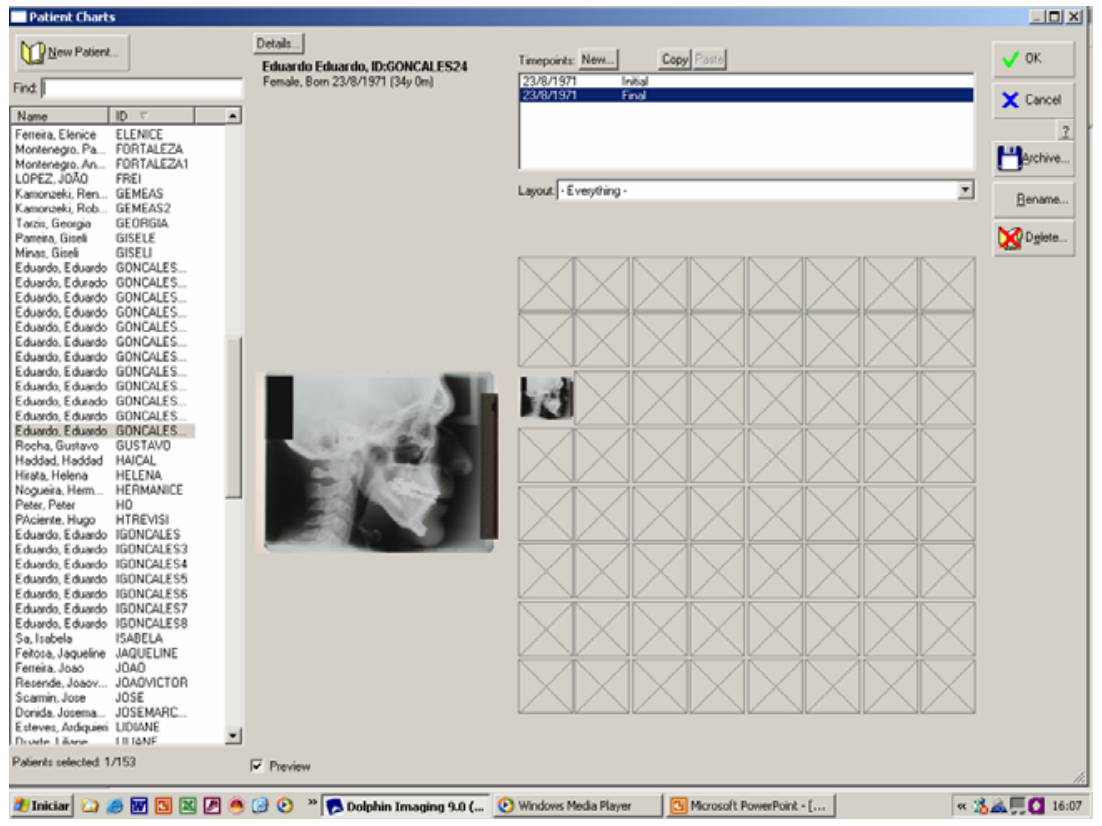

FIGURA 4.10-Telerradiografia final digitalizada, arquivada após melhora do contraste

- selecionou-se a análise cefalométrica desejada, o tipo de radiografia e a sessão (inicial ou alteração de pontos já digitalizados) (Figura 4.11);

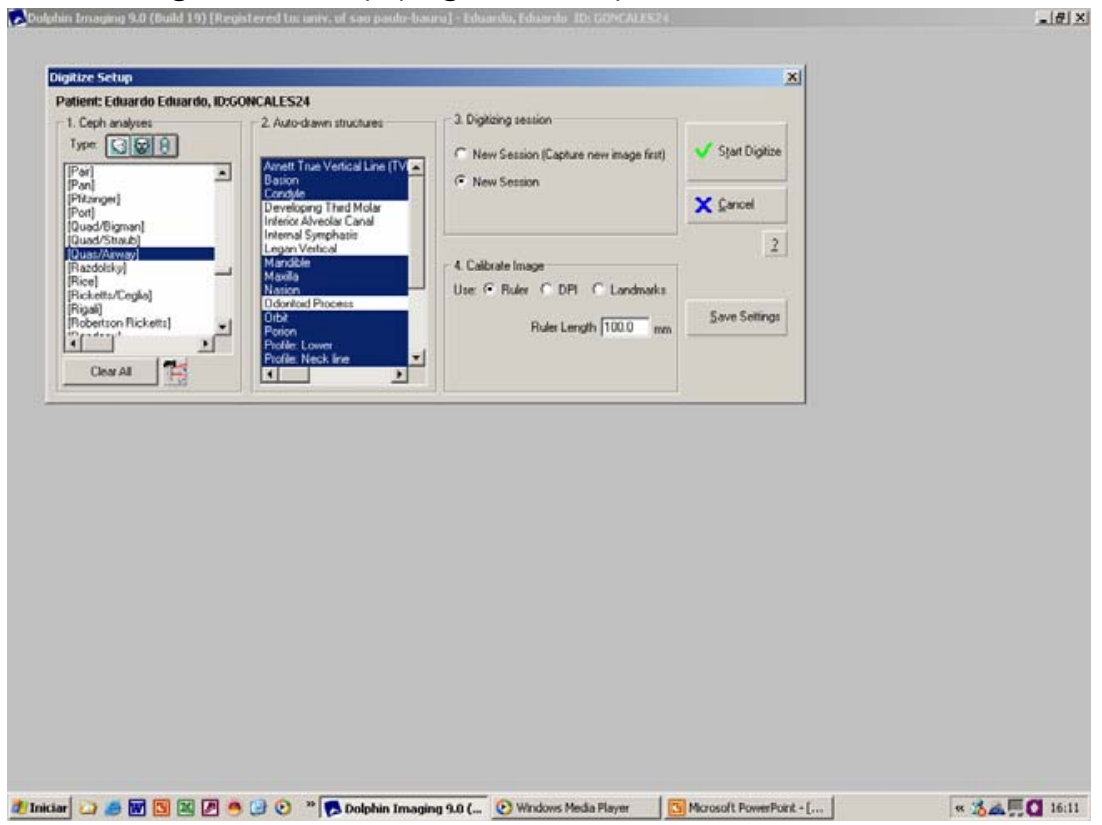

FIGURA 4.11-Seleção da análise cefalométrica, o tipo de radiografia e a sessão: passo inicial para digitalização dos pontos cefalométricos nas radiografias 
- iniciou-se a digitalização dos pontos cefalométricos solicitados pelas análises Arnett/McLauglin e Quas/airway (Figura 4.12). Os pontos cefalométricos digitalizados foram:

$\checkmark$ régua 1 (R1): ponto necessário para calibrar a imagem;

$\checkmark$ régua 2 (R2): ponto necessário para calibrar a imagem;

$\checkmark$ Pórion (Po): ponto mais superior do conduto auditivo externo;

$\checkmark$ orbitário (Or): ponto mais inferior do assoalho da órbita);

$\checkmark$ borda orbitária (Or'): ponto diretamente acima da borda infra-orbitária;

$\checkmark$ Osso zigomático (CB): ponto mais convexo da proeminência zigomática;

$\checkmark$ subpupilar (SP): ponto médio entre a borda infraorbitária e base alar;

$\checkmark$ base alar (AB): base da cartilagem alar;

$\checkmark$ pterigóide (PT): intersecção da borda inferior do forâmen redondo e parede posterior da fissura ptérigo-maxilar; 
$\checkmark$ sela (S): centro da fossa pituitária do osso esfenóide;

$\checkmark$ násio ( $\mathrm{N}$ ): intersecção da sutura internasal com a sutura nasofrontal;

$\checkmark$ básio (Ba): ponto mais inferior do osso occipital na margem anterior do forame occipital;

$\checkmark$ Glabela mole (G'): ponto mais anterior do osso frontal;

$\checkmark$ nasio mole (N'): ponto mais côncavo do dorso nasal mole;

$\checkmark$ dorso nasal (DN): ponto médio entre o násio e o ápice nasal;

$\checkmark$ ápice nasal (AP): ponto da curvatura anterior nasal;

$\checkmark$ subnasal (SN): ponto onde o nariz conecta-se ao lábio superior;

$\checkmark$ A': ponto A em tecido mole;

$\checkmark$ lábio superior (LS): ponto mais anterior do lábio superior;

$\checkmark$ estômio superior (ES): ponto mais inferior do lábio superior;

$\checkmark$ estômio inferior (EI): ponto mais inferior do lábio inferior; 
$\checkmark$ lábio inferior (LI): ponto mais anterior do lábio inferior;

$\checkmark$ B': ponto B em tecido mole: ponto de maior concavidade entre o lábio inferior e mento mole;

$\checkmark$ pogônio mole (Pog'): ponto mais anterior da curvatura do mento mole;

$\checkmark$ gnátio mole (Gn'): ponto médio entre o ponto mais anterior e inferior do mento mole;

$\checkmark$ mento mole (Me'): ponto mais inferior do mento mole;

$\checkmark$ submento-cervical (SC): intersecção das linhas que tangenciam o pescoço e a região submentoniana;

$\checkmark$ B: ponto mais posterior da concavidade anterior da sínfise;

$\checkmark$ pogônio (Pog): ponto mais anterior da sínfise;

$\checkmark$ gnátio anatômico (Gn): ponto médio entre os pontos mais anterior e inferior do mento ósseo;

$\checkmark$ mento (Me): ponto mais inferior da sínfise;

$\checkmark$ gônio (Go): ponto de maior convexidade ao longo da borda inferior do ramo;

$\checkmark$ ramo (R): ponto mais posterior na borda do ramo; 
$\checkmark$ meio do Ramo (MR): ponto de maior concavidade no interior do ramo;

$\checkmark$ chanfradura sigmóide (CS): ponto mais inferior da chanfradura da mandíbula;

$\checkmark$ articular (Ar): borda posterior do pescoço do côndilo;

$\checkmark$ condílio (Co): ponto mais superior e posterior do côndilo;

$\checkmark$ A: ponto mais profundo da curvatura maxilar entre a espinha nasal anterior e o osso alveolar;

$\checkmark$ ANS: ponta da espinha nasal anterior;

$\checkmark$ PNS: ponta da espinha nasal posterior;

$\checkmark$ oclusal do molar superior (1): ponta da cúspide mésio-vestibular do primeiro molar maxilar;

$\checkmark$ oclusal do molar inferior (2): ponta da cúspide mésio-vestibular do primeiro molar mandibular;

$\checkmark$ distal do molar superior (3): ponto mais inferior e distal da superfície distal do primeiro molar superior perpendicular ao plano oclusal;

$\checkmark$ mesial do molar superior (4): ponto mais inferior e mesial da superfície mesial do primeiro molar superior perpendicular ao plano oclusal; 
$\checkmark$ distal do molar inferior (5): ponto mais superior e distal da superfície distal do primeiro molar inferior perpendicular ao plano oclusal;

$\checkmark$ mesial do molar inferior (6): ponto mais superior e mesial da superfície mesial do primeiro molar inferior perpendicular ao plano oclusal;

$\checkmark$ borda gengival vestibular (L1): junção cementoesmalte vestibular do inciso inferior;

$\checkmark$ incisal (L1I): incisal do incisivo inferior;

$\checkmark$ raiz (L1A): ápice radicular do incisivo inferior;

$\checkmark$ borda gengival lingual (L1L- junção cementoesmalte lingual do inciso inferior);

$\checkmark$ borda gengival vestibular incisivo superior (U1): junção cemento-esmalte vestibular do inciso superior;

$\checkmark$ incisal incisivo superior (U1I): incisal do incisivo superior;

$\checkmark$ raiz incisivo superior (U1A): ápice radicular do incisivo superior;

borda gengival lingual incisivo superior (U1L): junção cemento-esmalte lingual do inciso superior; 
$\checkmark$ C2 superior posterior: ponto mais superior e posterior da segunda vértebra cervical;

$\checkmark \quad$ C3 inferior anterior: ponto mais inferior e anterior da terceira vértebra cervical;

$\checkmark$ C4 inferior posterior: ponto mais inferior e posterior da quarta vértebra cervical;

$\checkmark$ ápice da língua ( $A L$ ): ponto mais anterior da língua;

$\checkmark \quad$ V: fundo da epiglote;

$\checkmark$ Et: ponto mais superior da epiglote;

$\checkmark$ hióide (H) ponto mais anterior e superior do corpo do osso hióide;

$\checkmark$ ponta da úvula (U);

$\checkmark$ IAA: ponto mais anterior e inferior do espaço aéreo orofaríngeo;

$\checkmark$ IPA: ponto mais posterior e inferior do espaço aéreo orofaríngeo;

$\checkmark$ MPA: ponto médio da parede posterior da faringe;

$\checkmark$ PSP: ponto mais superior e posterior do dorso da língua;

$\checkmark$ PSPh: ponto médio entre a ponta da úvula e MPA. (Figura 4.13). 


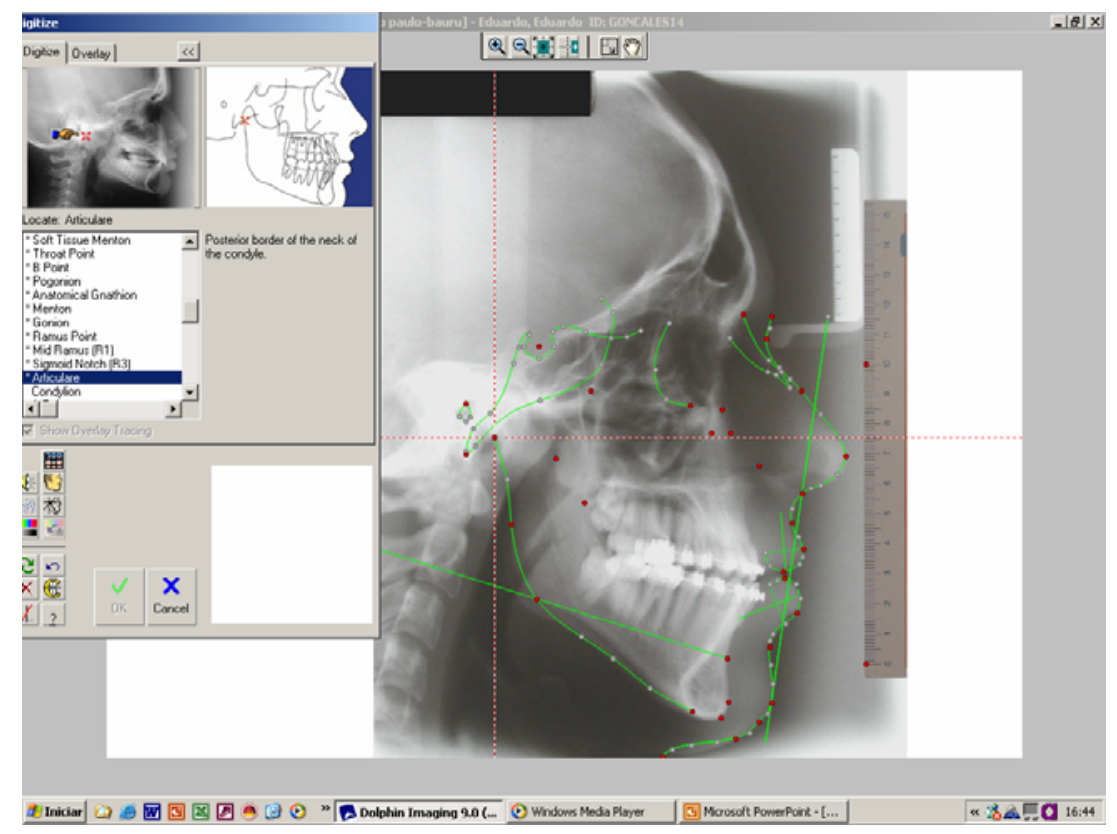

FIGURA 4.12-Telerradiografia com alguns pontos digitalizados e o traçado cefalométrico sendo construído, segundo análises Arnett/McLauglin e Quas/airway

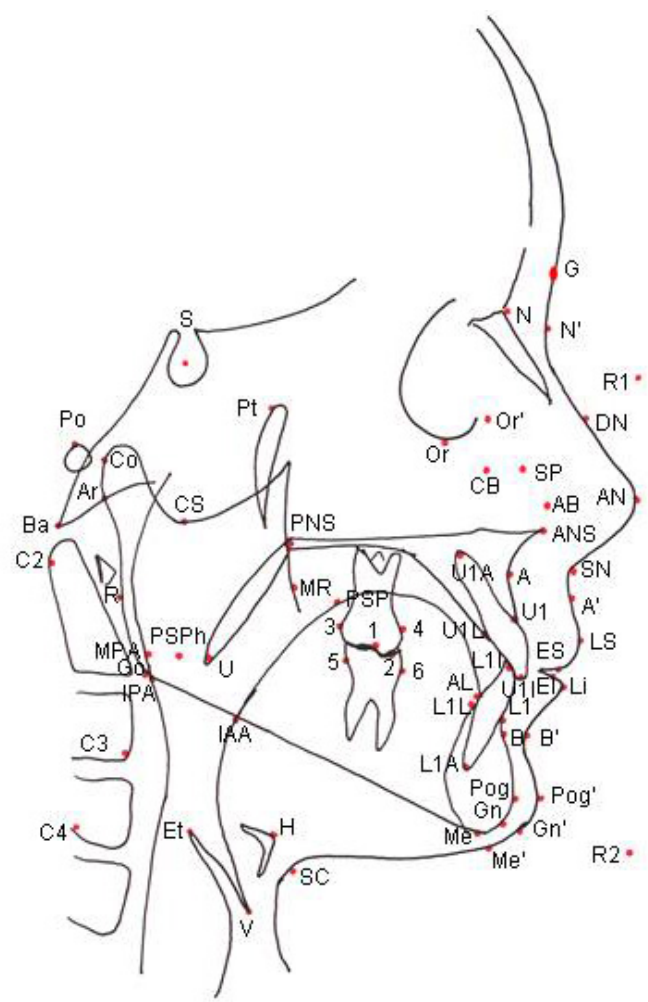

FIGURA 4.13-Representação esquemática dos pontos cefalométricos utilizados 
- concluiu-se a digitalização dos pontos solicitados pelas análises Arnett/McLauglin e Quas/airway; automaticamente o programa construiu as linhas e planos das respectivas análises (Figura 4.14);

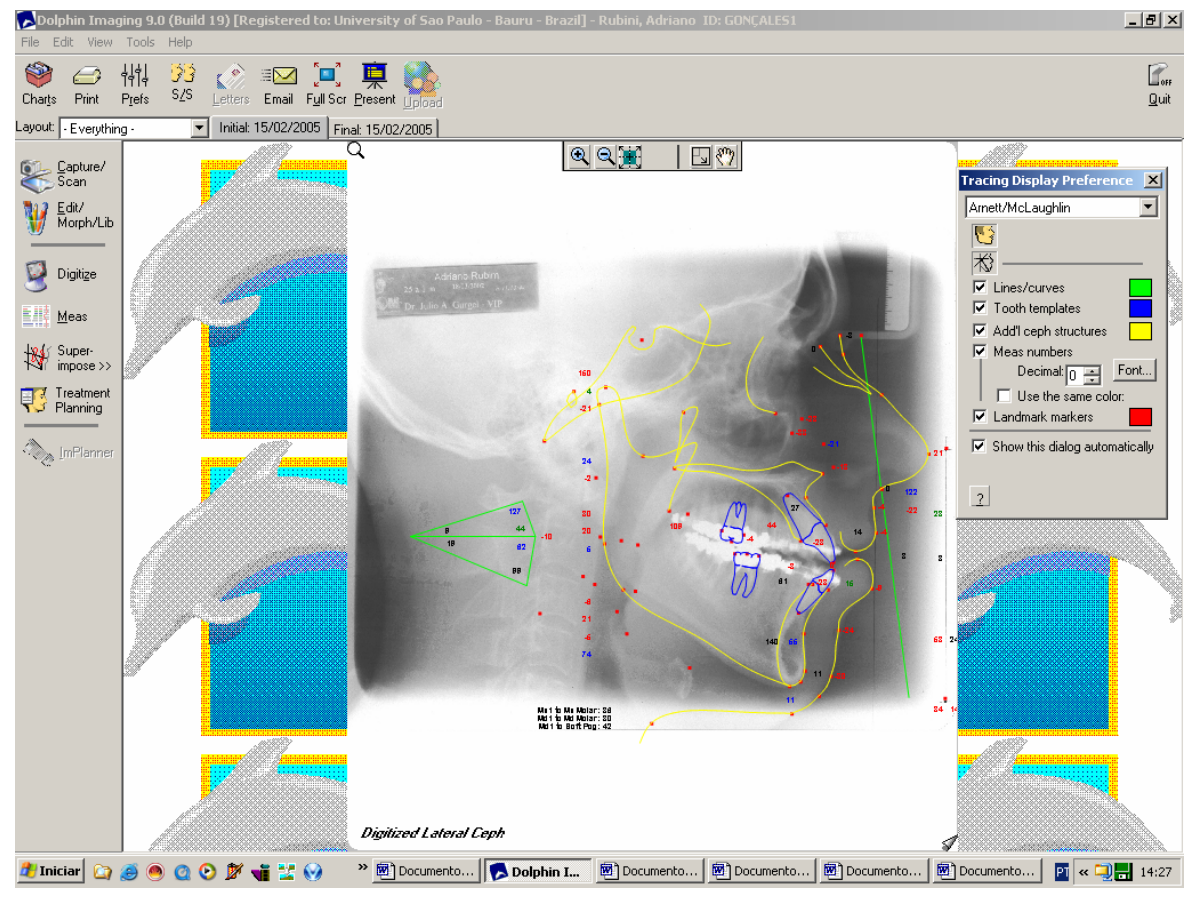

FIGURA 4.14- Telerradiografia com pontos digitalizados e traçado cefalométrico construído segundo análises Arnett/McLauglin e Quas/airway

- após digitalização dos pontos pré-determinados pelas análises, acionou-se a ferramenta "meas" e obteve-se as medidas lineares e angulares da análise Quas/Airway (Figura 4.15). 


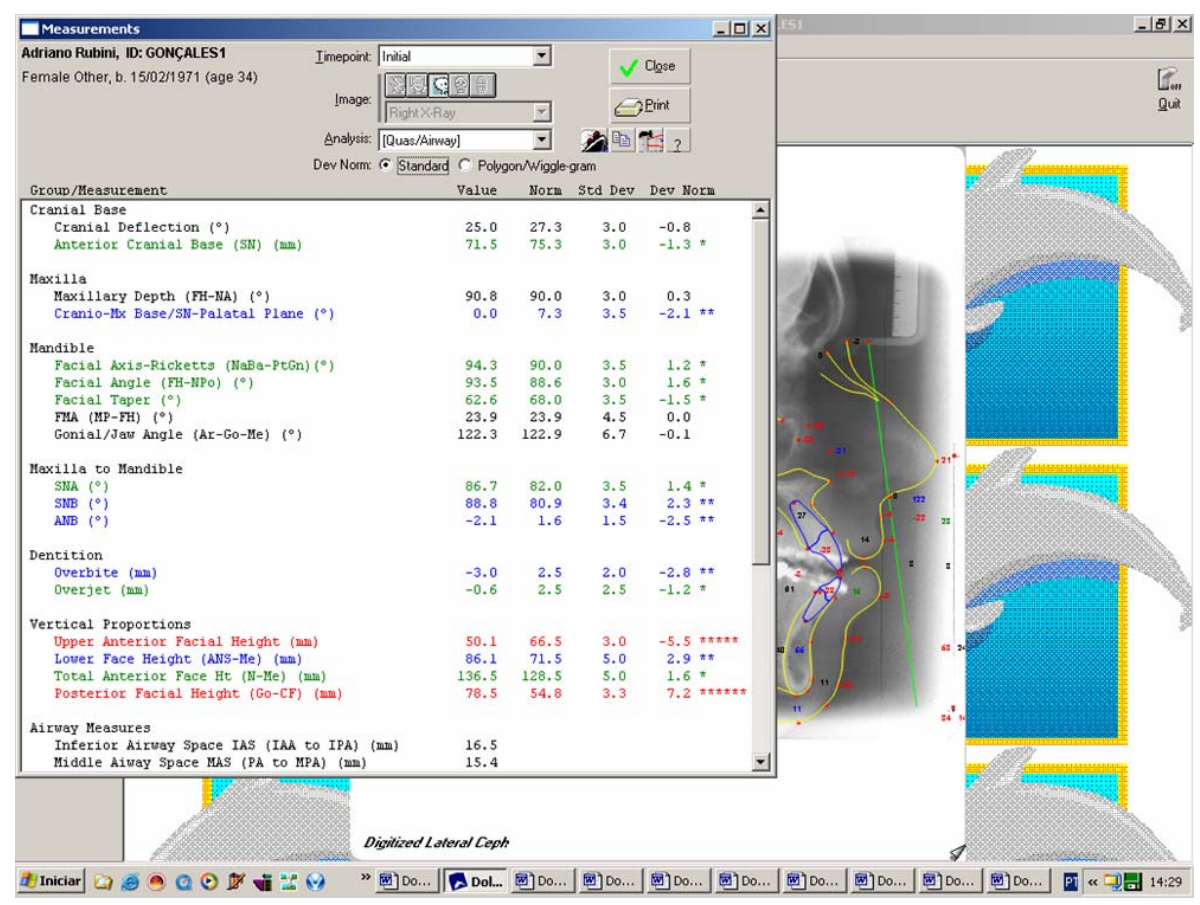

FIGURA 4.15- Medidas lineares e angulares da análise de Quas/Airway

A Tabela 4.1 apresenta os grupos medidos e os locais das medidas efetuadas neles, bem como as unidades utilizadas e a legenda estabelecida para identificação de cada uma das medidas. 
TABELA 4.1- Grupos de medidas, unidades e legendas utilizados nas mensurações em 19 indivíduos submetidos à cirurgia ortognática para correção de prognatismo mandibular

\begin{tabular}{|c|c|c|c|}
\hline GRUPO & MEDIDA & $\begin{array}{l}\text { UNI- } \\
\text { DADE }\end{array}$ & LEGENDA \\
\hline \multicolumn{4}{|c|}{ Base do Crânio } \\
\hline & Base anterior do crânio (SN) & $(\mathrm{mm})$ & B \\
\hline \multicolumn{4}{|l|}{ Maxila } \\
\hline & Profundidade maxilar (FH-NA) & $\left({ }^{\circ}\right)$ & C \\
\hline \multicolumn{4}{|l|}{ Mandíbula } \\
\hline & $\begin{array}{l}\text { Eixo facial de Ricketts (N.Ba-PtGn) } \\
\text { Ângulo facial (FH-NPo) } \\
\text { FMA (PM-FH) } \\
\text { Ar-Go-Me } \\
\text { Facial Taper: ângulo formado entre o plano mandibular } \\
\quad \text { (Go-Me) e o plano facial (N-Pg). }\end{array}$ & $\begin{array}{l}\left({ }^{\circ}\right) \\
\left({ }^{\circ}\right) \\
\left({ }^{\circ}\right) \\
\left({ }^{\circ}\right) \\
\left({ }^{\circ}\right)\end{array}$ & $\begin{array}{l}E \\
F \\
H \\
\text { I } \\
G\end{array}$ \\
\hline \multicolumn{4}{|c|}{ Maxila /Mandíbula } \\
\hline & $\begin{array}{l}\text { SNA } \\
\text { SNB } \\
\text { ANB }\end{array}$ & $\begin{array}{l}\left({ }^{\circ}\right) \\
\left({ }^{\circ}\right) \\
\left({ }^{\circ}\right)\end{array}$ & $\begin{array}{l}\mathrm{J} \\
\mathrm{K} \\
\mathrm{L}\end{array}$ \\
\hline \multicolumn{4}{|l|}{ Dentição } \\
\hline & $\begin{array}{l}\text { Trespasse vertical } \\
\text { Trespasse horizontal }\end{array}$ & $\begin{array}{l}(\mathrm{mm}) \\
(\mathrm{mm})\end{array}$ & $\begin{array}{l}M \\
N\end{array}$ \\
\hline \multicolumn{4}{|c|}{ Proporções verticais } \\
\hline & $\begin{array}{l}\text { Altura facial anterior superior (UAFH) } \\
\text { Altura facial inferior (ANS-Me) } \\
\text { Altura facial anterior total (N-Me) }\end{array}$ & $\begin{array}{l}(\mathrm{mm}) \\
(\mathrm{mm}) \\
(\mathrm{mm})\end{array}$ & $\begin{array}{l}\mathrm{O} \\
\mathrm{P} \\
\mathrm{Q}\end{array}$ \\
\hline \multicolumn{4}{|c|}{ Espaço aéreo } \\
\hline $\begin{array}{l}\text { IAS } \\
\text { MAS } \\
\text { SPAS } \\
\text { PNS-V } \\
\text { PNSPa } \\
\text { Hy-Me-MP }\end{array}$ & $\begin{array}{l}\text { Espaço aéreo inferior (IAS) (IAA /IPA) } \\
\text { Espaço aéreo médio (MAS) (PA /MPA) } \\
\text { Espaço aéreo superior (SPAS) (PSP to PSPh) } \\
\text { PNS - V } \\
\text { Esp. nasal posterior (ENP) ao Pa (palato inferior/úvula) } \\
\mathrm{H} \text { i- Me - Plano mandibular }\end{array}$ & $\begin{array}{c}(\mathrm{mm}) \\
(\mathrm{mm}) \\
(\mathrm{mm}) \\
(\mathrm{mm}) \\
(\mathrm{mm}) \\
\left({ }^{\circ}\right)\end{array}$ & $\begin{array}{l}\mathrm{S} \\
\mathrm{T} \\
\mathrm{U} \\
\mathrm{V} \\
\mathrm{X} \\
\mathrm{Z}\end{array}$ \\
\hline \multicolumn{4}{|c|}{ Posição do Hióide } \\
\hline $\begin{array}{l}\text { Hy-MP perp } \\
\text { Hy-S }\end{array}$ & $\begin{array}{l}\text { Hióide - Perp Plano Mandibular } \\
\mathrm{H} \text { i-S }\end{array}$ & $\begin{array}{l}(\mathrm{mm}) \\
(\mathrm{mm})\end{array}$ & $\begin{array}{l}\text { AA } \\
\text { DD }\end{array}$ \\
\hline
\end{tabular}


Após a coleta das medidas lineares e angulares nas telerradiografias iniciais e finais de todos os pacientes, os dados foram tabulados e submetidos à análise estatística pelo Teste $\mathbf{T}$ pareado, para determinar a sua significância.

Para a avaliação do erro sistemático e/ou casual (HOUSTON ${ }^{43}$, 1983), selecionou-se dez radiografias (uma do período pré-operatório e a outra do pós-operatório), de cinco indivíduos que foram escolhidos aleatoriamente entre os 19 pacientes estudados.

As radiografias selecionadas foram submetidas à repetição da análise cefalométrica, em dois períodos distintos (Medida 1 e 2), com intervalo de tempo não inferior a 15 dias. Tal procedimento resultou em dados que foram tabulados e analisados estatisticamente. 


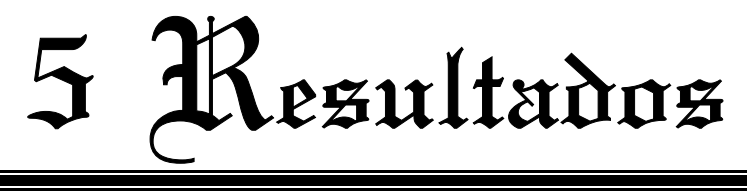





\section{RESULTADOS}

A Tabela 5.1 demonstra a amostra estudada, que constou de 19 indivíduos (nove do gênero masculino e dez do gênero feminino), com idade média de 25,58 anos (DP $=6,81$ anos) e período pós-operatório médio de 28,47 (DP = 15,64 meses).

Tabela 5.1- Gênero, idade e período pós-operatório de 19 indivíduos submetidos à cirurgia ortognática para correção de prognatismo mandibular (avanço de maxila + recuo de mandíbula)

\begin{tabular}{cccc}
\hline Paciente & Gênero & $\begin{array}{c}\text { Idade } \\
\text { (anos) }\end{array}$ & $\begin{array}{c}\text { Período pós-operatório } \\
\text { (meses) }\end{array}$ \\
\hline 1 & F & 24 & 13 \\
2 & M & 23 & 30 \\
3 & M & 23 & 11 \\
4 & F & 26 & 52 \\
5 & F & 41 & 18 \\
6 & F & 42 & 56 \\
7 & M & 29 & 34 \\
8 & F & 27 & 40 \\
9 & F & 23 & 11 \\
10 & M & 19 & 23 \\
11 & F & 26 & 35 \\
12 & M & 30 & 19 \\
13 & M & 24 & 50 \\
14 & F & 16 & 45 \\
15 & F & 18 & 15 \\
16 & M & 21 & 19 \\
17 & M & 19 & 10 \\
18 & M & 29 & 45 \\
19 & F & 26 & 15 \\
\hline
\end{tabular}


Os dados levantados quanto ao comportamento inicial e final, e a diferença das mensurações realizadas (entre final e inicial) para os 19 indivíduos da amostra encontram-se nos Anexos de B a M. Entre as medidas estudadas, as médias das diferenças entre Medida 1 (inicial) e Medida 2 (final) das medidas SN, FH-NA, FMA, Ar-Go-Me, trespasse vertical, UAFH, ANS-Me, N-Me, IAS, MAS e SPAS não apresentaram variações estatisticamente significativas $(p<0,05)$.

As médias das diferenças entre Medida 1 (inicial) e Medida 2 (final) das medidas NaBA-PtGn, FH-NPo, FT, SNA, SNB, ANB, Trespasse horizontal, PNS-V, PNSPa, Hy-Me-MP, Hy-MP Perp e HyS mostraram variações estatisticamente significativas $(p<0,05)$. Entre estas FT, SNA, ANB, Trespasse horizontal, PNS-V, PNSPa, Hy-Me-MP, Hy-MP Perp, Hy-S apresentaram aumento, enquanto que NaBa-PtGn, FH-NPo e SNB mostraram redução.

A Tabela 5.2 revela as médias iniciais e finais, e da diferença entre final e inicial, além dos desvios padrão iniciais, finais, da diferença entre final e inicial, o resultado do teste $T$ pareado $(t)$ e o valor de $P(P)$ das medidas dos 19 indivíduos submetidos à cirurgia ortognática para correção de prognatismo mandibular. 
TABELA 5.2- Médias iniciais (Média I), finais (Média F), da diferença entre final e inicial (média dif), desvios padrão iniciais (DP I), finais (DP F), da diferença entre final e inicial, Teste $T$ pareado $(t)$ e valor de $p$, das medidas de 19 indivíduos submetidos à cirurgia ortognática para correção de prognatismo mandibular

\begin{tabular}{|c|c|c|c|c|c|c|c|c|c|c|}
\hline & $\begin{array}{c}\text { Le- } \\
\text { gen } \\
\text { da }\end{array}$ & $\begin{array}{l}\text { Pa- } \\
\text { drão }\end{array}$ & Média I & | DP | & Média F & DP F & $\begin{array}{l}\text { mé- } \\
\text { dia } \\
\text { dif }\end{array}$ & $\begin{array}{l}\text { DP } \\
\text { dif }\end{array}$ & $\mathbf{t}$ & $\mathbf{p}^{*}$ \\
\hline \multicolumn{11}{|l|}{ Base do crânio } \\
\hline $\mathrm{SN}(\mathrm{mm})$ & B & 75,3 & 71,63 & 5,7 & 72,54 & 6,01 & 0,92 & 2,92 & 0,192 & 0,192 \\
\hline \multicolumn{11}{|l|}{ Maxila } \\
\hline FH-NA $\left({ }^{\circ}\right)$ & C & 90,0 & 91,55 & 4,8 & 93,16 & 6 & 1,62 & 4,02 & 1,746 & 0,098 \\
\hline \multicolumn{11}{|l|}{ Mandíbula } \\
\hline NBa-PtGn $\left(^{\circ}\right)$ & $E$ & 90,0 & 97,84 & 4,4 & 94,3 & 3,38 & $-3,54$ & 3,28 & 4,707 & 0,000 \\
\hline FH-NPo $\left({ }^{\circ}\right)$ & $\mathrm{F}$ & 88,6 & 96,31 & 4,1 & 92,8 & 3,78 & $-3,51$ & 3,65 & 4,187 & 0,001 \\
\hline $\mathrm{FT}\left({ }^{\circ}\right)$ & G & 68,0 & 62,45 & 5,3 & 65,39 & 3,81 & 2,95 & 3,75 & 3,422 & 0,003 \\
\hline FMA $\left(^{\circ}\right)$ & $\mathrm{H}$ & 23,9 & 21,77 & 7,7 & 21,8 & 6,09 & 0,07 & 9,76 & 0,027 & 0,979 \\
\hline Ar-Go-Me $\left(^{\circ}\right)$ & I & 122,9 & 130,71 & 9,8 & 128,26 & 8,94 & $-2,45$ & 7,19 & 1,484 & 0,155 \\
\hline \multicolumn{11}{|c|}{ Maxila e mandíbula } \\
\hline SNA $\left(^{\circ}\right)$ & $\mathrm{J}$ & 82,0 & 87,28 & 4,1 & 89,13 & 4,27 & 1,84 & 3,56 & 2,264 & 0,036 \\
\hline SNB $\left(^{\circ}\right)$ & $\mathrm{K}$ & 80,9 & 91,19 & 4,8 & 87,93 & 4,03 & $-3,26$ & 2,29 & 6,184 & 0,000 \\
\hline ANB $\left(^{\circ}\right)$ & L & 1,6 & $-3,91$ & 4,4 & 1,19 & 4,26 & 5,1 & 3,17 & 7,004 & 0,000 \\
\hline \multicolumn{11}{|l|}{ Dentição } \\
\hline Overbite (mm) & M & 2,5 & $-0,31$ & 1,6 & 0,34 & 0,76 & 0,65 & 1,78 & 1,588 & 0,13 \\
\hline Overjet (mm) & $\mathrm{N}$ & 2,5 & $-3,46$ & 3,2 & 3,14 & 1,29 & 6,59 & 3,58 & 5 & 0,000 \\
\hline \multicolumn{11}{|c|}{ Proporções verticais } \\
\hline UAFH $(\mathrm{mm})$ & $\mathrm{O}$ & 66,5 & 47,67 & 3,1 & 48,03 & 3,71 & 0,35 & 2,67 & 0,576 & 0,571 \\
\hline ANS-Me (mm) & $P$ & 71,5 & 72,24 & 6,4 & 71,74 & 6,15 & $-0,49$ & 3,14 & 0,686 & 0,502 \\
\hline $\mathrm{N}-\mathrm{Me}(\mathrm{mm})$ & $\mathrm{Q}$ & 128,5 & 120,13 & 8,5 & 119,86 & 9,03 & 0,25 & 3,2 & 0,365 & 0,719 \\
\hline \multicolumn{11}{|l|}{ Espaço aéreo } \\
\hline IAS (mm) & $\mathrm{S}$ & & 12,97 & 2,8 & 13,22 & 3,57 & 0,25 & 2,69 & 0,401 & 0,693 \\
\hline MAS (mm) & $\mathrm{T}$ & & 12,54 & 2,9 & 12,12 & 3,65 & $-0,42$ & 3,07 & 0,598 & 0,557 \\
\hline SPAS (MM) & $\mathrm{U}$ & & 21,65 & 8,6 & 23,38 & 7,57 & 1,74 & 4,62 & 1,64 & 0,118 \\
\hline PNS - V (mm) & $\mathrm{V}$ & & 64,45 & 6,2 & 70,59 & 8,17 & 6,15 & 5,31 & 5,048 & 0,000 \\
\hline PNSPa $(\mathrm{mm})$ & $x$ & & 32,38 & 5,7 & 36,45 & 5,67 & 4,07 & 4,36 & 4,068 & 0,001 \\
\hline $\mathrm{Hy}-\mathrm{Me}-\mathrm{MP}\left(^{\circ}\right)$ & Z & & 14,37 & 4,9 & 19,53 & 6,1 & 5,16 & 4,59 & 4,899 & 0,000 \\
\hline \multicolumn{11}{|l|}{ Posição Hióide } \\
\hline Hy-MPperp (mm) & $A A$ & & 12,63 & 3,8 & 15,42 & 4,07 & 2,79 & 3,93 & 3,096 & 0,006 \\
\hline HyS (mm) & DD & & 111,72 & 10 & 115,55 & 12,04 & 3,83 & 6,18 & 2,704 & 0,015 \\
\hline
\end{tabular}


As Figuras 5.1, 5.2, 5.3, 5.4, 5.5, 5.6 e 5.7 ilustram os valores das médias inicial e final, bem como da média da diferença entre final e inicial (Tabela 5.2), dos 19 indivíduos submetidos à cirurgia ortognática para correção de prognatismo mandibular.

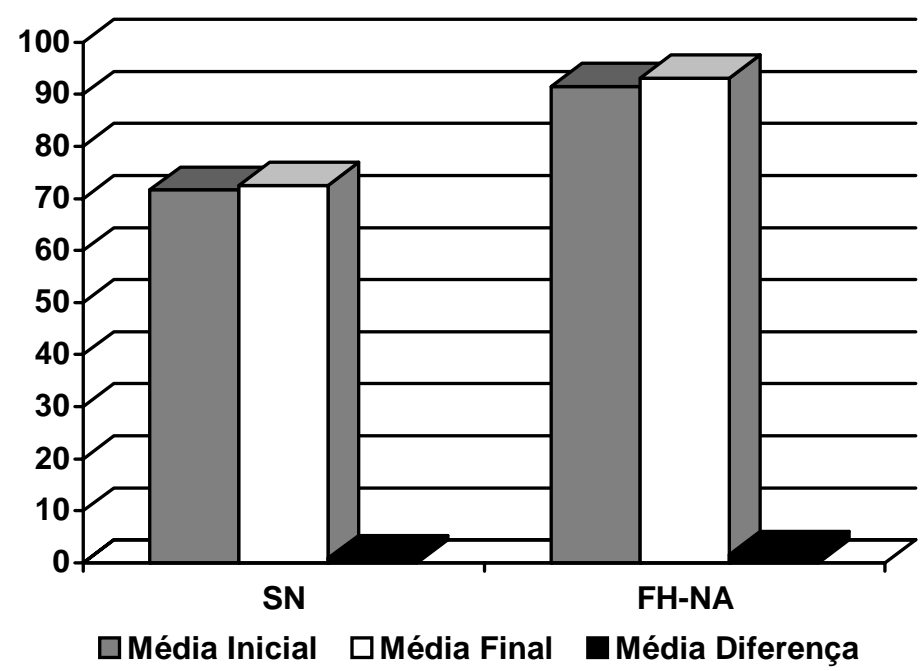

Figura 5.1- Média inicial, final e da diferença entre final e inicial dos valores de $\mathrm{SN}(\mathrm{mm})$ e FH-NA $\left({ }^{0}\right)$

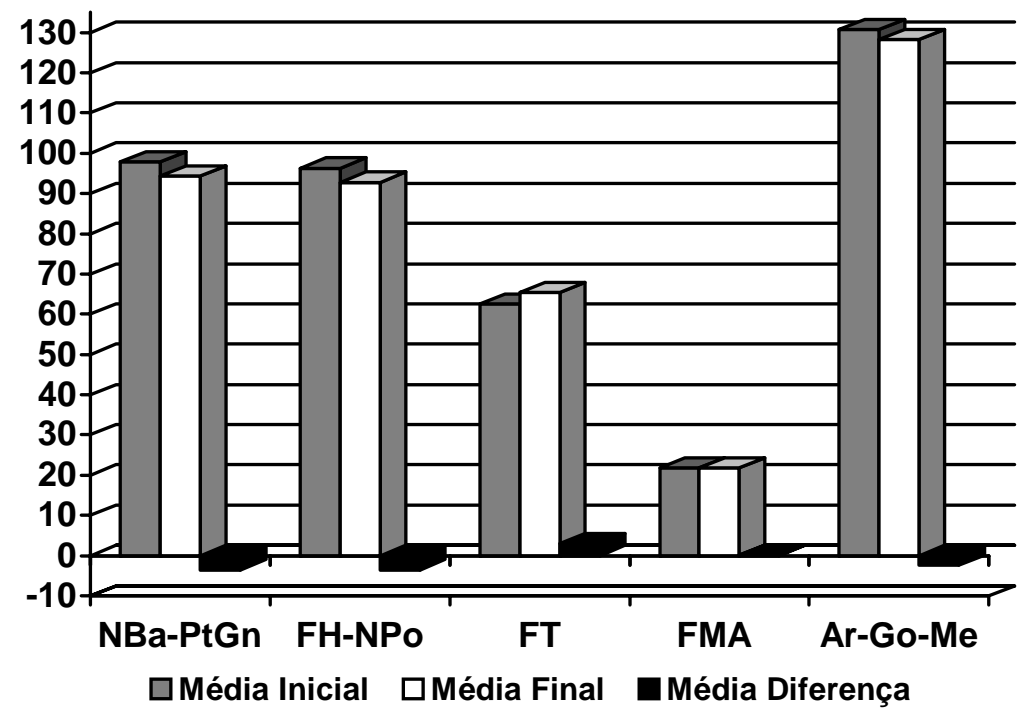

Figura 5.2- Média inicial, final e da diferença entre final e inicial dos valores de Nba-PtGn $\left({ }^{0}\right)$, FH-NPo $\left({ }^{0}\right)$, FT $\left(^{0}\right)$, FMA $\left(^{0}\right)$ e Ar-Go-Me $\left({ }^{0}\right)$ 


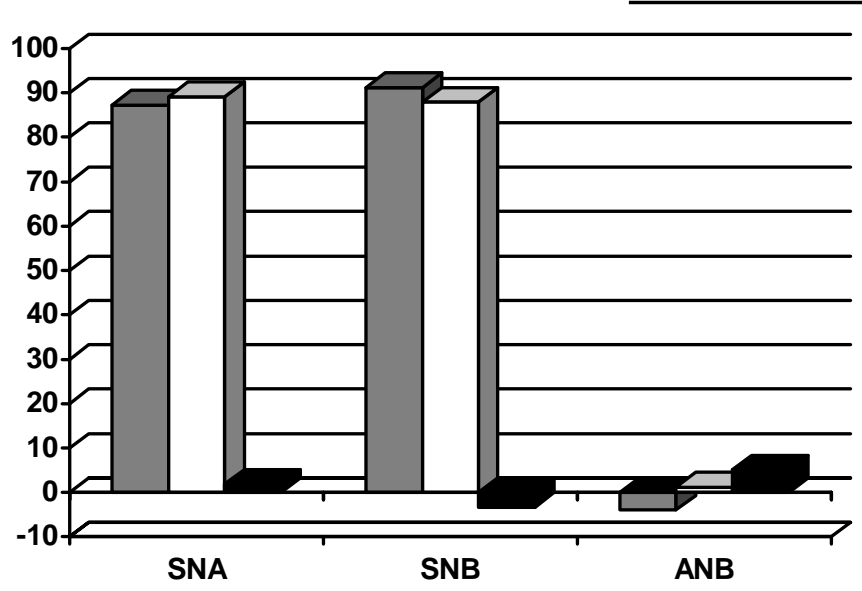

$\square$ Média Inicial $\square$ Média Final $\square$ Média Diferença

Figura 5.3- Média inicial, final e da diferença entre final e inicial dos valores de SNA $\left({ }^{0}\right)$, SNB $\left({ }^{0}\right)$, ANB $\left(^{0}\right)$

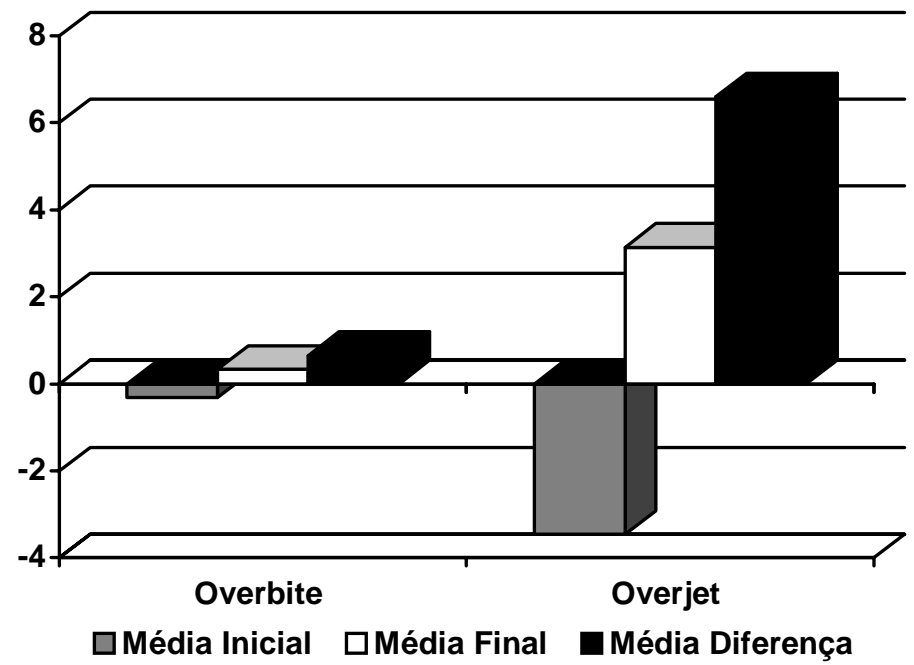

Figura 5.4- Média inicial, final e da diferença entre final e inicial dos valores de trespasse vertical (Overbite - $\mathrm{mm}$ ) e horizontal (Overjet - mm)

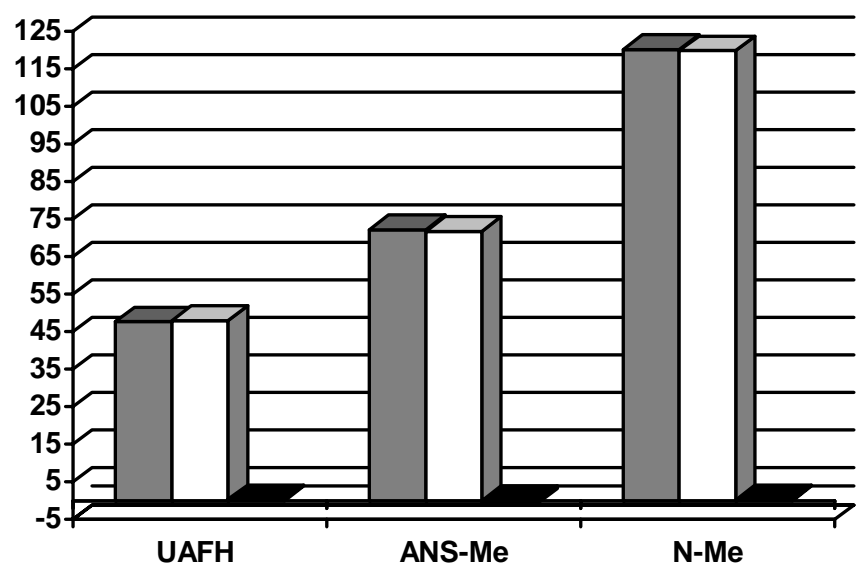

$\square$ Média Inicial $\square$ Média Final Média Diferença

Figura 5.5- Média inicial, final e da diferença entre final e inicial dos valores de $\mathrm{UAFH}(\mathrm{mm})$, ANS-Me (mm) e N-Me (mm) 


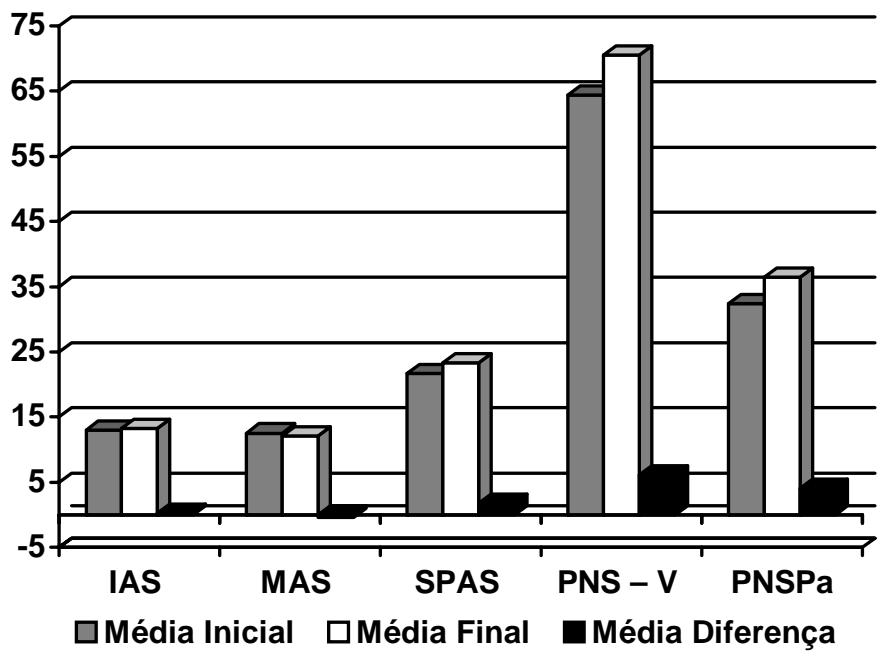

Figura 5.6- Média Inicial, Final e da Diferença entre Final e Inicial dos valores de IAS $(\mathrm{mm})$, MAS $(\mathrm{mm})$, SPAS $(\mathrm{mm})$, PNS-V $(\mathrm{mm})$ e PNSPa $(\mathrm{mm})$

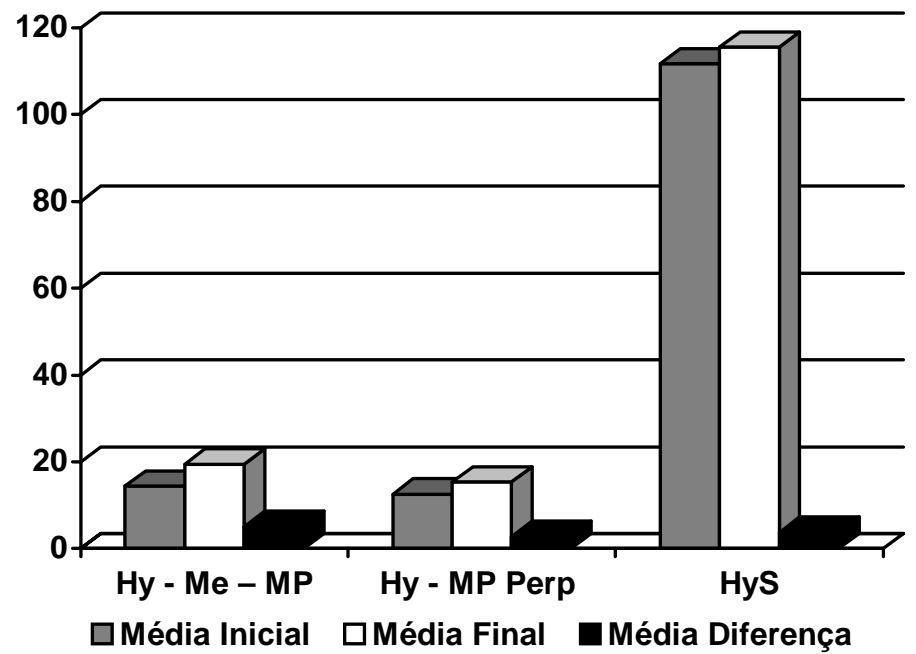

Figura 5.7- Média inicial, final e da diferença entre final e inicial dos valores de Hy-Me-MP $\left({ }^{0}\right)$, Hy-MPPerp (mm) e HyS (mm)

A Tabela 5.3 apresenta a média das medidas 1 e 2, os desvios padrão 1 e 2, o teste T pareado (t), o valor de $p(p)$ e o erro para as medidas 
das dez radiografias de cinco indivíduos da amostra, escolhidos aleatoriamente.

TABELA 5.3- Média da medida 1 (Média 1) e 2 (Média 2), desvios padrão 1 (DP1) e 2 (DP2), teste $T$ pareado (t), valor de $P(P)$ e Erro para as medidas 10 radiografias de indivíduos submetidos à cirurgia ortognática para correção de prognatismo mandibular

\begin{tabular}{|c|c|c|c|c|c|c|c|}
\hline Medida & Média 1 & DP 1 & Média 2 & DP 2 & $\mathbf{t}$ & p & Erro \\
\hline B & 73,06 & 4,22 & 73,18 & 4,33 & 0,751 & 0,472 & 0,35 \\
\hline $\mathrm{C}$ & 94,25 & 3,11 & 93,97 & 3,03 & 2,281 & 0,048 & 0,33 \\
\hline$E$ & 95,56 & 4,54 & 95,61 & 4,6 & 0,504 & 0,626 & 0,21 \\
\hline$F$ & 95,76 & 3,21 & 95,68 & 3,18 & 1,177 & 0,269 & 0,15 \\
\hline $\mathrm{G}$ & 64,25 & 4,24 & 64,23 & 4,13 & 0,162 & 0,875 & 0,26 \\
\hline $\mathrm{H}$ & 19,99 & 5,7 & 20 & 5,88 & 0,103 & 0,92 & 0,21 \\
\hline I & 129,52 & 9,23 & 129,45 & 9,08 & 0,429 & 0,678 & 0,35 \\
\hline $\mathrm{J}$ & 88,69 & 5,88 & 88,63 & 6,04 & 0,441 & 0,669 & 0,29 \\
\hline $\mathrm{K}$ & 89,59 & 5,06 & 89,5 & 5,03 & 0,523 & 0,614 & 0,37 \\
\hline L & $-0,9$ & 4,53 & $-0,77$ & 4,46 & 1,345 & 0,212 & 0,22 \\
\hline M & 0 & 1,4 & $-0,02$ & 1,45 & 0,259 & 0,801 & 0,16 \\
\hline $\mathrm{N}$ & 0,44 & 3,2 & 0,53 & 3,2 & 1,964 & 0,081 & 0,12 \\
\hline $\mathrm{O}$ & 47,39 & 2,04 & 47,43 & 2,08 & 0,292 & 0,777 & 0,29 \\
\hline $\mathrm{P}$ & 72,72 & 2,06 & 72,82 & 2,24 & 0,968 & 0,358 & 0,23 \\
\hline $\mathrm{Q}$ & 120,35 & 2,93 & 2,93 & 120,5 & 2,94 & 2,121 & 0,06 \\
\hline$S$ & 13,82 & 4,62 & 13,86 & 4,56 & 0,379 & 0,714 & 0,23 \\
\hline $\mathrm{T}$ & 14,34 & 3,76 & 14,45 & 3,66 & 0,974 & 0,356 & 0,25 \\
\hline$U$ & 22,88 & 12,83 & 22,95 & 12,91 & 1,105 & 0,298 & 0,14 \\
\hline V & 67,88 & 6,94 & 67,87 & 7,02 & 0,118 & 0,909 & 0,18 \\
\hline$x$ & 33,62 & 7,96 & 33,78 & 7,92 & 1,124 & 0,29 & 0,32 \\
\hline Z & 15,81 & 4,8 & 15,86 & 4,42 & 0,382 & 0,712 & 0,28 \\
\hline$A A$ & 13,31 & 3,81 & 13,21 & 3,93 & 1,557 & 0,154 & 0,17 \\
\hline DD & 113,07 & 7,91 & 113,06 & 7,76 & 0,091 & 0,93 & 0,23 \\
\hline
\end{tabular}





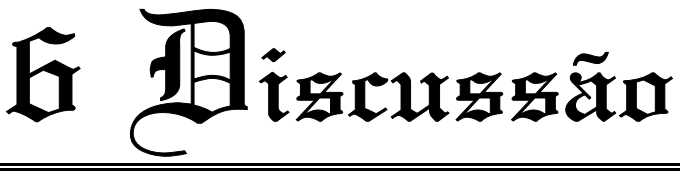





\section{DISCUSSÃO}

A via aérea superior é complexa e participa de várias funções fisiológicas, incluindo respiração, deglutição e fonação ${ }^{118}$, dividindo-se em três segmentos anatômicos: ${ }^{a}$ nasofaringe (região entre os cornetos nasais e palato duro), ${ }^{\text {b) }}$ orofaringe, que pode ser subdividida em retropalatal (velofaringe) e região retrolingual; $e,{ }^{c}$ hipofaringe (região da base da língua até a laringe).

Atuando como um tubo colabável ${ }^{134}$, a faringe pode ser considerada como via respiratória e alimentar única, onde um mecanismo sofisticado regula sua abertura e fechamento durante deglutição, protegendo a via aérea ${ }^{10}$.

O osso hióide é o local onde se dá a inserção dos músculos do sistema biodinâmico que regula a respiração, mastigação, deglutição e fonação ${ }^{110}$. Sendo um osso único e não articulado com outros ossos, fica suspenso no tecido mole por tendões e músculos, muda de posição de acordo com o posicionamento da cabeça, corpo e outros estados fisiológicos, além de mover-se durante várias funções orais, em conjunto com a atividade da língua, por causa da inter-relação das fibras do músculo geniohióideo e genioglosso ${ }^{94}$.

Tais músculos inserem-se no osso hióide e tubérculos genes na face lingual da mandíbula, logo, espera-se que alterações na posição mandibular, bem como o seu crescimento e desenvolvimento, acarretem alterações de posicionamento do osso hióide e da língua. O posicionamento do 
DISCUSSÃo

osso hióide e de ossos da face (especialmente as maxilas e mandíbula) são fatores que influenciam na colapsibilidade da via aérea superior, favorecendo a sua obstrução, mesmo na ausência de episódios de deglutição e em condições especiais (como o sono), permitindo a ocorrência da SAOS.

A postura mandibular de adultos saudáveis é influenciada pelo estágio do sono, em razão da hipotonia muscular que ocorre durante o sono REM, assumindo postura retrognata e reduzindo a hipofaringe. Em virtude do conseqüente retroposicionamento da língua e do osso hióide ${ }^{85}$, tal fato pode gerar ronco contínuo, pontuado por apnéias e hipopnéias, pela redução do tônus muscular que, por causa da posição supina, sofre ação da força gravitacional sobre os tecidos moles da língua e palato, reduzindo o diâmetro da via aérea faríngea ${ }^{54}$.

O avanço da idade diminui o espaço aéreo faríngeo e o palato mole torna-se mais longo e espesso, aumentando a incidência de SAOS em indivíduos com idade mais avançada ${ }^{50}$. Outros fatores, quando associados a esse quadro, como indivíduos obesos, com circunferência cervical aumentada e acúmulo de gordura em regiões que podem estreitar o espaço aéreo faríngeo, concretizam a possibilidade de existência de $\operatorname{SAOS}^{29,69}$.

Vários estudos relacionam a SAOS com alterações anatômicas faríngeas, dos músculos e dos ossos a ela relacionados. São as alterações mais freqüentemente citadas:

$$
\begin{aligned}
\checkmark & \text { deficiência } \\
& \\
& \text { mandibular, } \\
&
\end{aligned}
$$


Dıscussão

$\checkmark$ deficiência ântero-posterior ${ }^{47}$ ou transversal de maxila ${ }^{46,119}$

$\checkmark$ redução das dimensões do espaço aéreo superior $^{7,12,47,76,149}$;

$\checkmark$ aumento do palato mole $7,12,47,58,107,127,149,150$;

$\checkmark$ aumento das dimensões da língua ${ }^{7,47}$;

$\checkmark$ osso hióide localizado mais inferiormente $7,14,26,28,42,47,58,107,110,149,150$;

$\checkmark$ redução da base do crânio ${ }^{7,12,61,96}$;

$\checkmark$ aumento do volume do pescoço ${ }^{86}$;

$\checkmark$ espessamento dos tecidos moles e da parede posterior e estreitamento do lúmen do espaço velofaríngeo ${ }^{28,58}$;

$\checkmark$ face longa, grande ângulo ANB, plano mandibular acentuado ${ }^{7}$;

$\checkmark$ relativo posicionamento anterior da maxila, aumento da altura média facial ${ }^{42}$; e,

$\checkmark$ estreitamento significativo da via aérea em nível da úvula ${ }^{150}$

Uma vez que a obstrução da via aérea superior resulta de vários fatores e que a anatomia da faringe pode ser considerada como uma complexa inter-relação entre músculos e ossos, espera-se que tais obstruções ocorram em mais de um lugar na via aérea faríngea, portanto, é lógica e 
fundamental a determinação do(s) local(ais) de obstrução, para adequado tratamento.

Entre os métodos para determinação do(s) local(ais) de obstrução, destaca-se a radiografia cefalométrica, pois é um exame barato, de fácil execução e que evidencia adequadamente estruturas moles e ósseas da via aérea faríngea, bem como do esqueleto facial e osso hióide ${ }^{47,78,110,117}$, permitindo clara visualização da oro e nasofaringe, língua, palato mole, epiglote, osso hióide, processo mastóide, coluna vertebral, seio frontal, seio maxilar, seio esfenoidal, sela túrcica, órbita (rebordo infra-orbitário), palato duro, soalho da fossa nasal, espinha nasal anterior, espinha nasal posterior, processo zigomático da maxila, fossa ptérigo-maxilar, apófise pterigóide, processo condilar, incisura da mandíbula, tubérculo articular, asa maior do esfenóide, canal mandibular, base da mandíbula, forame mentoniano, arco zigomático e tábua óssea interna da mandíbula ${ }^{4}$, razões estas responsáveis pela utilização de tais radiografias neste estudo.

Esse fato corrobora-se pela vasta gama de estudos cefalométricos relacionados com a SAOS $7,12,14,26,28,42,44,46,47,50,58,60,61,76,85,93,97$, 107,110,113,119,125,127,145,146,149,150 e com o efeito da movimentação de ossos da face e/ou de suas alterações sobre a via aérea faríngea ${ }^{1,6,11,15,16,22,25,35,36,40,41,51,52,62,73,83,88,103,104,112,114,130,136,137,138,144}$.

Apesar disso, as cefalometrias possuem limitações, entre as quais se destaca o fato de ser um exame bidimensional ${ }^{110}$, realizado com paciente acordado e fora da posição supina ou em posição diferente daquela 
que dorme ${ }^{7}$, além da necessidade de padronização e tomada ao final da expiração, uma vez que o calibre da via aérea pode ser afetado com o ciclo respiratório ${ }^{117}$. Tais limitações, porém, não contra-indicam sua utilização para determinação de locais de obstrução em tecido mole ou duro ${ }^{115}$, pois conforme indica a literatura, podem ser corrigidas pelo uso da cefalometria associada à videoendoscopia ${ }^{87}$ e cefalometria associada à ressonância magnética ${ }^{18}$.

Modernamente, a análise cefalométrica pode ser realizada em radiografia cefalométrica digital ${ }^{20,38,79,124}$, mesmo utilizando-se sistemas computadorizados para visualização de objetivos de tratamento (VTO) em cirurgia ortognática ${ }^{80,137}$. Tais programas apresentam diferenças perceptíveis em sua capacidade e precisão ${ }^{126}$, porém, podem ser utilizados, uma vez que sua precisão compara-se à dos métodos convencionais (manuais ou não informatizados $)^{34}$. Apesar de SMITH et al. ${ }^{126}, 2004$, terem considerado o programa Dolphin Imaging System 8.0 inferior ao Dentofacial Planner Plus, e POWER et al. $.^{99}, 2005$, terem citado que a versão 8.0 do programa Dolphin Imaging necessitava de revisão para correção de erros que resultavam em erros de cálculos clinicamente significantes, GOSSETT et al. ${ }^{34}, \quad 2005$, consideraram-no preciso.

Neste estudo, utilizou-se o programa Dolphin Imaging 10.0, que é uma versão atualizada e, provavelmente, melhorada do Dolphin Imaging 8.0. Tais melhorias foram, eventualmente, motivadas pelo artigo de POWER et al. ${ }^{99}$, 2005, porém, é provável que ainda possam ocorrer erros nas medidas, tanto lineares quanto angulares, pois a referência linear de distâncias e todos os 
pontos cefalométricos são marcados pelo operador do sistema. Desta forma, uma eventual marcação de ponto cefalométrico realizada de forma errônea pelo operador, acarretará erro nos cálculos das medidas.

Os resultados da análise de erro sistemático e casual ${ }^{43}$, realizada nesta pesquisa, mostraram-se aceitáveis, pois estatisticamente não foram significativos, descartando a possibilidade de erro do operador do sistema. Faltam, no entanto, dados literários a respeito da versão 10.0, o que dificulta comparações conclusivas entre este e outros estudos. Apesar disso, o Programa Dolphin Imaging 10.0 pode ser utilizado como ferramenta para análise cefalométrica do espaço aéreo faríngeo.

É importante destacar que a SAOS é uma desordem respiratória do sono, resultante de obstruções anatômicas na via aérea faríngea, podendo ocorrer na naso e orofaringe, estendendo-se comumente para a laringofaringe $\mathrm{e}^{101}$. Tais obstruções podem ser decorrentes de deformidades dento-faciais esqueléticas e são definidas como defeito no crescimento e desenvolvimento dos ossos da face (especialmente na maxila e mandíbula), que resultam em: alteração desses ossos propriamente ditos e no posicionamento incorreto dos dentes e suas relações; alterações na função mastigatória, na deglutição, na fonação, nas articulações têmporo-mandibulares, na respiração e na harmonia e estética da face ${ }^{89}$. Cabe ressaltar ainda, que se a faringe é um órgão muscular que se sustenta pela sua inserção em ossos, então, as alterações no desenvolvimento da maxila e mandíbula podem gerar ou predispor o paciente à obstrução faríngea em 
situações especiais, como durante o sono, já que o tônus muscular se reduz nesse momento ${ }^{85}$.

Uma vez que 1/3 das obstruções ocorrem em um único nível, enquanto que $2 / 3$ em dois ou mais níveis ${ }^{13}$, e que as regiões principais de obstrução são palato mole, parede lateral da faringe e base da língua (hipofaringe) ${ }^{105}$, fica claro que o tratamento de tais obstruções deve considerar formas de desobstruir a via aérea, relacionado-as com os seus locais. Nesse ínterim, destaca-se que as obstruções passíveis de ocorrerem em pacientes portadores de deformidades dento-facial-esqueléticas decorrem, especialmente, do hipodesenvolvimento ântero-posterior maxilo/mandibular. Para esses pacientes, o avanço cirúrgico maxilo/mandibular pode corrigir a deformidade, bem como a possível obstrução e SAOS, pois, provavelmente, aumentam o espaço aéreo faríngeo ${ }^{83,62,91}$. A estabilidade dos resultados é uma questão que traz preocupação e, nesse aspecto, existem estudos que afirmam que o aumento parece ser instável em relação ao tempo ${ }^{22,24148}$ embora também já tenha sido demonstrado que a recidiva não ocorre ${ }^{32}$, sendo, portanto, estável.

Da mesma forma que o avanço maxilo/mandibular aumenta a via aérea faríngea, espera-se que o recuo mandibular também afete a via aérea faríngea, reduzindo-a. Nesse raciocínio, fica claro que, em pacientes portadores de prognatismo mandibular, o tratamento cirúrgico (recuo mandibular) favoreceria a redução do espaço aéreo faríngeo, especialmente na região de orofaringe e hipofaringe. Nesta pesquisa não se observou variação 
DIscussão

estatisticamente significativa nos espaços aéreos faríngeos inferior, médio e superior, apesar de redução estatisticamente significante nas medidas relacionadas com a mandíbula (NaBa-PtGn, FH-Npo e SNB), que comprovam o recuo mandibular. Por outro lado, as medidas que avaliaram a posição da maxila mostraram-se estatisticamente significativas e comprovaram o avanço de maxila (por exemplo: aumento de $1,84^{0}$ no SNA entre o pré e o pósoperatório).

Da mesma forma, os recuos de mandíbula realizados por ATHANASIOU et al. ${ }^{6}$, 1991, não reduziram o espaço aéreo, possivelmente, em decorrência de readaptação fisiológica da morfologia faríngea, como citado por SAITOH ${ }^{112}$, 2004. No caso desta pesquisa, apesar da redução da mandíbula, verificou-se que o avanço da maxila, apesar de discreto, pode ter favorecido tal readaptação, uma vez que a musculatura associada à maxila contribuiu para uma ampliação do espaço aéreo, provavelmente neutralizando a possibilidade de sua redução como conseqüência do recuo mandibular.

É importante salientar a existência de estudos como os de SAYINZU et al. ${ }^{116}$, 2006, e SAITO et al. ${ }^{111}, 2006$, - que observaram que a correção de deficiências transversais e/ou antero-posteriores de maxila melhora a respiração e interfere no espaço aéreo nasofaríngeo (aumentando-o) - e o de MEHRA et al. ${ }^{83}, 2001$, que observaram que, em pacientes submetidos a avanço maxilar e recuo mandibular, o decréscimo do espaço aéreo da nasofaringe é menor. 
RILEY et al. ${ }^{104}$, 1987, relacionaram as alterações do espaço aéreo faríngeo com o resultante posicionamento mais inferior e posterior do osso hióide, língua e mandíbula, dados corroborados por outros autores $^{1,25,73,138,144}$ e em portadores de outros fatores de risco ${ }^{15,136}$, podendo predispor o paciente à $\mathrm{SAOS}^{35,113}$.

Neste estudo, apesar do posicionamento mais inferior do osso hióide, não se observou redução dos espaços aéreos faríngeos inferior, médio e superior. Entretanto, é importante salientar que, com o envelhecimento, existe uma tendência de redução do espaço aéreo faríngeo (decorrente do alongamento do palato mole), perda do tônus muscular e possibilidade de aumento de peso (especialmente em homens) ${ }^{55,56}$, o que torna imprescindível uma atenção especial a esses fatores durante o planejamento de recuos de mandíbula. Portanto, concorda-se com PAOLI et al. ${ }^{96}$, 2000, que lembraram que o risco de desenvolvimento da SAOS deve ser incluído como um parâmetro para a indicação do recuo de mandíbula, e com RAMESH et al. ${ }^{102}$, 2005, que observaram uma considerável redução da via aérea em todos os pacientes, predispondo-os à SAOS.

Tendo em vista os resultados obtidos por esta pesquisa, entende-se que discrepância antero-posteriores devam ser corrigidas por meio de osteotomias maxilo-mandibulares combinadas. 



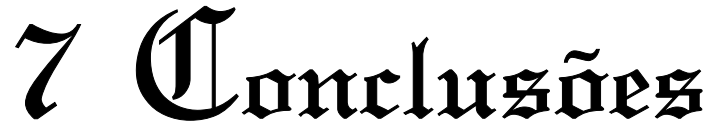





\section{CONCLUSÕES}

Em face ao exposto neste estudo e com base na literatura e nos resultados obtidos com as radiografias avaliadas, pôde-se concluir que:

- a cirurgia ortognática maxilo/mandibular para correção de prognatismo mandibular não comprometeu os espaços aéreos faríngeos superior (nasofaringe), médio (orofaringe) e inferior (hipofaringe);

- o Programa Dolphin Imaging 10.0 pode ser utilizado como ferramenta para análise cefalométrica do espaço aéreo faríngeo;

- nos recuos de mandíbula, o osso hióide posiciona-se mais inferiormente, podendo predispor o paciente à SAOS;

- especialmente em homens, quando necessário o recuo de mandíbula, deve-se considerar a possibilidade de cirurgia combinada maxilo/mandibular. 

Anexos 

ANEXo A

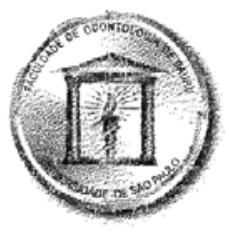

\section{Universidade de São Paulo Faculdade de Odontologia de Bauru \\ Al. Dr. Octávio Pinheiro Brisolla, 9-75 - Bauru-SP - CEP 17012-901 - C.P. 73 PABX (0XX14)3235-8000 - FAX (0XX14)3223-4679 \\ Comitê de Ética em Pesquisa}

Processo $n^{\circ} 42 / 2004$

Bauru, 10 de maio de 2004

Senhor Professor,

O projeto de pesquisa encaminhado a este Comitê de Ética em Pesquisa em Seres Humanos, denominado "Estudo cefalométrico computadorizado do espaço aéreo de pacientes submetidos cirurgia ortognática maxilo-mandibular com rotação horária do plano oclusal mandibular", de autoria de Eduardo Sanches Gonçales, que será desenvolvido sob sua orientação, foi enviado ao relator para avaliação.

Na reunião de 28 de abril de 2004 o parecer do relator, aprovando o projeto, foi aceito pelo Comitê, considerando que não existem infrações éticas pendentes.

Informamos que após o envio do trabalho concluído, este Comitê enviará o parecer final, que será utilizado para publicação do trabalho.

Atenciosamente,

Prof ${ }^{\mathrm{D}}{ }^{\mathrm{a}}$ Ana Lúcia Alvares Capelozza

Coordenadora

$\mathrm{Ilm}^{\circ}$ Sr. Prof. Dr. Eduardo Sant'Ana

DD. Docente do Departamento de Estomatologia 


\section{ANEXO B}

Medidas da base anterior do crânio média inicial (BI), final (BF) e diferença entre final e inicial (BF-I) e medidas do FH-NA média inicial (Cl), final (CF) e diferença entre final e inicial (CF-I) de 19 indivíduos submetidos à cirurgia ortognática para correção de prognatismo mandibular

\begin{tabular}{ccccccc}
\hline Paciente & BI & BF & BF-I & CI & CF & CF-I \\
\hline 1 & 66,3 & 70,5 & $\mathbf{4 , 2}$ & 96,9 & 96,5 & $\mathbf{- 0 , 2}$ \\
2 & 70,4 & 75 & $\mathbf{4 , 6}$ & 90,7 & 98,1 & $\mathbf{7 , 4}$ \\
3 & 79,3 & 78 & $\mathbf{- 1 , 3}$ & 88,7 & 94 & $\mathbf{5 , 3}$ \\
4 & 72,9 & 71,5 & $\mathbf{- 1 , 4}$ & 95,9 & 96 & $\mathbf{0 , 1}$ \\
5 & 69,4 & 77,3 & $\mathbf{7 , 9}$ & 91 & 94,7 & $\mathbf{3 , 7}$ \\
6 & 69,7 & 64,9 & $\mathbf{- 4 , 8}$ & 85,7 & 83,3 & $\mathbf{- 2 , 4}$ \\
7 & 79,6 & 81,7 & $\mathbf{2 , 1}$ & 84,2 & 80,4 & $\mathbf{- 3 , 8}$ \\
8 & 66,4 & 67,6 & $\mathbf{1 , 2}$ & 91,3 & 94,5 & $\mathbf{3 , 2}$ \\
9 & 68,2 & 72,3 & $\mathbf{4 , 1}$ & 91,1 & 98,4 & $\mathbf{7 , 3}$ \\
10 & 72,4 & 71,8 & $\mathbf{- 0 , 6}$ & 97,9 & 100,9 & $\mathbf{3}$ \\
11 & 71,5 & 69,9 & $\mathbf{- 1 , 6}$ & 94,6 & 94,8 & $\mathbf{0 , 2}$ \\
12 & 79,8 & 81,5 & $\mathbf{1 , 7}$ & 91,5 & 94 & $\mathbf{2 , 5}$ \\
13 & 74,3 & 74,4 & $\mathbf{0 , 1}$ & 96,8 & 97,1 & $\mathbf{0 , 3}$ \\
14 & 68,3 & 70 & $\mathbf{1 , 7}$ & 97,2 & 97,1 & $\mathbf{- 0 , 1}$ \\
15 & 74,9 & 73,3 & $\mathbf{- 1 , 5}$ & 83,2 & 92,8 & $\mathbf{9 , 6}$ \\
16 & 75,6 & 78,1 & $\mathbf{2 , 5}$ & 89 & 86 & $\mathbf{- 3}$ \\
17 & 68,7 & 68,5 & $\mathbf{- 0 , 2}$ & 96,9 & 93,4 & $\mathbf{- 3 , 5}$ \\
18 & 76,9 & 75,6 & $\mathbf{- 1 , 3}$ & 92,6 & 97,1 & $\mathbf{4 , 5}$ \\
19 & 56,3 & 56,3 & $\mathbf{0}$ & 84,2 & 80,9 & $\mathbf{- 3 , 3}$ \\
\hline
\end{tabular}




\section{ANEXo C}

Medidas do Eixo facial de Rickets médio inicial (EI), final $(E F)$, diferença entre final e inicial (EF-I), ângulo facial médio inicial (FI), final (FF), diferença entre final e inicial (FF-I) de 19 indivíduos submetidos à cirurgia ortognática para correção de prognatismo mandibular

\begin{tabular}{ccccccc}
\hline Paciente & EI & EF & EF-I & FI & FF & FF-I \\
\hline 1 & 97,5 & 91,5 & $\mathbf{- 6}$ & 97,3 & 90,7 & $\mathbf{- 6 , 6}$ \\
2 & 92,7 & 96,4 & $\mathbf{3 , 7}$ & 92,3 & 94,7 & $\mathbf{2 , 4}$ \\
3 & 105,3 & 98,4 & $\mathbf{- 6 , 9}$ & 101,2 & 94,5 & $\mathbf{- 6 , 7}$ \\
4 & 98,3 & 93,4 & $\mathbf{- 4 , 9}$ & 99,7 & 97,4 & $\mathbf{- 2 , 3}$ \\
5 & 91,6 & 90,5 & $\mathbf{- 1 , 1}$ & 95,5 & 94,3 & $\mathbf{- 1 , 2}$ \\
6 & 103 & 94,5 & $\mathbf{- 8 , 5}$ & 100,5 & 90,5 & $\mathbf{- 1 0}$ \\
7 & 106,7 & 99,6 & $\mathbf{- 7 , 1}$ & 97,7 & 90,7 & $\mathbf{- 7}$ \\
8 & 89,6 & 88,7 & $\mathbf{- 0 , 9}$ & 91,3 & 91,5 & $\mathbf{0 , 2}$ \\
9 & 99 & 93,1 & $\mathbf{- 5 , 9}$ & 93,5 & 94,5 & $\mathbf{1}$ \\
10 & 95,2 & 93,7 & $\mathbf{- 1 , 5}$ & 100,8 & 95,8 & $\mathbf{- 5}$ \\
11 & 97,3 & 90,9 & $\mathbf{- 6 , 4}$ & 97,7 & 94 & $\mathbf{- 3 , 7}$ \\
12 & 99,9 & 94,8 & $\mathbf{- 5 , 1}$ & 94,6 & 88,4 & $\mathbf{- 6 , 2}$ \\
13 & 100,1 & 96,9 & $\mathbf{- 3 , 2}$ & 102,1 & 95,2 & $\mathbf{- 6 , 9}$ \\
14 & 93,7 & 93,7 & $\mathbf{0}$ & 92,6 & 93,5 & $\mathbf{0 , 9}$ \\
15 & 94,9 & 89,6 & $\mathbf{- 5 , 3}$ & 89,3 & 91,3 & $\mathbf{2}$ \\
16 & 95,7 & 95,8 & $\mathbf{0 , 1}$ & 93,3 & 88,1 & $\mathbf{- 5 , 2}$ \\
17 & 100,6 & 101,4 & $\mathbf{0 , 8}$ & 101,2 & 99,8 & $\mathbf{- 1 , 4}$ \\
18 & 99,9 & 96,2 & $\mathbf{- 3 , 7}$ & 99,2 & 95,2 & $\mathbf{- 4}$ \\
19 & 97,9 & 92,6 & $\mathbf{- 5 , 3}$ & 90,1 & 83,1 & $\mathbf{- 7}$ \\
\hline
\end{tabular}




\section{ANEXO D}

Medidas do FT média inicial (GI), final (GF), diferença entre final e inicial (GF-I), FMA média inicial (HI), final (HF), diferença entre final e inicial (HF-l) de 19 indivíduos submetidos à cirurgia ortognática para correção de prognatismo mandibular

\begin{tabular}{ccccccc}
\hline Paciente & GI & GF & GF-I & HI & HF & HF-I \\
\hline 1 & 60,9 & 66 & $\mathbf{5 , 1}$ & 21,8 & 23,3 & $\mathbf{1 , 5}$ \\
2 & 56,2 & 61,7 & $\mathbf{5 , 5}$ & 31,5 & 23,6 & $\mathbf{- 7 , 9}$ \\
3 & 68,1 & 70,8 & $\mathbf{2 , 7}$ & 10,7 & 14,7 & $\mathbf{4 , 7}$ \\
4 & 62,7 & 63,1 & $\mathbf{0 , 4}$ & 17,6 & 19,5 & $\mathbf{1 , 9}$ \\
5 & 68 & 65 & $\mathbf{- 3}$ & 16,5 & 20,7 & $\mathbf{4 , 2}$ \\
6 & 74,3 & 68,9 & $\mathbf{- 5 , 4}$ & 15,2 & 20,6 & $\mathbf{5 , 4}$ \\
7 & 62,8 & 71 & $\mathbf{8 , 2}$ & 19,5 & 18,3 & $\mathbf{- 1 , 2}$ \\
8 & 55,2 & 61,3 & $\mathbf{6 , 1}$ & 33,6 & 27,2 & $\mathbf{- 6 , 4}$ \\
9 & 60,5 & 65,8 & $\mathbf{5 , 3}$ & 26 & 19,7 & $\mathbf{- 6 , 3}$ \\
10 & 61 & 68 & $\mathbf{7}$ & 18,2 & 16,1 & $\mathbf{- 2 , 1}$ \\
11 & 62 & 64,4 & $\mathbf{2 , 4}$ & 20,3 & 21,6 & $\mathbf{1 , 3}$ \\
12 & 59,9 & 64 & $\mathbf{4 , 1}$ & 25,5 & 27,6 & $\mathbf{2 , 1}$ \\
13 & 68,4 & 67,5 & $\mathbf{- 0 , 9}$ & 9,5 & 17,3 & $\mathbf{7 , 8}$ \\
14 & 63,4 & 67,4 & $\mathbf{4}$ & 23,9 & 19,2 & $\mathbf{- 4 , 7}$ \\
15 & 53,5 & 56,5 & $\mathbf{3}$ & 37,2 & 32,2 & $\mathbf{- 5}$ \\
16 & 63,4 & 67,2 & $\mathbf{3 , 8}$ & 23,3 & 24,7 & $\mathbf{1 , 4}$ \\
17 & 57,6 & 66,1 & $\mathbf{8 , 5}$ & 21,2 & 14,1 & $\mathbf{- 7 , 1}$ \\
18 & 69,1 & 68,7 & $\mathbf{- 0 , 4}$ & 11,7 & 16 & $\mathbf{4 , 3}$ \\
19 & 59,5 & 59,1 & $\mathbf{- 0 , 4}$ & 30,4 & 37,8 & $\mathbf{7 , 4}$ \\
\hline
\end{tabular}




\section{ANEXo E}

Medidas do Ar-Go-Me médio inicial (II), final (IF), diferença entre final e inicial (IF-I), SNA médio (JI), final (JF), diferença entre final e inicial (JF-I) de 19 indivíduos submetidos à cirurgia ortognática para correção de prognatismo mandibular

\begin{tabular}{ccccccc}
\hline Paciente & II & IF & IF-I & JI & JF & JF-I \\
\hline 1 & 139,9 & 132,6 & $\mathbf{- 7 , 3}$ & 87,8 & 92,2 & $\mathbf{4 , 4}$ \\
2 & 138,9 & 134,3 & $\mathbf{- 4 , 6}$ & 96 & 97,7 & $\mathbf{1 , 7}$ \\
3 & 119,4 & 124,1 & $\mathbf{4 , 7}$ & 86,5 & 92,7 & $\mathbf{6 , 2}$ \\
4 & 135,4 & 136,8 & $\mathbf{1 , 4}$ & 82,7 & 80,9 & $\mathbf{- 1 , 8}$ \\
5 & 117,4 & 116,4 & $\mathbf{- 1}$ & 81,9 & 88,5 & $\mathbf{6 , 6}$ \\
6 & 113,2 & 125,9 & $\mathbf{1 2 , 7}$ & 81,3 & 85,7 & $\mathbf{4 , 4}$ \\
7 & 126,3 & 110,3 & $\mathbf{- 1 6}$ & 90,7 & 87,8 & $\mathbf{- 2 , 9}$ \\
8 & 138,8 & 132,1 & $\mathbf{- 6 , 7}$ & 85,6 & 85 & $\mathbf{- 0 , 6}$ \\
9 & 138 & 129,9 & $\mathbf{- 8 , 1}$ & 89,2 & 89,7 & $\mathbf{0 , 5}$ \\
10 & 127,7 & 124,7 & $\mathbf{- 3}$ & 90,1 & 95,2 & $\mathbf{5 , 1}$ \\
11 & 137,9 & 136,8 & $\mathbf{- 1 , 1}$ & 86,8 & 84,7 & $\mathbf{- 2 , 2}$ \\
12 & 135,4 & 141,1 & $\mathbf{5 , 7}$ & 91,3 & 93,8 & $\mathbf{2 , 5}$ \\
13 & 117,2 & 119 & $\mathbf{1 , 8}$ & 88 & 91,3 & $\mathbf{3 , 3}$ \\
14 & 130,9 & 120,9 & $\mathbf{- 1 0}$ & 91,1 & 90,5 & $\mathbf{- 0 , 6}$ \\
15 & 148,6 & 143,9 & $\mathbf{- 4 , 7}$ & 80,6 & 84,7 & $\mathbf{4 , 1}$ \\
16 & 127,1 & 122,5 & $\mathbf{- 4 , 6}$ & 84,4 & 85,8 & $\mathbf{1 , 4}$ \\
17 & 138,2 & 124,3 & $\mathbf{- 1 3 , 9}$ & 92,3 & 86,1 & $\mathbf{- 6 , 2}$ \\
18 & 119,4 & 123,3 & $\mathbf{3 , 9}$ & 85,4 & 92,2 & $\mathbf{6 , 8}$ \\
19 & 133,8 & 138,1 & $\mathbf{4 , 3}$ & 86,6 & 88,9 & $\mathbf{2 , 3}$ \\
\hline
\end{tabular}




\section{ANEXo $\mathrm{F}$}

Medidas do SNB médio inicial $(\mathrm{KI})$, final $(\mathrm{KF})$, diferença entre final e inicial (KF-I), ANB médio (LI), final (LF), diferença entre final e inicial (LF-I) de 19 indivíduos submetidos à cirurgia ortognática para correção de prognatismo mandibular

\begin{tabular}{ccccccc}
\hline Paciente & KI & KF & KF-I & LI & LF & LF-I \\
\hline 1 & 87,5 & 85,9 & $\mathbf{- 1 , 6}$ & 0,3 & 6,3 & $\mathbf{6}$ \\
2 & 97,1 & 93,6 & $\mathbf{- 3 , 5}$ & $-1,1$ & 4,1 & $\mathbf{5 , 2}$ \\
3 & 96,8 & 92,8 & $-\mathbf{4}$ & $-10,3$ & $-0,1$ & $\mathbf{1 0 , 2}$ \\
4 & 86,4 & 83 & $\mathbf{- 3 , 4}$ & $-3,6$ & $-2,1$ & $\mathbf{1 , 5}$ \\
5 & 85,1 & 87,7 & $\mathbf{2 , 6}$ & $-3,3$ & 0,8 & $\mathbf{4 , 1}$ \\
6 & 95 & 91,6 & $\mathbf{- 3 , 4}$ & $-13,7$ & $-5,9$ & $\mathbf{7 , 8}$ \\
7 & 103,2 & 96,5 & $\mathbf{- 6 , 7}$ & $-12,5$ & $-8,7$ & $\mathbf{3 , 8}$ \\
8 & 84,7 & 81,1 & $\mathbf{- 3 , 6}$ & 0,8 & 3,9 & $\mathbf{3 , 1}$ \\
9 & 90,9 & 84,9 & $\mathbf{- 6}$ & $-1,7$ & 4,8 & $\mathbf{6 , 5}$ \\
10 & 92,4 & 89,4 & $\mathbf{- 3}$ & $-2,2$ & 5,8 & $\mathbf{8}$ \\
11 & 90,4 & 84,1 & $\mathbf{- 6 , 3}$ & $-3,6$ & 0,6 & $\mathbf{4 , 2}$ \\
12 & 92,6 & 86,7 & $\mathbf{- 5 , 9}$ & $-1,3$ & 7 & $\mathbf{8 , 3}$ \\
13 & 92,6 & 88,4 & $\mathbf{- 4 , 2}$ & $-4,6$ & 2,8 & $\mathbf{7 , 4}$ \\
14 & 87,1 & 86,4 & $\mathbf{- 0 , 7}$ & 4 & 4,1 & $\mathbf{0 , 1}$ \\
15 & 86,4 & 82,4 & $\mathbf{- 4}$ & $-5,8$ & 2,4 & $\mathbf{8 , 2}$ \\
16 & 87,7 & 86,9 & $\mathbf{- 0 , 8}$ & $-3,4$ & $-1,1$ & $\mathbf{2 , 3}$ \\
17 & 95 & 90,8 & $\mathbf{- 4 , 2}$ & $-2,7$ & $-4,7$ & $\mathbf{- 2}$ \\
18 & 90,9 & 89,8 & $\mathbf{- 1 , 1}$ & $-5,4$ & 2,4 & $\mathbf{7 , 8}$ \\
19 & 90,8 & 88,7 & $\mathbf{- 2 , 1}$ & $-4,2$ & 0,2 & $\mathbf{4 , 4}$ \\
\hline
\end{tabular}




\section{ANEXO G}

Medidas do Trespasse vertical (overbite) médio inicial (MI), final (MF), diferença entre final e inicial (MF-I), Trespasse horizontal (overjet) médio (NI), final (NF), diferença entre final e inicial (NF-I) de 19 indivíduos submetidos à cirurgia ortognática para correção de prognatismo mandibular

\begin{tabular}{ccccccc}
\hline Paciente & MI & MF & MF-I & NI & NF & NF-I \\
\hline 1 & $-0,7$ & 0,8 & $\mathbf{1 , 5}$ & $-2,9$ & 3,9 & $\mathbf{6 , 8}$ \\
2 & $-0,8$ & 1 & $\mathbf{1 , 8}$ & $-3,8$ & 4,3 & $\mathbf{8 , 1}$ \\
3 & 3,1 & $-0,4$ & $\mathbf{- 3 , 5}$ & $-4,6$ & 3,3 & $\mathbf{7 , 9}$ \\
4 & $-1,6$ & 0,4 & $\mathbf{2}$ & $-0,5$ & 2 & $\mathbf{2 , 5}$ \\
5 & $-1,5$ & $-0,3$ & $\mathbf{1 , 2}$ & 0,4 & 2 & $\mathbf{1 , 6}$ \\
6 & $-0,1$ & $-0,8$ & $\mathbf{- 0 , 7}$ & $-6,4$ & 1,5 & $\mathbf{7 , 9}$ \\
7 & 2,5 & 0,7 & $\mathbf{- 1 , 8}$ & -10 & 4,3 & $\mathbf{1 4 , 3}$ \\
8 & $-0,2$ & 1,6 & $\mathbf{1 , 8}$ & $-1,2$ & 4,2 & $\mathbf{5 , 4}$ \\
9 & $-0,4$ & 0,7 & $\mathbf{1 , 1}$ & $-2,9$ & 2,9 & $\mathbf{5 , 8}$ \\
10 & $-1,3$ & 1,3 & $\mathbf{2 , 6}$ & $-5,7$ & 3,5 & $\mathbf{9 , 2}$ \\
11 & $-1,7$ & $-0,7$ & $\mathbf{1}$ & 0,1 & 1,5 & $\mathbf{1 , 4}$ \\
12 & 0,7 & 0,4 & $\mathbf{- 0 , 3}$ & $-8,9$ & 2,1 & $\mathbf{1 1}$ \\
13 & 0,6 & $-0,8$ & $\mathbf{- 1 , 4}$ & $-2,4$ & 1,9 & $\mathbf{4 , 3}$ \\
14 & $-1,1$ & 1 & $\mathbf{2 , 1}$ & 1,4 & 3,6 & $\mathbf{2 , 2}$ \\
15 & $-4,4$ & $-0,2$ & $\mathbf{4 , 2}$ & 0,2 & 2,6 & $\mathbf{2 , 4}$ \\
16 & 0,7 & 1,3 & $\mathbf{0 , 6}$ & $-4,8$ & 6,3 & $\mathbf{1 1 , 1}$ \\
17 & 1,1 & 0,5 & $\mathbf{- 0 , 6}$ & $-6,3$ & 2,4 & $\mathbf{8 , 7}$ \\
18 & $-0,2$ & $-0,4$ & $\mathbf{- 0 , 2}$ & -3 & 4,9 & $\mathbf{7 , 9}$ \\
19 & $-0,5$ & 0,4 & $\mathbf{0 , 9}$ & $-4,4$ & 2,4 & $\mathbf{6 , 8}$ \\
\hline
\end{tabular}




\section{ANEXO H}

Medidas UAFH média inicial (OI), final (OF), diferença entre final e inicial (OFI), ANS-Me médio inicial (PI), final (PF), diferença entre final e inicial (PF-I) de 19 indivíduos submetidos à cirurgia ortognática para correção de prognatismo mandibular

\begin{tabular}{|c|c|c|c|c|c|c|}
\hline Paciente & OI & OF & OF-I & PI & PF & PF-I \\
\hline 1 & 49,4 & 48,7 & $-0,7$ & 72,3 & 76 & 3,7 \\
\hline 2 & 48,7 & 49,8 & 1,1 & 73,9 & 70,9 & -3 \\
\hline 3 & 44,8 & 44,2 & $-0,6$ & 72,8 & 75,1 & 2,3 \\
\hline 4 & 48,7 & 46,6 & $-2,1$ & 70,2 & 69,6 & $-0,6$ \\
\hline 5 & 45,2 & 47,8 & 2,6 & 72,9 & 73,5 & 0,6 \\
\hline 6 & 46,2 & 41,1 & $-5,1$ & 62,2 & 64,7 & 2,5 \\
\hline 7 & 50,6 & 56,5 & 5,9 & 82,8 & 77 & $-5,8$ \\
\hline 8 & 49,3 & 48,9 & $-0,4$ & 74,1 & 73,1 & -1 \\
\hline 9 & 45,1 & 50,6 & 5,5 & 72,3 & 72,7 & 0,4 \\
\hline 10 & 51,4 & 52,1 & 0,7 & 78,9 & 72,6 & $-6,3$ \\
\hline 11 & 44,9 & 47,9 & 3 & 69,8 & 66,8 & -3 \\
\hline 12 & 45,5 & 45,7 & 0,2 & 79,1 & 76,3 & $-2,8$ \\
\hline 13 & 49 & 48,1 & $-0,9$ & 68,7 & 68 & $-0,7$ \\
\hline 14 & 49 & 47,6 & $-1,4$ & 67,4 & 71 & 3,6 \\
\hline 15 & 46,3 & 48 & 1,7 & 81,6 & 80 & $-1,6$ \\
\hline 16 & 53,1 & 53,2 & 0,1 & 78,8 & 84,2 & 5,4 \\
\hline 17 & 48,3 & 46,9 & $-1,4$ & 69,2 & 66,2 & -3 \\
\hline 18 & 50,5 & 47,8 & $-2,7$ & 68,2 & 69,2 & 1 \\
\hline 19 & 39,8 & 41 & 1,2 & 57,3 & 56,2 & $-1,1$ \\
\hline
\end{tabular}




\section{ANEXo I}

Medidas da N-Me médio inicial (QI), final (QF), diferença entre final e inicial (QF-I), IAS inicial (SI), final (SF), diferença entre final e inicial (SF-I) de 19 indivíduos submetidos à cirurgia ortognática para correção de prognatismo mandibular.

\begin{tabular}{ccccccc}
\hline Paciente & QI & QF & QF-I & SI & SF & SF-I \\
\hline 1 & 121,6 & 124,3 & $\mathbf{2 , 7}$ & 13,1 & 17,7 & $\mathbf{4 , 6}$ \\
2 & 124,1 & 121,6 & $\mathbf{- 2 , 5}$ & 16,8 & 18,3 & $\mathbf{1 , 5}$ \\
3 & 116,8 & 119,9 & $\mathbf{3 , 1}$ & 14,8 & 20,2 & $\mathbf{5 , 4}$ \\
4 & 118,7 & 116,3 & $\mathbf{- 2 , 4}$ & 10,8 & 12 & $\mathbf{1 , 2}$ \\
5 & 118 & 120,8 & $\mathbf{2 , 8}$ & 9,1 & 5,4 & $\mathbf{- 3 , 7}$ \\
6 & 108,4 & 106,2 & $\mathbf{- 2 , 2}$ & 12,2 & 8,5 & $\mathbf{- 3 , 7}$ \\
7 & 133,9 & 134,8 & $\mathbf{0 , 9}$ & 13,3 & 13,6 & $\mathbf{0 , 3}$ \\
8 & 122,9 & 121,3 & $\mathbf{- 1 , 6}$ & 9,2 & 10,3 & $\mathbf{1 , 1}$ \\
9 & 117,7 & 122,9 & $\mathbf{5 , 2}$ & 15,1 & 16,7 & $\mathbf{1 , 6}$ \\
10 & 130,9 & 124,9 & $\mathbf{- 6}$ & 17,8 & 14,8 & $\mathbf{- 3}$ \\
11 & 115 & 114,3 & $\mathbf{- 0 , 7}$ & 10,6 & 11,3 & $\mathbf{0 , 7}$ \\
12 & 125,2 & 122,1 & $\mathbf{3 , 1}$ & 14,7 & 12,8 & $\mathbf{- 1 , 9}$ \\
13 & 118,4 & 116,3 & $\mathbf{- 2 , 1}$ & 15,6 & 12,5 & $\mathbf{- 3 , 1}$ \\
14 & 116,4 & 118,3 & $\mathbf{1 , 9}$ & 7,9 & 9,5 & $\mathbf{1 , 6}$ \\
15 & 127,9 & 127,8 & $\mathbf{- 0 , 1}$ & 12,2 & 12,4 & $\mathbf{0 , 2}$ \\
16 & 131,9 & 137,6 & $\mathbf{5 , 7}$ & 13,7 & 14,4 & $\mathbf{0 , 7}$ \\
17 & 118,4 & 113,5 & $\mathbf{- 4 , 9}$ & 14,6 & 15,6 & $\mathbf{1}$ \\
18 & 119 & 117,2 & $\mathbf{1 , 8}$ & 9,9 & 13,1 & $\mathbf{3 , 2}$ \\
19 & 97,3 & 97,3 & $\mathbf{0}$ & 15,1 & 12,1 & $\mathbf{- 3}$ \\
\hline
\end{tabular}




\section{ANEXO J}

Medidas do MAS médio inicial (TI), final (TF), diferença entre final e inicial (TFI) e medidas SPAS médio inicial (UI), final (UF), diferença entre final e inicial (UF-I) de 19 indivíduos submetidos à cirurgia ortognática para correção de prognatismo mandibular

\begin{tabular}{ccccccc}
\hline Paciente & TI & TF & TF-I & UI & UF & UF-I \\
\hline 1 & 17,5 & 15,2 & $\mathbf{- 2 , 3}$ & 5,5 & 18,7 & $\mathbf{1 3 , 2}$ \\
2 & 15,2 & 13,2 & $\mathbf{- 2}$ & 25,8 & 26,8 & $\mathbf{1}$ \\
3 & 13,2 & 17,2 & $\mathbf{4}$ & 36,6 & 29,6 & $\mathbf{- 7}$ \\
4 & 16,6 & 19 & $\mathbf{2 , 4}$ & 7,4 & 5,6 & $\mathbf{- 1 , 8}$ \\
5 & 9,1 & 7,2 & $\mathbf{- 1 , 9}$ & 36,6 & 36,2 & $\mathbf{- 0 , 4}$ \\
6 & 10,4 & 8,8 & $\mathbf{- 1 , 6}$ & 26,4 & 28,6 & $\mathbf{2 , 2}$ \\
7 & 15 & 14 & $\mathbf{- 1}$ & 22,2 & 31,8 & $\mathbf{9 , 6}$ \\
8 & 10,4 & 12,3 & $\mathbf{1 , 9}$ & 23,5 & 26,5 & $\mathbf{3}$ \\
9 & 12,8 & 13,2 & $\mathbf{0 , 4}$ & 26,9 & 22,1 & $\mathbf{- 4 , 8}$ \\
10 & 12,2 & 14,9 & $\mathbf{2 , 7}$ & 28,9 & 30,2 & $\mathbf{1 , 3}$ \\
11 & 11,7 & 12,8 & $\mathbf{1 , 1}$ & 29,9 & 27,8 & $\mathbf{- 2 , 1}$ \\
12 & 16,6 & 11,1 & $\mathbf{- 5 , 5}$ & 26,1 & 31,8 & $\mathbf{5 , 7}$ \\
13 & 10 & 11,7 & $\mathbf{1 , 7}$ & 15,3 & 17,7 & $\mathbf{2 , 4}$ \\
14 & 6,6 & 7,4 & $\mathbf{0 , 8}$ & 14,4 & 15,6 & $\mathbf{1 , 2}$ \\
15 & 11,6 & 9,1 & $\mathbf{- 2 , 5}$ & 17,6 & 19,6 & $\mathbf{2}$ \\
16 & 13,5 & 17,7 & $\mathbf{4 , 2}$ & 18,8 & 18,3 & $\mathbf{- 0 , 5}$ \\
17 & 13,1 & 7,1 & $\mathbf{- 6}$ & 14,4 & 15,7 & $\mathbf{1 , 3}$ \\
18 & 8,9 & 9,8 & $\mathbf{0 , 9}$ & 16,1 & 17,2 & $\mathbf{1 , 1}$ \\
19 & 13,8 & 8,5 & $\mathbf{- 5 , 3}$ & 18,9 & 24,5 & $\mathbf{5 , 6}$ \\
\hline
\end{tabular}




\section{ANEXO K}

Medidas PNS-V média inicial (VI), final (VF), diferença entre final e inicial (VF-I) e PNS-Pa média inicial (XI), final (XF), diferença entre final e inicial (XF-I) de 19 indivíduos submetidos à cirurgia ortognática para correção de prognatismo mandibular

\begin{tabular}{ccccccc}
\hline Paciente & VI & VF & VF-I & XI & XF & XF-I \\
\hline 1 & 60,8 & 71,5 & $\mathbf{1 1}$ & 29,1 & 30,5 & $\mathbf{1 , 4}$ \\
2 & 60 & 68,9 & $\mathbf{8 , 9}$ & 30,8 & 39,4 & $\mathbf{8 , 6}$ \\
3 & 61 & 73,6 & $\mathbf{1 3}$ & 31,2 & 38,1 & $\mathbf{6 , 9}$ \\
4 & 63,5 & 65,5 & $\mathbf{2}$ & 21,2 & 26 & $\mathbf{4 , 8}$ \\
5 & 72,8 & 81,2 & $\mathbf{8 , 4}$ & 46,2 & 43,7 & $\mathbf{- 2 , 5}$ \\
6 & 57,8 & 63,5 & $\mathbf{5 , 7}$ & 36,1 & 35,7 & $\mathbf{- 0 , 4}$ \\
7 & 64,6 & 81,7 & $\mathbf{1 7}$ & 32,3 & 35,9 & $\mathbf{3 , 6}$ \\
8 & 57,1 & 66,6 & $\mathbf{9 , 5}$ & 35 & 40,7 & $\mathbf{5 , 7}$ \\
9 & 64,1 & 71,3 & $\mathbf{7 , 2}$ & 29,8 & 29,5 & $\mathbf{- 0 , 3}$ \\
10 & 68,7 & 62,6 & $\mathbf{- 6 , 1}$ & 37 & 33,7 & $\mathbf{- 3 , 3}$ \\
11 & 61,4 & 64,1 & $\mathbf{2 , 7}$ & 31,2 & 31,6 & $\mathbf{0 , 4}$ \\
12 & 75,2 & 84,5 & $\mathbf{9 , 3}$ & 32,3 & 46,2 & $\mathbf{1 3 , 9}$ \\
13 & 69,3 & 79,2 & $\mathbf{9 , 9}$ & 34,2 & 41 & $\mathbf{6 , 8}$ \\
14 & 63,1 & 70,5 & $\mathbf{7 , 4}$ & 33,3 & 35,8 & $\mathbf{2 , 5}$ \\
15 & 69,6 & 72,5 & $\mathbf{2 , 9}$ & 31,8 & 36,6 & $\mathbf{4 , 8}$ \\
16 & 75,8 & 81,5 & $\mathbf{5 , 7}$ & 39 & 40,8 & $\mathbf{1 , 8}$ \\
17 & 56,2 & 55,9 & $\mathbf{- 0 , 3}$ & 27,7 & 34,3 & $\mathbf{6 , 6}$ \\
18 & 67,2 & 68 & $\mathbf{0 , 8}$ & 35,4 & 44,7 & $\mathbf{9 , 3}$ \\
19 & 56,3 & 58,7 & $\mathbf{2 , 4}$ & 21,7 & 28,4 & $\mathbf{6 , 7}$ \\
\hline & & & & & &
\end{tabular}




\section{ANEXO L}

Medidas do Hy-Me-PM médio inicial (ZI), final (ZF), diferença entre final e inicial (ZF-I) e Hy-MPperp médio inicial (AAI), final (AAF), diferença entre final e inicial (AAF-I) de 19 indivíduos submetidos à cirurgia ortognática para correção de prognatismo mandibular

\begin{tabular}{ccccccc}
\hline Paciente & ZI & ZF & ZF-I & AAI & AAF & AAF-I \\
\hline 1 & 13 & 21,8 & $\mathbf{8 , 8}$ & 11,4 & 14,8 & $\mathbf{3 , 4}$ \\
2 & 9,2 & 16,5 & $\mathbf{7 , 3}$ & 7,2 & 13,3 & $\mathbf{6 , 1}$ \\
3 & 9,1 & 18,7 & $\mathbf{9 , 6}$ & 9,9 & 19 & $\mathbf{9 , 1}$ \\
4 & 12,2 & 15,9 & $\mathbf{3 , 7}$ & 10,5 & 12,2 & $\mathbf{1 , 7}$ \\
5 & 19,8 & 21,9 & $\mathbf{2 , 1}$ & 17,7 & 17,2 & $\mathbf{- 0 , 5}$ \\
6 & 6,8 & 18,1 & $\mathbf{1 1 , 3}$ & 6 & 13,6 & $\mathbf{7 , 6}$ \\
7 & 7,4 & 16,1 & $\mathbf{8 , 7}$ & 8,5 & 16,1 & $\mathbf{7 , 6}$ \\
8 & 12,2 & 18,4 & $\mathbf{6 , 2}$ & 10,7 & 15,2 & $\mathbf{4 , 5}$ \\
9 & 13,5 & 25,2 & $\mathbf{1 1 , 7}$ & 11,1 & 15,5 & $\mathbf{4 , 4}$ \\
10 & 13 & 11,5 & $\mathbf{- 1 , 5}$ & 14,7 & 9,4 & $\mathbf{- 5 , 3}$ \\
11 & 13,3 & 16,8 & $\mathbf{3 , 5}$ & 10,6 & 11,8 & $\mathbf{1 , 2}$ \\
12 & 22 & 34 & $\mathbf{1 2}$ & 17,5 & 22,7 & $\mathbf{5 , 2}$ \\
13 & 21,2 & 24,4 & $\mathbf{3 , 2}$ & 18,1 & 23,7 & $\mathbf{5 , 6}$ \\
14 & 18,6 & 22,7 & $\mathbf{4 , 1}$ & 13,1 & 16,1 & $\mathbf{3}$ \\
15 & 24,3 & 31,5 & $\mathbf{7 , 2}$ & 18 & 22,4 & $\mathbf{4 , 4}$ \\
16 & 12,9 & 11,6 & $\mathbf{- 1 , 3}$ & 11,2 & 10,8 & $\mathbf{- 0 , 4}$ \\
17 & 14,6 & 15,4 & $\mathbf{0 , 8}$ & 15,6 & 14,9 & $\mathbf{- 0 , 7}$ \\
18 & 15,8 & 12,5 & $\mathbf{- 3 , 3}$ & 16,8 & 12,5 & $\mathbf{- 4 , 3}$ \\
19 & 14,1 & 18,1 & $\mathbf{4}$ & 11,4 & 11,8 & $\mathbf{0 , 4}$ \\
\hline
\end{tabular}




\section{ANEXO M}

Medidas do Hy-S médio inicial (DDI), final (DDF), diferença entre final e inicial (DD-I) de 19 indivíduos submetidos à cirurgia ortognática para correção de prognatismo mandibular

\begin{tabular}{cccc}
\hline Paciente & DDI & DDF & DDF-I \\
\hline 1 & 106,1 & 120,8 & $\mathbf{1 4 , 7}$ \\
2 & 115,5 & 119 & $\mathbf{3 , 5}$ \\
3 & 114,9 & 123,8 & $\mathbf{8 , 9}$ \\
4 & 102,2 & 100,3 & $\mathbf{- 1 , 9}$ \\
5 & 111,6 & 116,5 & $\mathbf{4 , 9}$ \\
6 & 108,3 & 107,5 & $\mathbf{- 0 , 8}$ \\
7 & 130,4 & 144 & $\mathbf{1 3 , 6}$ \\
8 & 99,1 & 104 & $\mathbf{4 , 9}$ \\
9 & 107,3 & 121,2 & $\mathbf{1 3 , 9}$ \\
10 & 116,5 & 117,7 & $\mathbf{1 , 2}$ \\
11 & 105 & 102,9 & $\mathbf{- 2 , 1}$ \\
12 & 127,6 & 130,3 & $\mathbf{2 , 7}$ \\
13 & 123,4 & 117,8 & $\mathbf{- 5 , 6}$ \\
14 & 108,5 & 116,8 & $\mathbf{8 , 3}$ \\
15 & 116,9 & 119,6 & $\mathbf{2 , 7}$ \\
16 & 119,4 & 125,6 & $\mathbf{6 , 2}$ \\
17 & 107,2 & 108,1 & $\mathbf{0 , 9}$ \\
18 & 116,3 & 109,1 & $\mathbf{- 7 , 2}$ \\
19 & 86,5 & 90,5 & \\
\hline & & & $\mathbf{4}$ \\
\hline
\end{tabular}





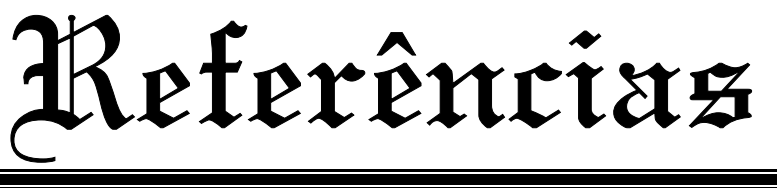





\section{REFERÊNCIAS}

1- Achilleos S, Krogstad O, Lyberg T. Surgical mandibular setback and changes in uvuloglossopharyngeal morphology and head posture: a shortand long-term cephalometric study in males. Eur $\mathrm{J}$ Orthod. 2000;22(4):383-94.

2- Aharon PA, Eisig S, Cisneros GJ. Surgical prediction reliability: a comparison of two computer software systems. Int J Adult Orthodon Orthognath Surg. 1997;12(1):65-78.

3- $\quad$ Almeida FR, Lowe AA, Sung JO, Tsuiki S, Otsuka R. Long-term sequellae of oral appliance therapy in obstructive sleep apnea patients: Part 1. Cephalometric analysis. Am J Orthod Dentofacial Orthop. 2006;129:195204.

4- $\quad$ Alvares LC, Tavano O. Curso de radiologia em odontologia. 4a ed. São Paulo: Santos; 1998. p.151-3.

5- Angle EH. Classification of maloclussion. Dental Cosmos. 1899;1(14):248357.

6- Athanasiou AE, Toutontizakis N, Mavreas D, Ritzau M, Wenzel A. Alterations of hyoid bone position and pharyngeal depth and their relationship after surgical correction of mandibular prognatism. Am J Orthod Dentofacial Orthop. 1991;100:259-65.

7- $\quad$ Baik UB, Suzuki M, Ikeda K, Sugawara J, Mitani H. Relationship between cephalometric characteristics and obstructive sites in obstructive sleep apnea syndrome. Angle Orthod. 2002;72:124-34.

8- Bailey LJ, Haltiwanger LH, Blakey GH, Proffit WR. Who seeks surgicalorthodontic treatment: a current review. Int J Adult Orthod Orthognath Surg. 2001;16(4):280-92.

9- Barros CC. Análise cefalométrica de McNamara. In: Ferreira FV. Ortodontia: diagnóstico e planejamento clínico. 4a ed. São Paulo: Artes Médicas; 2001. 357 p.

10- Barsh LI. Dentistry's role in the recognition and treatment of sleepbreathing disorders: the need for cooperation with the medical community. CDA J. 1998;26(8):591-6.

11- Battagel JM, Johal A, L'Estrange PR, Croft CB, Kotecha B. Changes in the airway and hyoid position in subjects with obstructive sleep apnoea (OSA). Eur J Orthod. 1999;21:363-76.

12- Battagel JM, L'Estrange, PR. The cephalometric morphology of patients with obstructive sleep apnea (OSA). Eur J Orthod. 1996;18:557-69. 
13- Bohlman ME, Haponick EF, Smith PL, Allen RP, Bleecker ER, Goldman SM. CT demonstration of pharyngeal narrowing in adult obstructive sleep apnea. Am J Roentgenol. 1983;140:543-8.

14- Buccheri A, Mastrangelo C, Stella R, Poladas EG. Valutazione cefalometrica della posizione dell'osso oide in soggetti affetti da apnea ostruttiva notturna. Minerva Stomatol. 2004;53:33-9.

15- Chen F, Terada K, Hanada K, Saito I. Predicting the pharyngeal airway space after mandibular setback surgery. J Oral Maxillofac Surg. 2005;63:1509-14.

16- Chou JI, Fong HJ, Kuang SH, Gi LY, Huang F, Lai CY, et al. A retrospective analysis of the stability and relapse of soft and hard tissue change after bilateral sagittal split osteotomy for mandibular setback of 64 Taiwanese patients. J Oral Maxillofac Surg. 2005; 63:355-61.

17- Conley, SR, Legan, HL. Correction of the severe obstructive sleep apnea with bimaxillary transverse distraction osteogenesis and maxillomandibular advancement. Am J Orthod Dentofacial Orthop. 2006;129:283-92.

18- Dieuleveult T, Wagner I, Meulien P, Fleury B, Hausser-Hawn C, Chabolle $F$. Analyse céphalométrique rétrospective dans les syndromes dápnées du sommeil traités par chirurgie. Ann Otolaryngol Chir Cervicofac. 2000;117(6):339-48.

19- Donastsky O, Bjorn-Jorgensen J, Holmqvist-Larsen M, Hillerup S. Computerized cephalometric evaluation of orthognathic surgical precision and stability in relation to maxillary superior repositioning combined with mandibular advancement or setback. J Oral Maxillofac Surg. 1997;55(10):1071-9.

20- Eales EA Newton C, Jones ML. The accuracy of computerized prediction of the soft tissue profile: A study of 25 patients treated by means of the Le Fort I osteotomy. Int J Adult Orthod Orthognath Surg. 1994;9:141.

21- Eckhardt CE, Cunningham SJ. How predictable is orthognathic surgery? Eur J Orthod. 2004;26(3):303-9.

22- Eggensperger N, Smolka K, Johner A, Rahal A, Thüer U, lizuka T. Longterm changes of hyoid bone and pharyngeal airway size following advancement of the mandible. Oral Surg Oral Med Oral Pathol Oral Radiol Endod. 2005;99:404-10.

23- Eggensperger N, Smolka W, lizuka T. Long-term changes of hyoid bone position and pharyngeal airway size following mandibular setback by sagittal split ramous osteotomy. J Cranio Maxillofac Surg. 2005;3:111-7. 
24- Eggensperger N, Smolka W, Luder J, lizuka T. Short and long-term skeletal relapse after mandibular advancement surgery. Int $\mathrm{J}$ Oral Maxillofac Surg. 2006;35:36-52.

25- Enacar A, Aksoy AÜ, Sençift $Y$, Haydar B, Aras K. Changes in the hypopharyngeal airway space and in tongue and hyoid bone position following the surgical correction of the mandibular prognathism. Int J Adult Orthod Orthognath Surg. 1994;9:285-90.

26- Endo S, Mataki S, Kurosaki N. Cephalometric evaluation of craniofacial and upper airway structures in Japanese patients with obstructive sleep apnea. J Med Dent Sci. 2003;50:109-20.

27- Figún ME, Garino RR. Anatomia odontológica funcional e aplicada. São Paulo: Panamericana;1989. p.65-9.

28- Finkelstein Y, Wexler D, Horowitz E, Berger G, Nachmani A, ShapiroFeinberg $M$. Frontal e lateral cephalometry in patients with disordered breathing. Laryngoscope. 2001;11:634-41.

29- Friedlander AH, Friedlander IK, Pogrel MA. Dentistry's role in the diagnosis and co-management of patients with sleep apnoea/hypopnoea syndrome. Brit Dent J. 2000;189(2):76-80.

30- Friedlander AH, Walker LA, Friedlander IK, Felsenfeld AL. Diagnosis and comanaging patients with obstructive sleep apnea syndrome. J Am Dent Assoc. 2000;131:1178-84.

31- Gardner E, Gray DJ, O'Rahilly R. Anatomia: estudo regional do corpo humano. Rio de Janeiro: Guanabara Koogan; 1978. p.730-49.

32- Gonçalves JR, Buschang PH, Gonçalves DG, Wolford LM. Postsurgical stability of orpharyngeal airway changes following counter-clockwise maxillo-mandibular advancement surgery. J Oral Maxillofac Surg. 2006;64:755-62.

33- Goodday RHB, Precious DS, Morrison AD, Robertson CG. Obstructive sleep apnea syndrome: diagnosis end management. J Can Dent Assoc. 2001;67(11):652-8.

34- Gossett CB, Preston CB, Dunford R, Lampasso J. Prediction accuracy of computer-assisted surgical visual treatment objectives as compared with conventional visual treatment objectives. J Oral Maxillofac Surg. 2005;63:609-17.

35- Greco JM, Frohberg U, Van Sickels JE. Long-term airway space changes after mandibular setback using bilateral sagittal split osteotomy. Int J Oral Maxillofac Surg. 1990;19:103-5.

36- Gu GM, Nagata J, Suto M, Anraku Y, Nakamura K, Kuroe K, et al. Hyoid position, pharyngeal airway and head posture in relation to relapse after the mandibular setback in skeletal Class III. Clin Orthod Res. 2000;3:6777. 
37- Guilleminault, C, Connolly SJ, Winkel RA. Cardiac arrhythmia and conduction disturbances during sleep in 400 patients with sleep apnea syndrome. Am J Cardiol. 1983;52:490-4.

38- Harradine NW, Birnie DJ. Computerized prediction of the results of orthognathic surgery. J Maxillofac Surg. 1985;13:245.

39- Heller JB, Gabbay JS, Kwan D, O'Hara CM, Garri JI, Urregi A et al. Genioplasty distraction osteogenesis and hyoid advancement for correction of upper airway obstruction in patients with Treacher Collins and Nager syndromes. Plast Reconstr Surg. 2006;117(7):2389-98

40- Hiyama S, Ono T, Ishiwata $\mathrm{Y}$, Kuroda $\mathrm{T}$. Changes in the mandibular position and upper airway dimension by wearing cervical headgear during sep. Am J Orthod Dentofacial Orthop. 2001;120:160-8.

41- Hochban W, Schürmann R, Brandenburg U, Conrad R. Mandibular setback for surgical correction of mandibular hyperplasia - does it provoke sleep-related breathing disorders. Int J Oral Maxillofac Surg. 1996;25:3338.

42- Hoekma A, Hovinga B, Stegenga B, De Bont LGM. Craniofacial morphology and obstructive sleep apnoea: a cephalometric analysis. J Oral Rehabil. 2003;30:690-6.

43- Houston WJB. The analysis of errors in orthodontic measurements. American Orthod. 1983;83:382-90.

44- Ingman T, Nieminen T, Hurmerinta K. Cephalometric comparison of pharyngeal changes in subjects with upper airway resistance syndrome or obstructive sleep apnoea in upright and supine positions. Eur J Orthod. 2004;26(3):321-6.

45- Isik F, Nalbantgil D, Sayinsu K, Arun TA comparative study of cephalometric and arch width characteristics of Class II division 1 and division 2 malocclusions. Eur J Orthod. 2006;28(2):179-83.

46- Johal A, Conaghan C. Maxillary morphology in obstructive sleep apnea: a cephalometric and model study. Angle Orthod. 2004;74(5):648-56.

47- Johns FR, Strollo PJ, Buckley M, Constantino J. The influence of craniofacial structure on obstructive sleep apnea in young adults. J Oral Maxillofacial Surg. 1998;56:596-602.

48- Johns, MW. A new method for measuring daytime sleepiness: the Epworth sleepiness scale. Sleep. 1991;14(6):540-5.

49- Johnson DR, Moore WJ. Anatomy for dental students. Oxford: Oxford University Press; 1983. p.184-93.

50- Johnston CD, Richardson A. Cephalometric changes in adult pharyngeal morphology. Eur J Orthod. 1999;21:357-62. 
51- Kawakami M, Yamamoto K, Fugimoto M, Ohgi K, Inoue M, Kirita T. Changes in tongue and hyoid positions, and posterior airway spacefollowing mandibular setback surgery. J Craniomaxillofac Surg. 2005;33:107-10.

52- Kawakami M, Yamamoto K, Noshi T, Miyawaki S, Kirita T. Effect of surgical reduction of the tongue on dentofacial structure following mandibular setback. J Oral Maxillofac Surg. 2004;62:1188-92.

53- Kim SH, Eisele DW, Smith PL, Schneider H, Schwartz AR. Evaluation of patients with sleep apnea after tracheotomy. Arch Otolaryngol Head Neck Surg. 1998;124:996-1000.

54- Kneisley LW. Medical and nondental treatment of snoring and sleep apnea syndrome. CDA J. 1998;26(8):572-8.

55- Kollias I, Krogstad $O$. Adult craniocervical and pharyngeal changes - a longitudinal cephalometric study between 22 and 42 years of age. Part I: morphological craniocervical and hyoid bone changes. Eur J Orthod. 1999;21:333-44.

56- Kollias I, Krogstad O. Adult craniocervical and pharyngeal changes - a longitudinal cephalometric study between 22 and 42 years of age. Part II: morphological uvulo-glossopharyngeal changes. Eur $\mathrm{J}$ Orthod. 1999;21:345-55.

57- Kubota Y, Nakayama H, Takada H, Matsuyama M, Sakai K, Yoshizawa H, et al. Facial axis angle as a risk factor for obstructive sleep apnea. Intern Med. 2005;44:805-10.

58- Lam B, Ooi CGC, Peh WCG, Lauder I, Tsang KWT, Lam WK, et al. Computed tomographic evaluation of the role of craniofacial and upper airway morphology in obstructive sleep apnea in Chinese. Respir Med. 2004;98:301-7.

59- Li KK, Guilleminault C, Riley RW, Powell NB. Obstructive sleep apnea and maxillomandibular advancement: an assessment of airway changes using radiographic and nasopharyngoscopic examinations. J Oral Maxillofac Surg. 2002;60:526-30.

60- Li KK, Kushida C, Powell NB, Riley RW, Guilleminault, C. Obstructive sleep apnea syndrome: a comparison between far-east Asian and white men. Laryngoscope. 2000;110:1689-93.

61- Li KK, Powell NB, Kushida C, Riley RW, Adornato B, Guilleminault C. A comparison of Asian and white patients with obstructive sleep apnea syndrome. Laryngoscope. 1999;109:1937-40.

62- Li KK, Powell NB, Riley RW, Guilleminault C. Distraction osteogenesis in adult obstructive sleep apnea surgery: a preliminary report. J Oral Maxillofac Surg. 2002;60:6-10. 
63- Li KK, Powell NB, Riley RW, Troell R, Guilleminaut C. Overview of phase I surgery for obstructive sleep apnea syndrome. Ear Nose Throat $\mathrm{J}$. 1999;78(11):836-45.

64- Li KK, Powell NB, Riley RW, Troell R, Guilleminaut C. Overview of phase II surgery for obstructive sleep apnea syndrome. Ear Nose Throat $\mathrm{J}$. 1999;78(11):851-7.

65- Li KK, Powell NB, Riley RW, Zonato A, Gervacio L, Guilleminault, C. Morbidly obese patients with severe obstructive sleep apnea: is airway reconstructive surgery a viable treatment option? Laryngoscope. 2000;110:982-7.

66- Li KK, Riley RW, Powell NB, Guilleminault, C. Maxillomandibular advancement for persistent obstructive sleep apnea after phase I surgery in patients without maxillomandibular deficiency. Laryngoscope. 2000;110:1684-8.

67- Li KK, Riley RW, Powell NB, Guilleminault C. Patient's perception of the facial appearance after maxillomandibular advancement for obstructive sleep apnea syndrome. J Oral Maxillofac Surg. 2001;59:377-80.

68- Li KK, Riley RW, Powell NB, Troell RJ. Obstructive sleep apnea surgery: genioglossus advancement revisited. J Oral Maxillofac Surg. 2001;59:1181-4.

69- Li KK, Riley RW, Powell NB, Zonato A, Troell R, Guilleminault C. Postoperative airway findings after maxillomandibular advancement for obstructive sleep apnea syndrome. Laryngoscope. 2000;110:325-8.

70- Li KK, Troell RJ, Riley RW, Powell NB, Koester U, Gilleminault C. Uvulopalatopharyngoplasty, maxilomandibular advancement and the velopharynx. Laryngoscope. 2001;111:1075-8.

71- Li KK. Surgical therapy for adult obstructive sleep apnea. Sleep Med Rev. 2005;9:201-9.

72- Liu Y, Zeng X, Fu M, Huang X, Lowe AA. Effects of a mandibular repositioner on obstructive sleep apnea. Am J Orthod Dentofacial Orthop. 2000;118:248-56.

73- Liukkonen M, Vahatalo K, Peltomaki T, Tiekso J, Happonen RP. Effect of mandibular setback surgery on the posterior airway size. Int J Adult Orthod Orthognath Surg. 2002;17(1):41-6.

74- Loh S, Heng JK, Ward-Booth P, Winchester L, McDonald F. A radiographic analysis of computer prediction in conjunction with orthognathic surgery. Int J Oral Maxillofac Surg. 2001;30(4):259-63.

75- Loh S, Yow M. Computer prediction of hard tissue profiles in orthognathic surgery. Int J Adult Orthodon Orthognath Surg. 2002;17(4):342-7. 
76- Lowe AA, Santamaria ID, Fleethman JA, Price C. Facial morphology and obstructive sleep apnea. Am J Orthod Dentofacial Orthod. 1986;90(6):484-91.

77- Malhotra A, White DP. Obstructive sleep apnea. Lancet. 2002;360:237-45.

78- Malkoc S, Usumez S, Nur M, Donaghy CE. Reproducibility of airway dimensions and tongue and hyoid positions on lateral cephalograms. Am J Orthod Dentofacial Orthop. 2005;28:513-6.

79- Mankad B, Cisneros GJ, Freeman K. Prediction accuracy of soft tissue profile in orthognathic surgery. Int J Adult Orthod Orthognath Surg. 1999;14:19.

80- Maple JR, Vig KWL, Beck M, Larsen PE, Shanker S. A comparison of providers' and consumers' perceptions of facial-profile attractiveness. Am J Orthod Dentofacial Orthop. 2005;128:690-6.

81- Marshall MW. Surgical options for obstructive sleep apnea. CDA J. 1998;26(8):578-90.

82- Martins AS, Cotrim-Ferreira FA. Classificação das más oclusões. In: Ferreira FV. Ortodontia: diagnóstico e planejamento clínico. 4a ed. São Paulo: Artes Médicas; 2001. p.99-114.

83- Mehra P, Downe M, Pitta M, Wolford LM. Pharyngeal airway space changes after counterclockwise rotation of the maxilomandibular complex. Am J Orthod Dentofacial Orthop. 2001;120:154-9.

84- Miranda SL. Cirurgia ortognática em apnéia. In: Araújo, A. Cirurgia ortognática. São Paulo: Ed. Santos; 1999. p. 365-74.

85- Miyamoto K, Özbek MM, Lowe AA, Sjöholm TT, Love LL, Fleethan JA, et al. Mandibular posture during sleep in healthy adults. Arch Oral Biol. 1998;43:269-75.

86- Mortimore IL, Marshal I, Wraith PK, Sellar RJ, Douglas NJ. Neck and total body fat deposition in no obese and obese patients with sleep apnea compared with that in control subjects. Am J Respir Crit Care Med. 1998;157:280-3.

87- Naganuma H, Okamoto M, Woodson, T, Hirose H. Cephalometric and fiberoptic evaluation as a case-selection technique for obstructive sleep apnea syndrome. Acta Otolaryngol. 2002;547:57-63.

88- Nakagawa F, Ono T, Ishiwata Y, Kuroda T. Morphologic changes in the upper airway structure following surgical correction of mandibular prognathism. Int Adult Orthod Orthognath Surg. 1998;13:299-306.

89- Nary Filho H, Gonçales ES, Ribeiro PDJr. Abordagem cirúrgica voltada para a estética. Biodonto. 2004;1(1):2-11.

90- Neville BW, Damm DD, Allen CM, Bouquot JE. Patologia Oral \& Maxilofacial. Rio de Janeiro: Guanabara Koogan; 1998. p.33-5. 
91- Nimkarn Y, Miles PG, Waite PD. Maxillomandibular advancement surgery in obstructive sleep apnea syndrome patients: long-term surgical stability. J Oral Maxillofac Surg. 1995;53:1414-8.

92- Otsuka R, Almeida FR, Lowe AA, Ryan F. A comparison of responders and nonresponders to oral appliance therapy for the treatment of obstructive sleep apnea. Am J Orthod Dentofacial Orthop. 2006;129:2229.

93- Özdemir H, Altin R, Sögüt A, Çmar F, Mahmutyaziciolu K, Kart L, et al. Craniofacial differences according to $\mathrm{AHI}$ scores of children with obstructive sleep apnoea syndrome: cephalometric study in 39 patients. Pediatr Radiol. 2004;34:393-9.

94- Pae EK, Blasius JJ, Nanda R. Heterogeneity in vertical positioning of the hyoid bone in relation to genioglossal activity in men. Angle Orthod. 2004;74:343-8.

95- Panula K, Keski-Nisula K. Irreversible alteration in occlusion caused by a mandibular advancement appliance: an unexpected complication of sleep apnea treatment. Int J Adult Orthod Orthognath Surg. 2000;15:192-6.

96- Paoli JR, Lauwers F, Cances V. Upper airway changes after mandibular setback osteotomy. Concerns for obstructive sleep apnea. Rev Stomatol Chir Maxillofac. 2000;101(3):129-34.

97- Paoli JR, Lauwers F, Lacassagne L, Tiberge M, Dodart LBoutault F. Craniofacial differences according to the body mass index of patients with obstructive sleep apnoea syndrome: cephalometric study in 85 patients. Brit J Oral Maxillofac Surg. 2001;39:40-5.

98- Phillipson, EA. Sleep apnea. Med North Am. 1982;23:2314-23.

99- Power G, Breckon J, Sherriff M, McDonald F. Dolphin Imaging Software: an analysis of the accuracy of cephalometric digitization and orthognathic prediction. Int J Oral Maxillofac Surg. 2005;34:619-26.

100- Prinsell JR. Maxillomandibular advancement surgery in a site-specific treatment approach for obstructive sleep apnea in 50 consecutive patients. Chest. 1999;116(6):1519-29.

101- Rama AN, Tekwani SH, Kushida CA. Sites of obstructions in obstructive sleep apnea. Chest. 2002;122:1139-47.

102- Ramesh BV, Vinod N, Murgesan K. Pharyngeal airway changes following mandibular setback surgery. Indian J Dent Res. 2005;16(4):147-50.

103- Reynolds ST, Ellis III E, Carlson DS. Adaptation of the suprahyoid complex muscle to large mandibular advancements. J Oral Maxillofacial Surg. 1988;46(12):1077-85. 
104- Riley RW, Powell NB, Guilleminault C, Ware W. Obstructive sleep apnea syndrome following surgery for mandibular prognathism. J Oral Maxillofac Surg. 1987;47:450-2.

105- Riley RW, Powell NB, Guilleminault C. Current surgical concepts for treating obstructive sleep apnea syndrome. J Oral Maxillofac Surg. 1987;45:149-57.

106- Riley RW, Powell NB, Guilleminault C. Inferior mandibular osteotomy and hyoid myotomy suspension for obstructive sleep apnea: a review of 55 patients. J Oral Maxillofac Surg. 1989; 47:159-64.

107- Riley RW, Powell NB, Guilleminault C. Maxillary, mandibular, and hyoid advancement for treatment of obstructive sleep apnea: a review of 40 patients. J Oral Maxillofac Surg. 1990;48:20-6.

108- Riley RW, Powell NB, Guilleminault C. Maxillofacial surgery and nasal CPAP: a comparison of treatment for obstructive sleep apnea syndrome. Clin Chest Med. 1990;98(6):1421-5.

109- Riley RW, Powell NB, Guilleminault C. Obstructive sleep apnea syndrome: a surgical protocol for dynamic upper airway reconstruction. J Oral Maxillofac Surg. 1993;51:742-7.

110- Robertson CJ. The effect of long-term mandibular advancement on the hyoid bone and pharynx as it relates to the treatment of obstructive sleep apnoea. Aust Orthod J. 2000;16(3):157-66.

111- Saito K, Ono T, Mochida M, Ohyama K. Changes in nasorespiratory function in association with maxillary distraction osteogenesis in subjects with clef lip and palate. Cleft palate. Craniofacial J. 2006;43(1):75-83.

112- Saitoh K. Long-term changes in pharyngeal airway morphology after mandibular setback surgery. Am J Orthod Dentofacial Orthop. 2004;125:556-61.

113- Samman N, Mohammadi H, Xia J. Cephalometric norms for the upper airway in a healthy Honk Kong Chinese population. Hong Kong Med J. 2003;9(1):25-30.

114- Samman N, Tang SS, Xia J. Cephalometric study of the upper airway in surgically corrected Class III skeletal deformity. Int J Adult Orthod Orthgnath Surg. 2002;17(3):180-90.

115- Santos-Pinto CCM, Santos-Pinto PR, Ramalli EL, Santos-Pinto A, Ravelli DB. Espaço nasofaringiano: avaliação pela telerradiografia. $R$ Clin Ortodon Dental Press. 2005/2006;4(6):56-62.

116- Sayinzu K, Isik F, Arun T. Sagittal airway dimensions following maxillary protraction: a pilot study. Eur J Orthod. 2006;28:184-9.

117- Schwab RJ, Goldberg AN. Upper airway assessment. Radiographic and other imaging techniques. Otolaryngol Clin North Am. 1998;31(6):931-68. 
118- Schwab RJ, Gupta KB, Gefter WB, Metzger LJ, Hoffman EA, Pack Al. Upper airway and soft tissue anatomy in normal subjects and patients with sleep-disordered breathing. Am J Respir Crit Care Med. 1995;152:167389.

119- Seto BH, Gotsopoulos H, Sims MR, Cistulli PA. Maxillary morphology in obstructive sleep apnoea syndrome. Eur J Orthod. 2001;23:703-14.

120- Shepard JW. Hypertension, cardiac arrhythmia, myocardial infarction, and stroke in relation with obstructive sleep apnea. Clin Chest Med. 1992;13: 437-58.

121- Sher A, Schechtman K, Piccirrillo J. The efficacy of surgical modifications of the upper airway in adults with obstructive sleep apnea syndrome. Sleep. 1996;19:156.

122- Sherring D, Vowles N, Antic R, Krishnan S, Goss AN. Obstructive sleep apnoea: a review to the orofacial implications. Austr Dent J. 2001;46(3):154-65.

123- Simmons $\mathrm{JH}$. Diagnostic sleep testing in the evaluation of snoring and sleep apnea. CDA J. 1998;26(8):566-70.

124- Sinclair PM, Kilpelainen P, Phillips C. The accuracy of video imaging in orthognathic surgery. Am J Orthod Dentofac Orthop. 1995;107:177.

125- Smith AM, Battagel JM. Non-apneic snoring and the orthodontist: radiographic pharyngeal dimension changes with supine posture and mandibular protrusion. J Orthod. 2004;31:124-31.

126- Smith JD, Thomas PM, Proffit WR. A comparison of current prediction imaging Programs. Am J Orthod Dentofacial Orthop. 2004;125:527-36.

127- Solow B, Skov S, Ovesen J, Norup PW, Wildschiodtz G. Airway dimensions and head posture in obstructive sleep apnoea. Eur J Orthod. 1996;18:571-9.

128- Stauffer JL, Buick MK, Bixler EO, Sharkey FE, Abt AB, Mandres EK, et al. Morphology of the uvula in obstructive sleep apnea. Am Rev Respir Dis. 1989;140:724-8.

129- Stuck BA, Neff W, Hörmann H, Verse T, Bran G, Baisch A. Anatomic changes after hyoid suspension for obstructive sleep apnea: an MRI study. Otolaryngol Head Neck Surg. 2005;133:397-402.

130- Takagi Y, Gamble JW, Proffit WR, Christiansen RL. Postural change of the hyoid bone following osteotomy of the mandible. J Oral Surg, Oral Medicine, Oral Pathol. 1967;23(5):688-92.

131- Tangugsorn V, Krogstad O, Espeland L, Lyberg T. Obstructive sleep apnea (OSA): a cephalometric analysis of severe and non-severe OSA patients. Part II: a predictive discriminant function analysis. Int J Adult Orthodontic Orthognath Surg. 2000;15:179-91. 
132- Tangugsorn $V$, Skatevedt $O$, Krogstad $O$, Lyberg T. Obstructive sleep apnoea: a cephalometric study. Part II. Uvulo-glossopharyngeal morphology. Eur J Orthod. 1995;17:57-67.

133- Tecco S, Festa F, Tete S, Longhi V, D'Atillio M. Changes in head posture after rapid maxillary expansion in mouth-breathing girls: a controlled study. Angle Orthod. 2005;75:167-72.

134- Thornton WK. Should the dentist independently assess and treat sleepdisordered breathing? CDA J. 1998;26(8):599-608.

135- Tsang KH, Cooke MS. Comparison of cephalometric analysis using a nonradiographic sonic digitizer (DigiGraph Workstation) with conventional radiography. Eur J Orthod. 1999;21(1):1-13.

136- Tselnik M, Pogrel MA. Assessment of the pharyngeal airway space after mandibular setback surgery. J Oral Maxillofac Surg. 2000;58:282-5.

137- Tsuiki S, Almeida FR, Lowe AA, Su J, Fleethan JA. The interaction between changes in upright mandibular position and supine airway size in patients with obstructive sleep apnea. Am J Orthod Dentofacial Orthop. 2005;128:504-12.

138- Turnbull NR, Battagel JM. The effects of orthognathic surgery on pharyngeal airway dimensions and quality of sleep. J Orthod. 2000; 27:235-47.

139- Verstraeten E, Cluydts R, Verbraecken J. Neuropsychological functioning and determinants of morning alertness in patients with obstructive sleep apnea syndrome. J Intern Neuropsych Soc. 1996;2:306-14.

140- Vilaseca I, Morello A, Montserrat JM, Santamaría J, Iranzo A. Usefulness of uvulopalatopharyngoplasty with genioglossus and hyoid advancement in the treatment of obstructive sleep apnea. Arch Otolaryngol Head Neck Surg. 2002;128(4):435-40.

141- Vilella BS, Vilella OV, Koch HA. Growth of the nasopharynx and adenoidal development in Brazilian subjects. Braz Oral Res. 2006;20(1):70-5.

142- Villaneuva ATC, Buchanana PR, Yee BJ, Grunstein RR. Ethnicity and obstructive sleep apnoea. Sleep Medicine Rev. 2005;9:419-36.

143- Wang X, Wang XX, Liang C, Yi B, Lin, Y, Li ZL. Distractions osteogenesis in correction of micrognathia accompanying obstructive sleep apnea syndrome. Plast Reconstr Surg. 2003; 112(6):1549-57.

144- Wickwire NA, White Jr. RP, Proffit WR. The effect of mandibular osteotomy on tongue position. J Oral Surg. 1972;30:184-90.

145- Yildirim N, Fitzpatrick MF, Whyte KF, Jalleh R, Wightman AJA, Douglas NJ. The effect of posture on upper airway dimensions in normal subjects and in patients with the sleep apnea/hypopnea syndrome. Am Rev Respir Dis. 1991;144:845-7. 
146- Young JW, McDonald JP. An investigation into relationship between the severity of obstructive sleep apnoea/hypopnoea syndrome and the vertical position of the hyoid bone. Surg J R Coll Surg Edinb Irel. 2004;2:145-51.

147- Young T, Peppard PE, Gottlieb DJ. Epidemiology of obstructive sleep apnea. A population health perspective. Am J Respir Crit Care Med. 2002;165:1217-39.

148- Yu LF, Pogrel MA, Ajayi M. Pharyngeal airway changes associated with mandibular advancement. J Oral Maxillofac Surg. 1994;52:40-3.

149- Yu X, Fujimoto K, Urushibata K, Matsuzawa MD, Kubo K. Cephalometric analysis in obese and nonobese patients with obstructive sleep apnea syndrome. Chest. 2003;124:212-8.

150- Yucel A, Unlu M, Haktanir A, Acar M, Fidan F. Evaluation of the upper airway cross-sectional area changes in different degrees of severity of obstructive sleep apnea syndrome: cephalometric and dynamic CT study. Am J Neuroradiol. 2005;26:2624-9.

151- Zhou YH, Hägg U, Bark A, Rabie M. Concerns and motivations of skeletal Class III patients receiving orthodontic-surgical correction. Int J Adult Orthod Orthognath Surg. 2001; 16(1):7-17. 


\section{ABSTRACT}

\section{Computer based cephalometric study of the pharyngeal airway after surgical correction of mandibular prognatism}

Pharynx is a muscular organ with is sustained by craniofacial bones. It is divided into nasal, oral and hipopharynx, and can be considered as a tube that can be closed serving both respiratory and digestive systems, participating of breathing, swallowing and speech. Its anatomical morphology permits that factors such as obesity, muscular hipotony, and mandibular deficiency, among others, facilitate its obstruction, leading to the sleep apnea syndrome (OAS). The treatment consists of surgical mandibular advancement for the desobstruction of the pharynx, once this procedure increases pharyngeal dimensions. In this context, the determination of the site of the obstruction is essential for an adequate treatment, and conventional or digital cephalometries are useful tools for this diagnosis. If mandible advancement increases pharyngeal air space it is expected that mandible setback decreases such space. In order to evaluate cephalometric alterations of pharyngeal air space after orthognatic surgeries for the correction of mandibular prognatism, cephalometric analysis of 18 patients before and after surgical correction were performed using Dolphin Imaging 10.0 Program. The surgical technique consisted of bilateral mandibular sagital osteotomy associated to maxilla advancement and mentoplasty. Results did not reveal statistical differences for 
the superior (naso), medium (oral), and inferior (hypopharynx) pharyngeal air spaces, leading to the conclusion that Dolphin Imaging 10.0 Program can be used for the analysis of the pharyngeal air space and that the surgical procedure seems not to interfere in the airway space.

Keywords: Mandibular setback. Pharyngeal airway. Sleep apnea. 